NBSIR 75-940

\title{
The National Measurement System for Spectrophotometry
}

William H. Venable, Jr.

Institute for Basic Standards

National Bureau of Standards

Washington, D.C. 20234

November 1977

Final

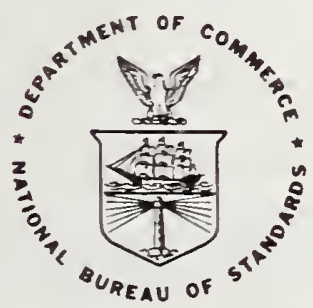

QC

100

.456

i. DEPARTMENT OF COMMERCE

IIONAL BUREAU OF STANDARDS

\#75-940 
. 
NBSIR $75-940$

\section{THE NATIONAL MEASUREMENT SYSTEM FOR SPECTROPHOTOMETRY}

William H. Venable, Jr.

Institute for Basic Standards

National Bureau of Standards

Washington, D.C. 20234

November 1977

Final

U.S. DEPARTMENT OF COMMERCE, Juanita M. Kreps, Secretary

Dr. Sidney Harman, Under Secretary

Jordan J. Baruch, Assistant Secretary for Science and Technology

NATIONAL BUREAU OF STANDARDS, Ernest Ambler, Acting Director 
FORWORD

This is one of the reports from the 1972-75 NBS Study of the National Measurement System. It deals specifically with the current structure, status, and trends of the system used in this country for the measurement of transmittance, reflectance and related quantities.

The "Concept of a National Measurement System" has been discussed by NBS authors and spokesmen for a number of years, since the publication by Dr. R. D. Huntoon of an article by that title in the October 6, 1967 issue of Science (Vol. 158, No. 3797, pages 67-71). Dr. Huntoon began his article with the following paragraph:

"Concurrently with the growth and industrialization of this nation, there has developed within it a vast, complex system of measurement which has made possible the very growth that brought the system into being. This National Measurement System (NMS) stands today as one of the key elements in a worldwide measurement system that links all major nations together in a consistent, compatible network for communication and trade."

The U. S. National Measurement System is defined as comprising all of the activities and mechanisms--intellectual and operational, technical and institutional--used by this country to produce the physical measurement data needed to create the objective, quantifiable knowledge required by our society. This knowledge is used to describe, predict, communicate, control, and react, in many aspects of our personal and social lives, science, and technology.

Dr. Huntoon continued his discussion in 1967:

"Our National Measurement System is one of a number of mutually interacting systems within our technologically based society that form the environment in which the individual citizen must live and function. Familiar examples are the communication, transportation, educational, medical and legal systems, all of which may be included under the general heading of social systems."

"In view of the demonstrated value of the systems approach for the understanding and improvement of hardware such as computers and weapons, some of these social systems are being subjected to the same type of analysis. The National Measurement System, which evolved in this country with little formal recognition as a system, is now being examined in this way at the National Bureau of Standards (NBS) which undertook the study of the National Measurement System partly because of the al1-pervasive nature and great economic importance of the nation's measurement activities, and partly because of the challenge to NBS in putting its splendid new facilities to optimum use for the benefit of the nation. Such optimum use can be approached only when the National Measurement System, of which NBS is a central element, and the services it requires for effective operation are sufficiently well understood."

Over the years both before and since 1967, NBS has taken a number of approaches to the study of our national system for physical measurements. The current series of studies was initiated in 1972 by Dr. Ernest Ambler, then Dr. Huntoon's successor as Director of the NBS Institute for Basic Standards, now Director of the Bureau. The reports of these studies are being presented to the public at large for the purpose of increasing national understanding, and the operational effectiveness, of our National Measurement System. They are presented as an intial or interim, not final, word on the subject. NBS welcomes contributions from all sectors of the System which can aid it in increasing its understanding of and effectiveness in supporting that System. 
NOTICE

A diligent effort has been made to make this report comprehensive and accurate as of March 1975. Since that time no important changes or additions have been made. There have, however, been a few significant changes in the National Measurement System for Spectrophotometry. The interested reader may wish to contact the author for his opinions on these changes. 
FORWORD.

i $i \mathrm{i}$

NOTICE

iv

EXECUTIVE SUMMARY.

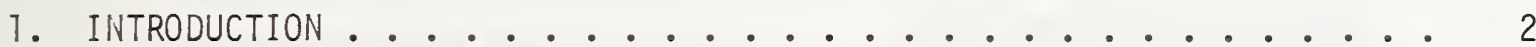

2. STRUCTURE OF THE MEASUREMENT SYSTEM. . . . . . . . . . . . . . 2

2.1 Conceptual System ......................... 2

2.2 Basic Technical Infrastructure............. 3

2.2.1 Documentary Specification System ......... 3

2.2.2 Instrumentation System ........... 4

2.2.3 Reference Data............... 5

2.2.4 Reference Materials............. . . 5

2.2.5 Science and People.............. 5

2.3 Realized Measurement Capabilities . . . . . . . . . . 6

2.4 Dissemination and Enforcement Network .......... . 7

2.4.7 Central Standards Authorities. . . . . . . . . 7

2.4.2 State and Local Offices of Weights and Measures. . . . 7

2.4.3 Standards and Testing Laboratories and Services. . . . . 7

2.4.4 Regulatory Agencies. ............ 7

2.5 Direct Measurements ............... . . 7

2.5.7 Analysis of Suppliers and Users........... 7

2.5.2 Highlights re Major Users............. 12

3. IMPACT, STATUS AND TRENDS OF MEASUREMENT SYSTEM. . . . . . . . . 12

3.1 Impact of Measurements............... 13

3.1.1 Functional, Technological, and Scientific Applications . 13

3.1.2 Economic Impacts - Costs and Benefits......... 14

3.1.3 Socia1, Human, Person-on-the-Street Impacts. . . . . 14

3.2 Status and Trends of the System . . . . . . . . . 15

4. SURVEY OF NBS SERVICES . . . . . . . . . . . . . 15

4.1 The Past. . . . . . . . . . . . . . . 15

4.2 The Present - Scope of NBS Services............ 16

4.2.1 Description of NBS Services............ 16

4.2.2 Users of NBS Services. . . . . . . . . . . 17

4.2.3 Alternate Sources.................. 17

4.2.4 Funding Sources for NBS Services......... . . 17

4.2.5 Mechanism for Supplying Services........ 18

4.3 Impact of NBS Services. . . . . . . . . . . 18

4.3.1 Economic Impact of Major User Classes. . . . . . . 18

4.3.2 Technological Impact of NBS Services........ 18

4.3.3 Payoff from Changes in NBS Services......... 18 


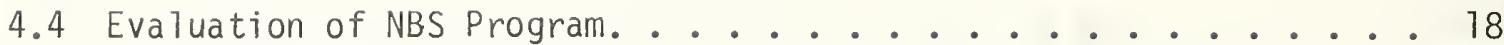

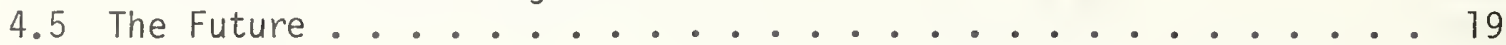

5. SUMMARY AND CONCLUSIONS................................... 19

APPENDIX A. METHODOLOGY OF THE STUDY. . . . . . . . . . . . . . . 20

APPENDIX B. A PROPOSED DIRECTION FOR NBS EFFORTS. . . . . . . . . 27-28

APPENDIX C. EVALUATING THE BENEFITS OF IMPROVING SPECTROPHOTOMETRIC

MEASUREMENTS............................... 291

APPENDIX D. FACTORS AFFECTING ACCURACY IN SPECTROPHOTOMETRIC MEASUREMENTS • 42-53

APPENDIX E. WHAT IS AN APPEARANCE MEASUREMENT?............. . 54-65

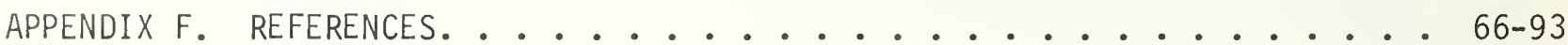

LIST OF TABLES

Table 1. Direct Transaction Matrix for Spectrophotometry . . . • . . 9 
A special study of the spectrophotometric measurement system was made in order to determine what could be done to improve these measurements and what benefits would result from the improvements. It was found that improvements in the measurements could make large contributions to productivity, health, and safety in the U.S., and that, because of the fragmented nature of this measurement community, the improverients in spectrophotometric measurements can be realized most efficiently through the efforts of a centralized agency such as NBS. With the aid of this study, the program in spectrophotometry at NBS has been revised in order to bring about these improvements more rapidly and effectively.

Key words: Absorption spectra; automation, chemical analysis; colorimetry; heat transfer; reflectance; remote sensing; retroreflectance; spectrophotometry; transmittance. 
THE NATIONAL MEASUREMENT SYSTEM FOR SPECTROPHOTOMETRY

William H. Venable, Jr.

Optical Physics Division

August, 1977

\section{EXECUTIVE SUMMARY}

This microstlidy covers the field of spectrophotometry and particularly the work in this field being conducted in the Radiometric Physics Section at NBS. In general, spectrophotometry provides an answer to such questions as how much light is reflected by an object or transmitted through it. ("Light" is used here in a very general sense which includes the light we see and other electromagnetic radiation in the adjacent portions of the spectrum which behaves in a manner simiar to light.) The technological significance of spectrophotometric measurements lies in its use as a tool for determining something about the object. Combined with a knowledge of the way the human eye functions, spectrophotometry can be used to predict and control the way an object will appear. Thus spectrophotometry can become the "eyes" for the automated production and quality control in the manufacture of objects and materials in which appearance is important. Taken with knowledge of the optical properties of chemicals, spectrophotometric data forms a basis for quantitative chemical analysis in a huge variety of fields from clinical testing to manufacturing. There are countless other applications in such areas as photography, remote sensing, warning devices for safety, and non-destructive inspection of agricultural products.

As the foreqoing indicates, the user community is huge. The processes in which spectrophotometric measurements are or could be significant are estimated to account for about one-fourth of the gross national product. It should be pointed out, that in most cases, the spectrophotometric measurement is only a small part of the total operation for a given user. As a result, the spectrophotometric measurement community for the most part is made up of a huge number of widely diverse individuals who use spectrophotometry as a tool and who do not have a strong knowledge of the field. They rely on the instructions which come with their instruments and on standard test procedures. This large, highly diverse community is the productive level of the spectrophotometric community.

At the next level above the user community lies practically all of the rest of this measurement system, e.g., the instrument manufacturers, the military, government, and commercial measurement laboratories, and the many committees which develop and publish the standard measurement techniques interact directly or nearly directly with the user community. The standards and services supplied by this second level are adequate for some applications but if the full value of spectrophotometry is to be realized, the error in these measurements must be reduced by a factor of ten.

In order to bring about such an improvement in the measurement system, a strong capability for highly accurate measurement must be built up. The instrumentation and labor required for this effort would be too much for any one of the instrument manufacturers or commercial laboratories to handle, much less for any individual user. Economically, this capability should be in a central laboratory, and, in the interest of fairness, this laboratory, should be on "neutral ground". Quite obviously, NBS is the laboratory for such universal standardization of these measurements to take place. From the mid 1950's until very recently, the spectrophotometry program at NBS was small and geared principally to measurements as a service to the rest of NBS and to other government agencies. However, during the past five years, the spectrophotometry program at NBS has been revised and our measurement capability is being built up to the point where we can supply the leadership required for increasing the accuracy and extending the range of spectrophotometric measurements.

Through this study and through our routine contacts with the technical community, we have clearly recognized the magnitude of the user community and the potential advantages which can come from an order of magnitude improvement in the measurements. We have gained an insight into what needs to be done by NBS in this respect and have initiated a program through which we can do our part. The new NBS capability should be fully developed during the next five years, at which time the full impact of our efforts will begin to be felt. The potential benefits which can be obtained from improving spectrophotometric measurements is estimated to be as great as two billion dollars annually. It is our intent to provide leadership which will enable the scientific, technical and industrial community to obtain those benefits as readily as possible. 


\section{INTRODUCTION}

What kind of measurement system is named by a word like "spectrophotometry" which has nearly as many interpretations as there are people who use it? What kind of a measurement system is one which really exists at only two levels? And what is NBS doing in the midst of all this? The purpose of this brief report is to clarify a few things about this important field of measurement.

Spectrophotometry, as used here, is a term which includes all measurements which quantify in terms of radiant power the way light and similar electromagnetic radiation is altered by interacting with objects. These measurements answer such questions as, "What fraction of the incoming light is reflected from an object?" and, "What fraction of the incoming light passes through an object?" The importance of these measurements 1 ies in the vast extent of their applications. Because of their wide use, a small improvement in the measurements and an accompanying small percentage of saving to each user can make a very large contribution to the economy.

During the five to ten years preceding the initial study in 1972, NBS did not assert strong leadership in this part of the measurement system. Because of the fragmented nature of the user community, advancement has been spotty, and the advances made by one group of users have not been passed along to the others. During the past four years, the Institute for Basic Standards (IBS) and the Institute for Materials Research (IMR) in NBS have been building up programs in spectrophotometry directed toward providing the leadership which is needed. These circumstances render inappropriate the negative approach suggested by the question, "What would happen if NBS were not involved in spectrophotometry?", and instead call for a positive approach through answering the question, "What can be gained by strong NBS involvement in spectrophotometry?" It is to the answer of this question that this study and the reports growing out of it are directed.

The study on which this reoort is based was begun before the National Measurement System (NMS) study which was the basis of most reports in this series. In January of 1971, the Spectrophotometry Section was made a part of the newly formed Optical Radiation Section in a reorganization within the Institute for Basic Standards (IBS). At that time, the Institute Director called for a thorough investigation of the needs in the field and the activities of the Spectrophotometry Section in the past to determine what course of action NBS should follow concerning this part of the measurement system. This investigation was completed and the results were presented to the IBS director in December of 1972 in a report entitled The Role of IBS in spectrophotometry. The findings in that report, along with other information acquired from other sources, particularly from NBS staff members in the IMR spectrophotometry group, are summarized here in a form consistent with that used for the other summary reports on the National Measurement System. Certain sections of the 1972 IBS report are included in their entirety as appendices to the present report as background information.

The spectrophotometry study led to a very definite conclusion. With a fairly substantial improvement in its instrumentation and by using a different over-all approach from the one it used in the past, NBS could make a very large contribution to the scientific and technical community in spectrophotometry, and this could be done with no increase in the number of NBS staff members working in the area.

\section{STRUCTURE OF THE MEASUREMENT SYSTEM}

\subsection{Conceptual System}

The quantity being measured in spectrophotometry is the ratio of a given portion of the radiative power transmitted by or reflected from an object to the radiative power incident on the object. The particular units involved in these ratios depend upon the particular type of spectrophotometric measurement. In some cases it is necessary to involve units of area, for which the square meter is the basic SI unit, and in other cases solid angle in steradians is involved. Generally, however the stated measured values are made dimensionless by comparing the way in which the object being measured interacts with radiation to the way in which some standard object, either real or idealized, would interact under the same circumstances.

The primary standard for spectrophotometric measurements is simply an accurately made measurement. In principal anyone can make accurate primary measurements, but in fact few laboratories have the facilities to make all of the peripheral measurements required to be assured of accuracy. However, a measurement in which the optical properties of two objects are compared can be made with high accuracy relatively easily. Therefore, an individual user tends to obtain a transfer standard, an object which is similar to the one he wishes to measure and one which 
has stable properties which have been accurately measured. He then compares the object he is trying to measure to the transfer standard.

In most spectrophotometric measurements, there is a definite limit to the need for accuracy. The limit in quality control applications, for example, can grow out of an economic compromise or be determined by the magnitude of random variations in the production process. In clinical chemistry, for example, sample preparation problems usually place an upper limit on the accuracy of the results of the test. Similar considerations apply to the many other applications. In each application, the spectrophotometric measurement need only be accurate enough so that its uncertainty is three to ten times smaller than the range of variation allowed for that application. From this viewpoint, the uncertainty in the measurement process itself is currently three to ten times too great in a very large percentage of the applications.

\subsection{Basic Technical Infrastructure}

If one thinks of the basic technical infrastructure as having two dimensions, depth in terms of the number of levels in the measurement chain and width in terms of the number of different groups involved at any particular level, then one can certainly say that the basic technical infrastructure for spectrophotometry is not very deep but it is quite wide. It is almost one-dimensional. As the system currently operates, there are usually just two levels of standardization, but there are many separate groups of users with activities which are almost in parallel. The reason for this will become more apparent with the discussion of the details of the infrastructure in the following paragraph.

\subsubsection{Documentary Specification System}

\subsubsection{Standardization Institutions}

There is no standardization organization devoted specifically to spectrophotometric measurements, but there are literally dozens of organizations which write spectrophotometric specifications and documents giving standard measurement procedures. Each organization within a given industry or field tends to adapt one of the more general documentary standards to its own special purposes with mixed degrees of success. The general documentary standards are written internationally by such organizations as Commission Internationale de l'Eclairage (CIE) and the International Organization for Standardization (ISO). Within the United States there are two principal organizations which produce general documentary standards, the American National Standards Institute (ANSI) and the American Society for Testing and Materiàls (ASTM). Beyond these, there are trade associations through which groups of users adapt these measurements to their own purposes. The following 1 ist, although by no means complete, $i 1$ lustrates the range of technology encompassed by these associations representing users of spectrophotometry:

- American Association of Clinical Chemists

- American Association of Textile Chemists and Colorists

- American Ceramic Society, Inc.

- American Chemical Society

- American College of Prosthodontists

- American Dental Association

- American Institute of Architects

- American 0il Chemists' Society

- American Society for Photogrammetry

- College of Clinical Pathologists

- Color Marketing Group

- Dry Color Manufacturers' Association

- Federation of Societies for Paint Technology

- Graphic Art's Technical Association

- Illuminating Engineering Society

- Institute of Food Technologists

- National Association of Printing Ink Manufacturers, Inc.

- National Paint, Varnish, and Lacquer Association

- Optical Society of America

- Paperboard Packaging Council

- Pharmaceutical Manufacturers Association

- Research and Engineering Council of the Graphic Arts Industry, Inc.

- Society of Motion Picture and Television Engineers

- Society of Plastics Engineers, Inc.

- Technical Association of the Graphis Arts

- Technical Association of the Pulp and Paper Industry

Through the recent years, the governmental legal and regulatory use of these measurements has been gradually increasing. Some of the regulatory agencies which have been or are becoming involved are the Department of Transportation and the Consumer Product Safety Commission in connection with reflectors and fluorescent warning markers for safety, the Food and Drug Administration in connection with testing foods for additives, and the Environmental Protection Agency in connection with remote sensing of pollution. The General Services Administration also places certain requirements on the optical performance of paints and reflectors purchased by the United States Government. The military agencies have tended to establish their own 
primary measurement capabilities in such laboratories as the Arnold Development Center, Michaelson Laboratory, Naval Electronics Laboratory, and Newark Air Force Station.

\subsubsection{Survey of Documentary Standards}

The organizations mentioned in the preceding paragraphs write the documentary standards which govern the measurement procedures used in spectrophotometry and which specify the optical properties of materials. International1y, the International Organization for Standardization writes specific test methods which are then adopted by industries and governments in various countries. The commission Internationale de 1'Eclairage operates in a slightly different mode in which it recommends definitions and procedures to be used in the measurements. These recommendations are then adapted by various local, national, and international standardization organizations as they write specific documentary standards of their own.

In the United States, the largest writer of documentary standards involving spectrophotometric measurements is the American Society for Testing and Materials. There are several documents covering spectrophotometric measurements in a very general way and approximately fifty testing methods which incorporate spectrophotometric measurements as part of a more general testing procedure. In addition, professional and trade associations incorporate spectrophotometric measurements into their test procedures. As a typical example of this, consider the Universal Product Code Symbol Specification Code put out by the Uniform Grocery Product code Council. This document specifies the bar code symbols to be used in identifying grocery products for automated checkout and inventory. This document specifies in detail the shape and structure of the symbols to be used, how they can be scaled larger or smaller, how they are to be evaluated for distinctness of printing, etc. A five page section of this forty-three page document deals with the contrast, opacity, colors, and other spectrophotometric properties of the printing and specifies the instruments to be used in testing for these properties. If one imagines hundreds of similar tocuments put out by dozens of independent groups, government agencies, and the military, he has an idea of the nature of the documentary standards for spectrophotometry. The significance of these standards comes from the large number of them and the wide range of activities which they affect.

\subsubsection{Instrumentation System}

\subsubsection{Measurement Tools and Techniques}

A typical spectrophotometric instrument consists of three parts, a source of radiation, a sample holder, and a radiation receiver. The source produces a given spectral and geometrical distribution of radiation upon the sample region, the sample holder places the sample in a given orientation within the radiation, and the receiver delimits the part of the radiation to be observed and detects it. Most modern instruments also include electronic circuitry to control the source and "read" the detector signal although some instruments are still produced which rely upon the human eye as a detector. The design of a large portion of the instruments developed for regular commercial sale are governed by the general specifications of the ASTM or related measurement methods with regard to the angles at which the radiation is incident, its spectral distribution, and the angles and wavelengths at which the receiver is sensitive. There is also a significant number of instruments developed for special purpose measurements, such as instruments which evaluate the protein content of grains.

The instruments can be separated into two general categories. In the first category are those instruments for which the geometrical arrangement and strength of the outgoing radiation is about the same as for the incoming radiation. Such an instrument can measure its own incident radiation and hence can establish a ratio without relying on a separate transfer standard for calibration. In the second category are those instruments in which the outgoing radiation differs greatly in strength or geometrical arrangement from the incident radiation. In such an instrument it is usually far more practical to calibrate the instrument by measuring a sample with known properties, i.e., by measuring a transfer standard. Since certain ranges of variations in the measurement parameters are usually allowed within a given class of measurements, it is important that the calibrating laboratory provide the value of a transfer standard obtained with the particular instrument with which the standard is to be used. Since most measurements are designed to be as insensitive as possible to peripheral parameters, differences between instruments can generally be taken into account through rather simple correction formulae. In addition to calibration standards for the second 
type of instrument, it is valuable in the case of both types of instruments to have special transfer standards which can be used to test for the quality of instrument performance, as, for example, to determine if incident radiation is present at wavelengths other than the desired one.

Typically, a user will use carefully preserved transfer standards to calibrate and check out his instrument when it is initially put into operation and at rather infrequent intervals to check it. After the instrument is working properly, the user will typically measure a separate "working standard", in those cases in which a transfer standard is required for calibration, and will use this for calibrations in his daily operations. The transfer standards measured by a primary calibration laboratory are not used often, and they are deliberately chosen to be very permanent. Furthermore, the material usually has a rather low intrinsic value, so that its main cost lies in the labor required to measure it. In spectrophotometry, then, one has a measurement system in which standards are very important but are cheap and long-lasting. As a result, the size and importance of the measurement system cannot be readily judged by either the monetary value or the number of standards which are issued.

\subsubsection{The Instrumentation Industry}

A spectrophotometric instrument is relatively expensive, ranging in cost from several hundred to tens of thousands of dollars in cost. The instruments are quite long1 ived, however, so that the $\$ 100$ million annual expenditure on analytical spectrophotometers and the similar amounts spent on spectrophotometric instruments for other purposes represents replacement and expansion for a very large number of instruments in the field. Because of the complexity of the instruments, the user deals directly with the instrument manufacturer or with his sales representative. U.S. instrument companies export about $10 \%$ of their products. Of the instruments purchased in the U.S., about $40 \%$ come from abroad, and a trend in the recent past has been for a decrease in exports and an increase in imports. The instrument manufacturer typically supplies or recommends the transfer standards to be used in calibrating his product. Because of the de-emphasis of spectrophotometry at NBS in the late nineteensixties, the standards issued by the manufacturers have not been properly traceable to NBS standards or correlated with each other.

\subsubsection{Reference Data}

The reference data which are generated through spectrophotometric measurements are application oriented. These data are published in the literature connected with the particular applications, as, for example, publ ished lists of absorption coefficients of various chemicals in solution. The data are not essential to making the spectrophotometric measurement, but rather they are used in interpreting the results of the measurement in connection with the particular application. It is important, of course, to have reference data on the materials and components used in building spectrophotometers, but this is of interest mostly to the relatively small community of instrument manufacturers which already have collected this data.

\subsubsection{Reference Materials}

Spectrophotometric measurements measure the properties of objects rather than materials. For example, the "reflectance of a powder" cannot be measured, although one can measure the reflectance of a pellet made by pressing a layer of the powder onto a backing material. Similarly the absorption of radiation by a particular chemical species is not measured directly, but instead one measures the transmittance of a container filled with a solution of the chemical and deduces the absorption. Therefore, it only makes sense to provide reference materials in the cases in which the connection between the material and the object made from it is particularly simple. One such case is that of the standard reference solutions produced for the NBS Office of Standard Reference Materials by the Institute for Materials Research which is covered in a separate summary report. For convenience in marketing, several types of transfer standards such as filters and reflectors are sold through the office of Standard Reference Materials, but these are in reality standard reference objects, not standard reference materials.

\subsubsection{Science and People}

Many areas of technology provide support for the spectrophotometric measurement system. In terms of the sources of radiation, the older conventional radiation sources are constantly being improved, and new sources such as lasers and light emitting diodes are being rapidly developed. As an outgrowth of the interest in lasers and optical transmission 1 ines, many new materials, optical 
components and optical techniques have become available, and similar advances have been made in detectors. Dealing with the vast amounts of data generated in a set of spectrophotometric measurements has been a problem in the past, but automatic data taking systems and today's highly developed computers have overcome this handicap. In short, the technological advances of the past five to ten years have removed most of the obstacles which have been in the way of improving spectrophotometry in the past.

Since a large part of the technology and science undergirding spectrophotometry is optical and thus depends upon knowing the properties of optical materials, improved spectrophotometry can be an aid in developing optical technology. However, the greatest flow of benefit will probably be from optical technology through spectrophotometry to the rest of the scientific community rather than from spectrophotometry feeding back into optical technology.

In the description of the infrastructure in paragraph 2.2, the horizontal nature of the community of users was emphasized. The users in each given field usually have little communication with one another. The professional societies of these groups, who write the specialized test methods mentioned, tend to publish their findings in the journals connected with their own specialty. In some more complex fields there are specialized courses offered in educational institutions, as, for example, the course of color science offered at Renssalaer Polytechnic Institute. Some of the larger instrument manufacturers conduct seminar courses in various industrial centers. In the most part, however, the user of spectrophotometry picks up his techniques from the instruction manual with his instrument, from the textbooks and other 7 iterature in his field, from his associates, and from experience.

The educational background of the users of spectrophotometry ranges almost continuously from the high school level for the operator of a quality control test instrument on-1ine to the post-doctorate level for the research chemist or meteorologist. There are very few professional spectrophotometrists outside of the instrument development and standardization fields. To the typical user, spectrophotometry is a tool in his work, one of many tools, and as a tool the spectrophotometer should be as simple and foolproof as possible. The less educated users cannot understand the radiometric background behind their measurements, and the more advanced users should not have to constantly pay attention to details of the measurement. The principal need of a member of the user cominunity is to be supplied with the instruments, methods and standards with which to carry out his work effectively with as little difficulty as possible.

\subsection{Realized Measurement Capabilities}

As a general rule, the need for accuracy in a spectrophotometric measurement is 1 imited by very practical considerations connected with the application. In appearance measurements, for example, the ability of the human eye to distinguish differences in appearance under the conditions peculiar to a given application provides a limit beyond which it is not necessary to push the measurement accuracy. If a spectrophotometric instrument were used to control a finishing process $v i a$ a feedback 10op, the instrument should be a factor of three or so more discriminating than the eye in order to allow the feedback system room to operate, but still there would be a definite limit to the accuracy required. In chemical analysis, the practical considerations of sample purity and preparation limit the measurements, and in quality control in general there is always a point beyond which economic and other practical considerations indicate the measurements should not be pushed. As a rule of thumb, if the error in the measurement is a factor of three smaller than the uncertainty which can be tolerated in an application, the requirements for the measurement have been satisfied.

In discussing the present status of the measurements, one must distinguish carefully between precision and accuracy. Precision, can be defined as the ability of an instrument to repeat its own measurements from minute to minute or day to day. High precision indicates that the instrument is stable, is insensitive to extraneous parameters such as temperature or humidity, and has a low noise. As a result of technological advances most modern instruments are more than sufficiently precise to meet the requirements of the various applications. If an application requires measurements on only one kind of object by only one instrument, and if that instrument never changes, precision is all that is required. However, in most cases there is a definite need for accuracy, i.e., the ability to measure a defined quantity. In general, the uncertainty in the accuracy of spectrophotometric measurements at present is generally a factor of three or so larger than the uncertainty tolerable in the applications, in spite of the increased precision of the measurements. 


\subsection{Dissemination and Enforcement Network}

\subsubsection{Central Standards Authorities}

In international trade, there is a movement within the International Organization for Standardization (ISO) to designate certain laboratories as acceptable for providing standards for a given type of measurement. Those participating in the ISO program would then agree to use transfer standards provided by these laboratories. Within given countries, the national standardizing laboratories generally offer calibration services for spectrophotometric measurements. The National Bureau of Standards in the United States, the Physikalisch-Technische Bundesanstaldt in Germany, and the Nationa 7 Research Counci? Laboratories in Canada, and the National Physical Laboratory in England are four laboratories which have strong programs in this area of measurement. With the exception of those few cases in which specific governmental regulation requires the use of the national laboratory, the effectiveness of the national laboratory in providing standardization and measurement assurance is based largely upon the respect which the technical community has for the capabilities of the national laboratory.

\subsubsection{State and Local Offices of Weights and Measures}

State and local offices of weights and measures are almost totally uninvolved with spectrophotometric measurements. However, the procurement agencies for a number of states and large localities maintain spectrophotometric measurement capabilities in their laboratories in order to ascertain that specifications for items being procured are met and as an aid to decisions in procurement by competitive bidding.

\subsubsection{Standards and Testing Laboratories and Services}

There are a few prominent large testing laboratories which offer a fairly broad range of spectrophotometric measurements along with a variety of other measurement services. In addition, many industries which have spectrophotometric measurement capabilities will perform measurements for a fee providing the facilities are not in use for company business and the service does not offer advantage to a competing company.

\subsubsection{Regulatory Agencies}

Currently, the principal regulatory involvement with spectrophotometry has been in the field of safety in which performance requirements for retroreflective and fluorescent warning devices are being spelled out. The Consumer Product Safety Commission and the States of California and New York have all established regulations concerning reflectors used on bicycles. The Department of Transportation has specified the performance of the orange slow vehicle and emergency warning triangles, and has begun a new investigation into haze measurements on windshields.

\subsection{Direct Measurements Transactions Matrix}

\subsubsection{Analysis of Suppliers and Users}

The input-output matrix presented in table 2. with the corresponding key to the numbers presented in table 1. is an attempt to show in compact form the extent and value of interactions between various groups in the spectrophotometric measurement community, to give some idea of the way the role of these interactions is changing, and to indicate the adequacy of such interactions as it is affected by the quality and availability of spectrophotometric measurements. Although the large variety of uses to which spectrophotometric measurements are put prohibits a complete listing of all of the suppliers and users, a few examples will be 1 isted for each category in order to clarify what is meant by that category.

\section{The Knowledge Community}

This community consists of universities and centers for pure research, the academic and scientific organizations associated with them, and the corresponding technical publishers. This section of the measurement community both supplies and uses spectrophotometric measurement techniques and data generated from spectrophotometric measurements.

\section{International Metrological Organizations}

In our case this refers almost exclusively to national standardization laboratories of other countries, since BIPM and other metrological agencies have little activity in spectrophotometry. These laboratories both supply and use techniques and data, and they 
Each intersection in the matrix in Table 1 contains an array of five numbers which quantify our estimates of the interactions. The five keys in this figure are arranged in the same pattern as the numbers in a given intersection. An $X$ in the intersection indicates that this transaction was deliberately not considered, a ? in any position indicates insufficient information for a judgement, and a ? in any position indicates insufficient information, but we are making a strong effort to get it.

IMPORTANCE

How important is this transaction in terms of its economic worth or other value such as contribution to health or safety?

1 - Of minor importance

2 - Important or desirable

3 - No alternative or legally required

4 - Essential

\author{
ADEQUACY \\ Is this type of transaction pro- \\ ceeding adequately? \\ 0 - Yes \\ 1 - Yes, but some improvement \\ is needed \\ 3 - No, it is less than adequate. \\ 4 - No, it is completely in- \\ adequate.
}

\section{MAGN ITUDE}

What number of measurements or interactions are involved, or what quantity of goods or number of services does this interaction represent?

Blank - A negligible number or quantity.

1 - A rather smal1 number of quantity.

2 - A moderate number or quantity.

3 - A large number or quantity.

4 - A huge number or quantity.

\section{RATE OF CHANGE}

What word best describes the change in the number or importance of the transactions represented here?

$\mathrm{N}$ - Decreasing

0 - Not Changing

2 - Increasing

4 - Increasing very rapidly
POTENTIAL EFFECT BY NBS

With a successful program at NBS of the magnitude proposed as a result of this study, what percentage increase in the potential value (magnitude, effectiveness, or importance) of this transaction would result?

1 - Little or no increase.

2 - A moderate increase

3 - A large increase

4 - A very large increase 


\begin{tabular}{|c|c|c|c|c|c|c|c|c|c|c|c|c|c|c|c|c|c|c|c|}
\hline $\begin{array}{l}\text { General } \\
\text { Public }\end{array}$ & $\stackrel{\infty}{\sim}$ & & & & & & & & & & $\mid \begin{array}{lll}-1 & & \\
& 0 & \\
0 & & \\
\end{array}$ & & 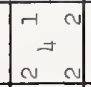 & 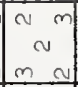 & 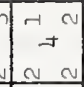 & $\mid \begin{array}{ll}n & 9 \\
2 & -2\end{array}$ & & & \\
\hline $\begin{array}{l}\text { Medical and } \\
\text { Health }\end{array}$ & $=$ & ${ }_{n}^{n}$ & $a_{-1}^{-1}$ & $a_{n} a n$ & & 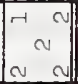 & 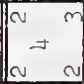 & 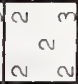 & 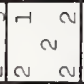 & $N$ & $\mid \begin{array}{lll}4 & n \\
4 & n & \\
& n & \end{array}$ & $\therefore$ & $\left.\mid \begin{array}{cc}-1 & -1 \\
-1 & 9\end{array}\right]$ & & & & & $\left|\begin{array}{cc}0 & m \\
0 & -7 \\
c & c\end{array}\right|$ & \\
\hline $\begin{array}{l}\text { Remote } \\
\text { Sensing }\end{array}$ & $\underset{\sim}{+}$ & $a^{-1}{ }^{2}$ & $\begin{array}{ll} \pm & 0 \\
N^{-1} & 0\end{array}$ & & & $\left|\begin{array}{cc}m & -7 \\
0 & -1 \\
0 & 0\end{array}\right|$ & & \begin{tabular}{ll|}
$m$ & 9 \\
0 & -1
\end{tabular} & 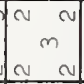 & 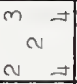 & & $\left.\begin{array}{cc}a & m \\
\sim & -1\end{array}\right]$ & $\mid \begin{array}{cc}m & a \\
-1 & a\end{array}$ & & & 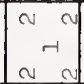 & $\int_{n}^{m-1}$ & & \\
\hline $\begin{array}{l}\text { Energy-Related } \\
\text { Industry }\end{array}$ & $\cong$ & 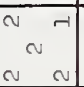 & & 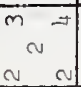 & & $\left|\begin{array}{ll}m & 0 \\
0 & -1\end{array}\right|$ & & \begin{tabular}{ll|}
$m$ & 9 \\
0 & -7
\end{tabular} & $\left|\begin{array}{cc}-1 & 0 \\
-1 & -1\end{array}\right|$ & 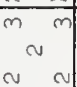 & & $\begin{array}{ccc}\alpha & m \\
\alpha & -1 & \\
\alpha & \alpha\end{array}$ & & & & 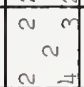 & $\infty \sim^{2}$ & & \\
\hline $\begin{array}{l}\text { Food } \\
\text { Production } \\
\text { Industry }\end{array}$ & $\exists$ & 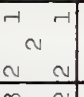 & & $\begin{array}{lll}m & m \\
v^{-1} & & \sim \\
\end{array}$ & $m^{-7}$ & 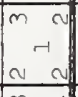 & & {$\left[\begin{array}{rr}-1 & \\
-4 & -1\end{array}\right]$} & & 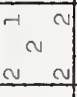 & & 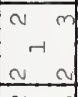 & & & ma & & $\mid \begin{array}{c}m \\
n \\
\sim\end{array}$ & & \\
\hline $\begin{array}{l}\text { Safety-Related } \\
\text { Industry }\end{array}$ & $m$ & $\mathrm{~m}^{4} \mathrm{~m}^{-1} \mathrm{c}$ & & $m^{m}=$ & $m^{n}-7$ & {$\left[\begin{array}{ll}m & -7 \\
0 & -7\end{array}\right]$} & & $\infty$ & & & & $\left.\begin{array}{cc}a & \\
0 & -1 \\
0 & 0\end{array}\right]$ & & 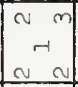 & & & & & \\
\hline $\begin{array}{l}\text { Appearance } \\
\text { Related } \\
\text { industry }\end{array}$ & $\approx$ & $a^{a}{ }^{n}$ & $a^{\infty}$ & ${ }^{m}{ }^{2}$ & & $\begin{array}{ll}m & 0 \\
& \sim\end{array}$ & & $\begin{array}{rr}-1 \\
-1\end{array}$ & & 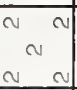 & & 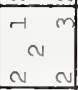 & $m_{n}=1$ & 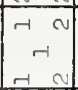 & and & & & & \\
\hline $\begin{array}{l}\text { Industrial } \\
\text { Irade } \\
\text { Associations }\end{array}$ & $\Rightarrow$ & $\begin{array}{lll}-4 & 4 \\
-1 & 4\end{array}$ & $m$ & $a^{a}$ & $\sim$ & & & $a^{m}$ & & & 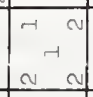 & 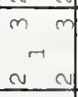 & & 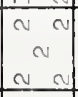 & & & & & \\
\hline $\begin{array}{l}\text { State and Local } \\
\text { Governmental } \\
\text { fencies }\end{array}$ & ? & 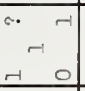 & $x$ & 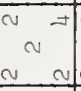 & $a^{2} v^{2}$ & & & & & a & 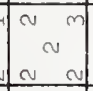 & 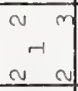 & & & & & & & \\
\hline $\begin{array}{l}\text { Other Federal } \\
\text { jovernment } \\
\text { A gencies }\end{array}$ & 0 & 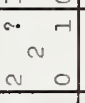 & $x$ & $\begin{array}{ccc}a & -7 \\
n^{2} & \\
n^{2} & \\
\end{array}$ & 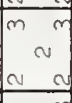 & 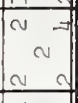 & & & $\begin{array}{|ll|}-1 & -1 \\
-1 & -1 \\
-1 & 0 \\
\end{array}$ & 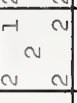 & & 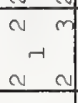 & & & & & $\left.\mid \begin{array}{ll|}a & \\
& \sim \\
a & \end{array}\right]$ & & \\
\hline $\begin{array}{l}\text { ther } \\
\text { Department } \\
\text { Defense }\end{array}$ & $\infty$ & $\sim c$ & $x$ & & $\begin{array}{ll}\cdots & \\
& 2 \\
0 & 4 \\
0 & 4\end{array}$ & $\int_{-1}^{-1}-1$ & & & 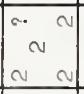 & & & & $\mid \begin{array}{ll}\infty & 0 \\
\infty & 0\end{array}$ & & & & 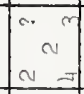 & & \\
\hline $\begin{array}{l}\text { Segulatory } \\
\text { A gencies }\end{array}$ & - & $\sim$ & & & $\begin{array}{lll}m & -7 \\
2 & -1 \\
0 & -7\end{array}$ & $\begin{array}{ll}4 \\
0 \\
0 \\
\end{array}$ & & 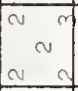 & & & $a^{-1}+1$ & 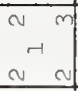 & & \begin{tabular}{ll|}
$\infty$ & \\
$\infty$ & \\
$\infty$ & \\
\end{tabular} & $a^{n}-1$ & & $\mid \begin{array}{ll}m & m \\
c & c\end{array}$ & $\begin{array}{lll}a & -4 \\
4 & -7\end{array}$ & \\
\hline $\begin{array}{l}\text { Cisandard and } \\
\text { lesting Labs } \\
\text { and Services }\end{array}$ & 6 & ᄀ $\sim$ & a & m & $\begin{aligned}-1 & \\
& \sim\end{aligned}$ & $a^{n}=$ & -1 & $\begin{array}{rr}\sim & \\
& \sim \\
\sim & 0 \\
\end{array}$ & & & & $\begin{array}{ccc}r & \\
u^{-1} & - \\
\end{array}$ & $\mid \begin{array}{lll}-1 & 0 \\
0 & 0 & 0 \\
\end{array}$ & & & & & & \\
\hline$\because B S$ & in & on & $a^{a}$ & 2 & {$\left[\begin{array}{lll}0 & -1 \\
-1\end{array}\right]$} & $a^{2}$ & $\sim^{a}$ & 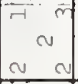 & $a^{2}$ & a & $a^{n}$ & 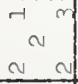 & $\int_{0}^{-1} \infty$ & $\begin{array}{|cc|}0 & 0 \\
0 & -1 \\
0 & 0\end{array} \mid$ & 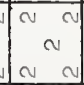 & & & and & \\
\hline $\begin{array}{l}\text { instrumentation - } \\
\text { Industry }\end{array}$ & & $\begin{array}{cc}-1 \\
\sim\end{array}$ & ${ }^{n}$ & & $\begin{array}{|cc|}m & -7 \\
& -1 \\
0 & 0\end{array} \mid$ & 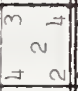 & & 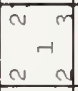 & $\begin{array}{cc}2 \\
0 \\
0\end{array}$ & $\begin{array}{ll}\mathrm{a} & \\
\sim & \\
\sim & \end{array}$ & ${ }_{-1}^{-1}$ & 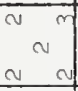 & $\sqrt{a} a^{n}$ & $\begin{array}{|cc|} & -1 \\
0 & -1 \\
\end{array}$ & ar & $\begin{array}{lll}7 & & \\
& N & \\
& & \end{array}$ & & $\begin{array}{ll}a \\
\cdots\end{array}$ & \\
\hline $\begin{array}{l}\text { Documentary } \\
\text { pecifications } \\
\text { pranization }\end{array}$ & $m$ & $\operatorname{cov}^{2}$ & $\mathrm{~A}^{2}$ & $\begin{array}{c}a \\
\sim\end{array}$ & $m \sim$ & 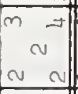 & $a^{n}+1$ & 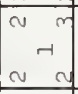 & 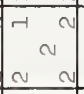 & a & $\begin{array}{ll}2 \\
2 \\
2\end{array}$ & $\begin{array}{lll}a & & \\
& \sim & \\
\sim & & \\
\end{array}$ & 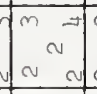 & 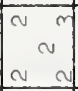 & $a^{2}{ }^{2}$ & & & 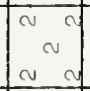 & \\
\hline $\begin{array}{l}\text { International } \\
\text { Metrological } \\
\text { zegsnizations }\end{array}$ & $\infty$ & $x$ & $x$ & $\star$ & $\Varangle$ & $\times$ & $\times$ & $x$ & $x$ & 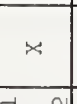 & $x$ & $x$ & $x$ & $x$ & $\star x$ & $x$ & 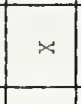 & $\not x$ & 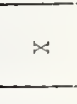 \\
\hline $\begin{array}{l}\text { Knowledge } \\
\text { :ommunity }\end{array}$ & $\neg$ & 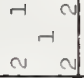 & $\begin{array}{ccc}0 & -11 \\
-1 & & 0 \\
-1 & 0\end{array}$ & $\begin{array}{rl}-1 & 0 \\
a^{-1} & 0 \\
\end{array}$ & {$\left[\begin{array}{cc}-1 & m \\
0 & 0 \\
0 & 0\end{array}\right]$} & $\alpha^{-}$ & 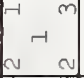 & $\left|\begin{array}{ll}-1 & -1 \\
-1 & -1 \\
-1 & 0\end{array}\right|$ & 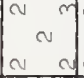 & $a^{2} \infty$ & ન & t & & & & - & $m$ & & \\
\hline 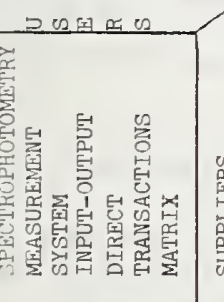 & 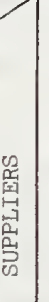 & 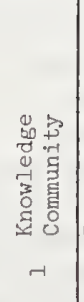 & 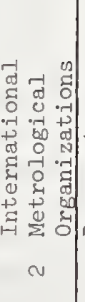 & 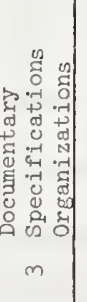 & 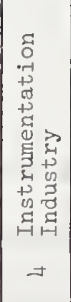 & $\begin{array}{l}\text { 筧 } \\
\text { in }\end{array}$ & 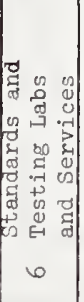 & 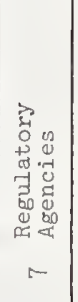 & 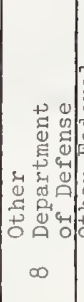 & $\begin{array}{c}0 \\
0 \\
0 \\
0\end{array}$ & 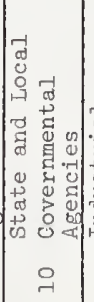 & 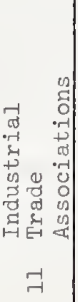 & 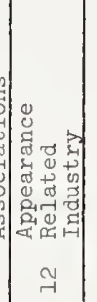 & 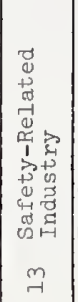 & 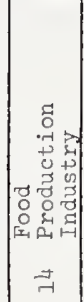 & 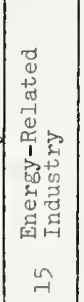 & 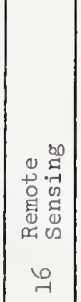 & 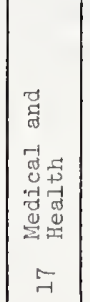 & 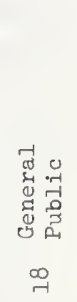 \\
\hline
\end{tabular}


also supply measurement services and transfer standards.

\section{Documentary Specifications Organizations}

These include the major ones such as ISO, ASTM and ANSI and those committees of industrial trade associations which write standard methods and procedures. It also includes governmental and military organizations which deal in specification and documentary standards. These organizations make use of data and techniques in the general sense and supply documented standard procedures and specifications based on spectrophotometric measurements.

\section{The Instrumentation Industry}

This is a key part of the measurement system. Most of the users are not in a position to modify or improve their instruments, so that the state of the measurements is determined to a great extent by the instrument manufacturers. The instrument manufacturers make use of data, techniques, documentary standards, and transfer standards to supply instruments, related techniques, and standards. Many instrument companies also supply consultation services on special measurement problems.

\section{NBS}

In general, the role of NBS is similar to that of the other National Standards Laboratories as indicated in category 2 . Specific details of the NBS programs are given in section 4 of this Summary Report.

\section{Standards and Testing Laboratories}

This category includes all commercial and governmental laboratoreis, beyond the national standardization laboratories, which supply measurements as their services. Some of these al so supply documentary standards and, in such cases, would also be included in item 3 above. These organizations make use of techniques, data and standards in their work.

\section{Regulatory Agencies}

The principal ones in this connection are involved in safety regulations governing the performance of reflectors and warning signs and governing color coding for safety signs. Other regulatory agencies dealing with such topics as health and communications also fall into this category since they make use of spectrophotometric measurements in enforcing other regulations such as those governing food additives.

\section{The Department of Defense}

In addition to its role in specification indicated in item 3 , and its internal standardization laboratories covered in item 6 , the Department of Defense makes great use of spectrophotometric measurements in procurement and in research. This latter activity provides a source of data and techniques for the rest of the measurement system.

\section{Other Federal Government Agencies}

This includes such organizations as the U.S. Department of Agriculture in both its research and information clearinghouse roles, the General Services Administration in its procurement role, the Weather Service in its data gathering operations, and the Postal Service in its automated mail handling operations. These organizations take advantage of techniques and data to provide services which people often do not associate with spectrophotometry.

\section{State and Local Government Agencies}

This category includes principally procurement of materials, e.g. reflective sheeting for highway signs by transportation departments and paints by maintenance departments. The extent of the direct use of spectrophotometric measurements by these groups varies widely from location to location.

\section{Industrial Trade Organizations}

Many trade groups are included in connection with their documentary standards functions in item 3 . In this section are included principally the instrument manufacturers' trade groups. These organizations provide a key interaction point between NBS and the instrument industry. One principal contribution is their supplying data on the performance of the measurement system through laboratory intercomparisons.

\section{The Appearance Related Industries}

This is the first of several classifications of industries in terms of their particular connection to spectrophotometry. The appearance related industries would include a11 industries which make products for producing appearances such as the paint industry, the printing ink industry, and the dye industry, and all industries making objects in which appearance is an important factor. Such industries include the textile industry, the appliance industry, the automotive industry, the printing industry, and the packaging and advertising industries. The objects involved 
range from spools of thread to railroad trains, and includes foods to the extent that their appearance is involved. These industries supply themselves with measurement services and the public with a wide variety of goods. They use instruments, standards, and measurement techniques. Large industrial organizations in this area often maintain their own spectrophotometric laboratories, the standardization and measurement service activities of which are included in item 6 . above.

\section{Safety-Related Industry}

This includes the industries making safety related devices such as reflectors and fluorescent safety vests. These products are related in general to appearance, but a separate category is included here because of a difference in the modes of interaction with the other groups.

\section{Food Production Industry}

This grouping includes groups dealing with food other than from an appearance or from a heal th-safety aspect. It includes a nondestructive testing of agricultural products for nutritional content, ripeness, storeability, spoilage and the effects of disease. These groups make use of measurement systems to provide food which might otherwise not be available for human consumption.

\section{Energy Related Industry}

This section emphasizes groups dealing with the radiative transfer of heat and light in order to make the most efficient use of the energy sources which are available. The principal item supplied here is energy transfer data and the principal users are architects and engineers within the same industry.

\section{Remote Sensing}

This quasi-governmental activity is listed separately both because it is so large and because it represents a cooperative effort which crosses the boundaries of many groups listed above. Its main requirements as a user are instruments and calibration services and its service is supplying data for a host of applications. Quantitative remote sensing from space is almost entirely dependent on either radiometry or on spectrophotometry.

\section{Medical and Health}

In terms of spectrophotometry, the largest transaction in this portion of the measurement community is the one in which the clinical laboratory supplies data to the physician to aid him in his diagnosis. Another part of this segment is the drug industry in which spectrophotometric measurements are used in research and quality control.

\section{The General Public}

The general public includes individual citizens and groups not included in the lists above. Almost no private citizen performs spectrophotometric measurement by means of instruments for himself in the same sense that he makes measurements of weight, length, and volume with scales, rulers and cups in his everyday activities. The closest the average citizen comes to such measurements are his "eyeball measurements" to determine whether paints match, are the right color, or are light or dark enough or whether the window or wall in his house needs washing. The average citizen is only indirectly connected with the more sophisticated spectrophotometric measurements and is, as he probably should be, usually unaware of their existence.

In examining this input-output transactions matrix, one must take into account the very broad range of relatively disconnected groups involved in each category. From row to row in each column the entries often apply to entirely different user groups as well as to different supplier groups, and from column to column in a given row the entries often apply to different supplier groups. In the same way that spectrophotometry is a tool for measurement among many for the typical user, so the transactions listed are very complex, involving more than spectrophotometric measurements in carrying them out and more than a change in the status of the spectrophotometric measurements to bring about a change in them. As a result, the matrix as a whole and its individual intersections are even less meaningful than is usually the case for such matrices. However, there are a few points to notice.

a) The transactions in almost every category are increasing, not only because of the general growth in the nation's population and industry, but even more because of the increasing use of automation and sophisticated technology.

b) The general public is involved almost entirely as a consumer of products, and not as a consumer of spectrophotometric services. Therefore, the blocks in the last column indicate public consumption of objects on which people make "measurements" based on their ability to see and feel. Although 
these measurements are crude in scientific terms, they are of the ultimate importance in judging the success of the more sophisticated spectrophotometric measurements used by the suppliers.

c) None of the importance entries are "essential". This is simply because there are alternative ways of doing the job in almost every case, and mankind would survive if the jobs for which there were no alternate method were not done. However, it would be logically obsurd to discount one way of doing a job simply because another existed. The extreme value of spectrophotometric measurements is described by "effective" not by "essential", for in many cases the spectrophotometric measurement is the most effective way of doing a job.

d) With the exception of the field of remote sensing, which is a field still struggling with its adolescence, there are no entries of 4 in the adequacy column. In most other transactions which have a longer historical background, ways have been found to eventually get results. In almost every case, however, there is room for significant improvement, and it is toward such improvements that the NBS spectrophotometry program should be directed.

e) The groups in the upper left hand corner generally interact in both directions with each other since they are all on essentially the same level in the system. It is only as one gets to the consumer level that the transaction is more or less one way. There is an indirect return transaction by the consumer which is not listed on the table because it is difficult to quantify. That transaction is the acceptance or rejection of a manufacturer's goods or services, which in a vague sense is conveying the results of sensual spectrophotometric measurements back to the manufacturer.

f) The lower right hand corner was coded to indicate the way the new NBS program is intended to interact with the measurement system. The regions marked for the highest increase in potential through NBS activities are those toward which the program is directly aimed. The regions with lower increase in potential are those where the NBS program could produce either incidental fallout benefits or else where the influence of the NBS program is indirect.

\subsubsection{Highlights re Major Users}

The users in categories 12 through 17 are the principal ones in terms of size. In order to properly interpret the matrix, one must visualize a jump in size of three or four orders of magnitude in going from entry 11 to entry 12 in the table. A11 of the groups have been described briefly in itemizing the categories in section 2.5.1. Because of the number and complexity of the major user groups, they will not be described in further detail here.

\section{IMPACT, STATUS AND TRENDS OF MEASUREMENT SYSTEM}

The basic appeal of spectrophotometry as a measurement technique lies in the possibilities inherent in an eye which can see in the entire range of wavelengths from the far ultraviolet to the far infrared; an eye which can accurately single out any desired portion or combination of portions of the spectrum for scrutiny; an eye which neither tires nor blinks and which can make accurate quantitative judgements over many orders of magnitude. To such an eye the possibilities for analysis, inspection, and automatic process control are almost limitless.

Spectrophotometry is clean, allowing, for example, chemical analyses to be performed without the complexity of wet chemical techniques. Spectrophotometric instruments are easily automated and can be made quite simple, making possible untended sensing stations which relay to a central point data concerning such phenomena as meteorological conditions, pollution levels in air or water, or the status of a product on an assembly line. Spectrophotometry is convenient, since the data can be obtained very rapidly and the output of the detectors is in the form of electric impulses or electric currents, either of which are readily interfaced to electronic analog or digital computers which can store and analyze the data, make corrections, perform complex computations, and present the results in a useful form.

Recent advances in technology add to the appeal of spectrophotometry. Many improvements have been made in photoelectric detectors over the past few years, increasing spectral range, efficiency, and stability and reducing noise. The continual trend in electronics has been toward reduction in size, decreased noise, increased efficiency, and greater gain so that the electronics need hardly ever be a limitation to a measurement. Digital computers have decreased in physical size and cost to the point that it is possible 
to include them as an integral part of even moderately priced measurement systems, and automatic data taking equipment and time sharing computers extend this capability to the lower priced systems. Smaller, stronger, and more stable radiation sources are available. Light emitting diodes and solid state detectors offer new possibilities for portable instruments. Tunable dye lasers which can be operated in a quasi-broadband mode appear to be an ideal radiation source for spectrophotometry, providing power levels which are completely impractical with an incandescent source followed by a monochromator. In addition to providing high power, the advent of the laser has stimulated the optics industry so that optical components are better and more readily available than ever before. Thin $f i 7 m$ technology has made rapid gains, offering many additional possibilities for producing special filters and reflectors.

In response to the advances in component technology and the ability to handle large amounts of data and complicated data reduction schemes which is provided by computers, a strong interest has arisen in developing new instruments and uses for spectrophotometry. The projected increase in the rate of purchase of spectrophotometric instrumentation by laboratories engaged in chemical analys is alone is from 110 million dollars per year in 1970 to 238 million dollars per year in 1980 , a rate which parallels the overall increase in analytical laboratory instrumentation. The potential for far more dramatic increases, however, lies in areas more closely related to the everyday world such as automation of industrial processes, quality control, routing of mail and freight, inventory control, and crime detection. In such areas the possibilities for increasing productivity, reducing confusion and drudge work, and improving safety conditions through spectrophotometric techniques are almost endless.

\subsection{Impact of Measurements}

3.1.1 Functiona 1, Technologica1, and Scientific Applications

In general, the measurements are used as an analytic probe. At one extreme is the chemical analysis use, in which the reflected or transmitted radiation is studied in terms of what is missing, that is, how much radiation is being absorbed in the sample. From this, one can deduce or monitor the chemical structure or content of the sample. At the other extreme is the appearance related industry, in which the reflected or transmitted radiation itself is of interest. From it, one can determine how an object will appear under given lighting. In between lie a large number of other uses, ranging from automatic inspection for flaws in fabrics to determining the structure of ice sheets and cloud formations from satellite observations. In general, spectrophotometric measurements are "eyes" of industry, but eyes which cover a much wider range of wavelengths than human eyes, and which are not as easily tired or prejudiced.

The measurements are involved in almost all areas of manufacturing and trade in consumer goods in which appearance is involved. This includes printing, food processing, the automotive industry, the printing industry, the photographic industry, the textile industry, the paint industry, the building industry, and many others. It also includes suppliers of these industries, such as the dyestuff industry, the plastics industry, and the manufacturers of pigments and inks. In the chemical analysis area, there is an extremely broad range of applications in manufacturing. One aspect of chemical analysis, clinical chemistry, has a very large impact, not only in terms of its monetary worth (over $\$ 1$ billion per year of clinical tests depend upon spectrophotometric measurements) but in terms of its impact on the health of individuals and communities. In addition, there are a large number of smaller but very important areas in which spectrophotometric measurements play a role. Retroreflectance measurements are key in the production of safety reflectors and traffic sign sheeting, which, while representing a relatively small fiscal outlay, play a large role in safety. Spectrophotometric measurements also play a role in the automatic inspection of bearing surfaces and the surfaces of other fine machine work, and the success of these measurements can have a large impact in terms of the lifetime and reliability of the end products.

Spectrophotometric measurements are used for automatic monitoring of the production or presence of dangerous pollutants, in which role they have a large impact on the safety and comfort of the public. In their role in non-destructive analysis of farm products and in remote sensing detection of crop disease, these measurements will have an increasing impact on the success of the effort to feed the world's populations.

A large number of fields of science involve spectrophotometric measurements. They have long been indispensible to chemical research. They are also used in studying the radiative transfer of energy, an investigative field which is taking on a new and larger importance in an age in which energy conservation is becoming more essential. With the advent of remote sensing via satellite, the use of spectrophotometric measurements for geological 
studies, meteorology, and large scale botanical research has been increasing rapidly.

\subsubsection{Economic Impacts - Costs and Benefits}

The costs and direct benefits of these measurements as they are done now were not calculated as part of this study. The measurement system has been practically selfsustaining for many years, and the object of this study was to determine the impact of renewed NBS effort. However, a conservative estimate would be that spectrophotometric measurements are or can be used in industries involving from one tenth to one half of the gross national product. These measurements, or their alternatives, are only one part of many aspects of these manufacturing processes. One would estimate the cost of the measurements in tenths to thousandths of a percent of the total in each area, which, while large, is not staggering. In order to determine the benefits, one must remember that for most spectrophotometric measurements, there are alternative techniques which could bring about the same end. For example, chemical analysis can be carried out to the point where the human eye or an analytical balance can be used to judge the results, and fabric inspection and color control has long been done by human observers and for the most part still is. The spectrophotometric measurement must be thought of in connection with its alternatives in any cost and benefit analysis.

In this study, an effort was made to avoid getting bogged down in the immensity of the measurement system both as it exists and as it might be, and to look at it from the point of view of the gains which might be made by more active NBS involvement. NBS would be completely over-extended if it went into applications research on spectrophotometric measurements, so it was assumed that the NBS role would be strictly one of making more accurate measurements readily available, and thereby increasing the potential for application. In some fields, alternative methods are probably superior to spectrophotometric techniques, and these fields were not studied further. Actualiy, some positive benefits could be gained by NBS's advising caution in the use of spectrophotometry for these applications. In many other fields a spectrophotometric technique is more rapid, costs less, and is more accurate than its competitors, or at least it has reasonable potential to be so if the state of the measurement art can be improved.

The benefits from improving the spectrophotometric measurement system can be very great. In almost every case, the cost of the instrumentation can be quickly recovered in the case of a successful system through increased productivity and reduced waste. The cost of failing to make these improvements is simply that the advantages will not be obtained.

Because the measurements are generally in terms of the ratio of the optical behavior of an object to that of a real or idealized standard, metrication will have little impact on the spectrophotometric measurement system. The numbers are usually the same in any system of measurement. Since many instruments in the analytic field are already constructed in metric dimensions, the secondary impact of metrication in terms of instrument construction and spare parts will be less than in many fields.

With the proper metrological support, spectrophotometry has a key role to play in the future of industry, science, and technology. Several particular aspects of the field which were accessible to analysis were looked into and from these alone, it was estimated that there is a potential for real benefit in terms of productivity and the prevention of waste of almost two billion dollars annually and this by no means covered all of the field. (See Appendix R of the original report, included here as Appendix C.) The study has obviously shown the importance of the field and clearly indicates where the larger areas of potential benefit are. Even if the estimate were ten times too high and even if only one tenth of one percent of the potential were put to use, both of which are on the outside edge of probability, it is clear from this study that if NBS does its job properly in this field, the approximately $\$ 400,000$ total budget (including overhead) for its activity in this field is easily justified.

\subsubsection{Social, Human, Person-on-the-Street Impacts}

To the extent that the more effective use of spectrophotometric measurements increase productivity and reduces waste, the benefit in an economic sense to the person-on-thestreet is apparent. He can satisfy his wants and needs without as much labor, thereby giving him more freedom to shape his life style. There are sociological and psychological benefits to having the appearance of one's surroundings under better control. The benefits to be gained from more accurate medical analysis are apparent, as are the benefits to be obtained from having safety devices work properly. The person-on-thestreet is almost always well removed from the measurements themselves, to the point that, in most cases, he is completely unaware of their existence. However this will not prevent him from enjoying and making use of the benefits derived from them. 


\subsection{Status and Trends of the System}

A certain level of accuracy in spectrophotometric measurements can be readily obtained without outside help by a competent scientist or technician. To the extent that these measurements can be used, they are being quite fully exploited. However, the more complex measurements and those in which high accuracy is required are not as successful. What is required to promote these measurements to their fullest potential is careful study by workers with sufficient radiometric training to be able to recognize the significance of the fine points of the measurements, workers who can determine the appropriate techniques and equipment for the measurements, who will translate these into equipment which can be used under ordinary laboratory conditions and by the present laboratory personnel, and who can provide clear instructions and appropriate standards to back those persons in their work.

There are several driving forces toward change in the spectrophotometric measurement system. As was mentioned earlier, new technology is available which makes advances in this field possible and attracts the interest of inventors and scientists. However, the strongest forces are the economic and social ones which are behind the trend toward automation in general. The constant watching in quality control, chemical process control, etc., is the sort of thing that the unblinking eyes of spectrophotometric instruments do best. This type of work is usually very tedious to the human observer, and he tends to become bored, lax in his efforts, and inattentive after a short time on the job. As a result, the human observer is costly and few people see a future in training for a job in which automation appears both possible and imminent. The result is that as more and more applications of spectrophotometry are successful, the impetus for using them will increase even more rapidly.

There is a negative force due to the historic development of the measurements. A number of years ago, when technology was not as advanced as it is currently and when the subtle difficulties in the measurements had not been recognized, spectrophotometric instruments were oversold in the sense that they did not deliver the end results which were promised. As a result, many companies and individuals had an expensive bad experience with the measurements and, quite natural$1 y$, developed a reluctance for further experimentation. The availability of new technology, coupled with the arrival of "new blood" on the management scene has dissipated a great deal of this reluctance. However, the subtleties of the measurements still remain and it is important that this unfortunate bit of history not be allowed to repeat itself.

\section{SURVEY OF NBS SERVICES}

\subsection{The Past}

Work in spectrophotometry began at NBS as early as 1906, and over the ensuing years a number of significant instrument developments, basic studies, and publications resulted from the program. Especially noteable were the work of Taylor in the earlier developments of reflectance measurements, and of Judd in the related fields of color and vision. A number of NBS workers left to form their own companies to produce spectrophotometric instruments, an indirect benefit of NBS activity in the field. A bibliography which thoroughly covers NBS publications related to spectrophotometry through 1970 and partially after that is available in NBS Special Publication 393, "Colorimetry and Spectrophotometry: A Bibliography of NBS Publications January 1906 Through January 1973", by Kenneth L. Kelley. During the sixties, NBS acquired some excellent commercially developed spectrophotometers and was able to provide a number of useful measurement services for industry, the military, and other government agencies.

The principal weakness of the NBS program in the recent past was that the capabilities of the NBS group were not being developed to the point of sophistication required to bring about the next stage of improvement in the measurement system. As a result, NBS was unable to provide leadership to the measurement community which would enable it to take advantage of the new technology that was becoming available in the late sixties. At that time, for example, there was a call for extremely accurate filters for use in calibrating instruments for clinical analysis. The Spectrophotometry Section in the Institute for Basic Standards (IBS) failed to respond satisfactorily to this challenge, and a group was formed in the Institute for Materials Research (IMR) to develop the filters. As a result, SRM 930A, a set of filters is now being issued with transmittance measured to nearly state-of-the-art accuracy by that group. This has provided a partial solution to the clinical chemist's problems, but only a partial solution. The matter of standard techniques is being addressed to some extent by that group, but the question of improving the instrumentation which is available to the average user and providing measurement assurance was left as a need to be satisfied by IBS.

Early in 1970, NBS management recognized that the IBS Spectrophotometry Section was in trouble and placed it under Dr. R.P. Madden, who 'served as Acting Section Chief while also conducting the affairs of the Vacuum Ultraviolet Physics Section of which he was Chief. Under his direction, work was begun on the 
first IBS reference instrument, one for measuring transmittance. In January 1971, the Spectrophotometry Section was dissolved, and its activities were placed in the Optical Radiation Section. At that time Dr.W.H. Venable was placed in charge of the group performing this work and began this study, the principal part of which was completed in 1972 .

\subsection{The Present - Scope of NBS Services \\ 4.2.1 Description of NBS Services}

There are four NBS organizational units dealing with spectrophotometry. Most of the general work in spectrophotometry is done by two of these, the Spectrophotometry group in the Radiometric Physics Section of IBS and the Spectrophotometry and Fluorimetry group in the Special Analytical Instrumentation section in IMR. The activities of the IMR group are generally related to analytical chemistry with the emphasis on measurement of absorption and fluorescence. The activities of the IBS group are directed toward radiometric and appearance measurements with the emphasis on the measurement of reflectance transmittance. Two smaller efforts are being carried out in other parts of NBS. In the Optics and Micrometrology Section of IBS, there is a program for supplying transmittance and reflectance step tablets in support of the photographic industry. The activities of this group are reported in the division summary report of the study, The National Measurement System for Optics. In the Laboratory Evaluation Technology Section of the Institute for Applied Technology (IAT) in NBS, there are several collaborative reference programs involving spectrophotometry. These programs provide well-controlled and regularly repeated intercomparisons of laboratory measurement capabilities in which individual laboratories can participate on a subscription basis. A spectrophotometric laboratory is maintained by this group for preparing samples and certain standards which are used in connection with this program. In addition, this laboratory supplies reflectance standards on a regular basis to the paper industry.

NBS participation has been strong in the spectrophotometric activities of the CIE, principally through participation in the activities of Technical Committee TC 2.3 "Materials" which deals with those properties of materials involved in radiative transfer, particularly with respect to applications to lighting. Dr. Mielenz of the IMR group is the chairman of the subcommittee on Fluorescense in TC 2.3 and Dr. Venable of the Radiometric Physics Section of IBS and Dr. Shumaker of the Optical Radiation Section of IBS are both active participants in the work of the committee.
Within the United States there is considerable NBS participation in committee activities directed towards standards and standard techniques. The IBS group participates in the work of the American Society for Testing and Materials (ASTM) and the Inter-Society Color Council. The IMR group receives considerable support for its work related to Clinical Chemistry from the American Association of Clinical Chemists. The IAT group, through the activities of Dr. Lashof and Mr. Hammond participates strongly in the work of both the ASTM and the Technical Association of the Paper and Pulp Industry. In addition to this principal committee work, members of al1 of the groups act as consultants for other committees and associations which develop specialized standard test methods.

The principal NBS activities at present are developing instruments and techniques. Since the former NBS Spectrophotometry Section did not maintain a leadership role in the measurement system, the instrumentation with which NBS was left at the beginning of this decade was only slightly above average. As a result, in 1971 NBS was not in a position to properly standardize the measurements at that time, much less to help provide improvements. The IBS Reference Transmittance Spectrophotometer which was started in 1970 by $\mathrm{Dr}$. Klaus Mielenz working under $\mathrm{Dr}$. Madden has been fully automated and is now operable in the ultraviolet and visible portions of the spectrum. An attachment by means of which this instrument can measure specular (mirror-like) reflectance has been constructed and awaits testing. A reference instrument for making directional incidence, hemispherical collection measurements under a wide variety of conditions has been constructed. That instrument has been sucessfully used to resolve the discrepancies between the absolute reflectance measurements of several national laboratories. Several measurement accessory systems have been designed and constructed to be used with the same instrument which provide a capability for bidirectional measurements of diffuse reflector, specular reflectance measurements, and the measurement of diffuse reflectance and transmittance, all with very high accuracy. Arrangements are under way at this writing for providing several secondary standards laboratories with master standards measured with this instrument. IBS has also constructed, with the help of funding from the Consumer Product Safety Commission, a reference instrument for retroreflectance measurements, which will be used for a number of applications related to safety. Two reference instruments have been built by the IMR spectrophotometry group. The first, built by Dr. Mavrodineanu, is a reference transmittance spectrophotometer designed 
especially for developing and calibrating standard filters and solutions for absorption spectrophotometry. The second, built by Dr. Mielenz, is a very versatile goniospectrofluorimeter. The principal remaining gap in NBS reference instrumentation for spectrophotometry is in the moderately long wavelength infrared region of the spectrum from 2 to 50 micrometers. Plans are under way in the IBS group to provide instrumentation in this spectral region. With this reference instrumentation, NBS is again assuming the role of leadership which it should have in the field of spectrophotometric measurements.

In the area of general purpose standards, the IBS spectrophotometry group has been currently working through the Office of Standard Reference Materials at NBS to supply as Standard Reference Materials rare earth glass filters for calibrating wavelength and white glass standards of diffuse reflectance. These materials, which had formerly been issued with little or no documentation as to their proper use, will be supplied with complete instructions including corrections for different instrument parameters such as bandpass and beam divergence, when needed. Work on supplying diffuse reflectance SRM's and replenishing the supply of standard mirrors in SRM is now under way in the IBS group, and this group is also developing standard retroreflectors as a potential SRM. The IMR group has developed and is supplying standard filters (SRM 930A) and solutions (SRM 931) which are used principally for calibrating and checking the performance of absorbance spectrophotometers for analytical chemistry. Standard filters for use at ultraviolet wavelengths and standards for measuring fluorescence are currently being developed by that group.

As the new NBS measurement capabilities are developed, means are being developed to use them to serve the scientific and industrial community. The support of groups in industries, in universities, and in other government agencies is being used in this work. In summary, the NBS spectrophotometry program is currently in a state of transition. It currently supplies a fair amount of consultation (an average of one call per day) and a very modest amount of measurement services and standards, principally aimed at developing improvements in the measurements. Efforts are being made to take full advantage of every contact with the measurement system as a whole in order to be able to make the best possible use of the new NBS measurement capabilities as they are developed.

\subsubsection{Users of NBS Services}

The users of NBS services fall into three general categories: (1) instrument manufacturers and secondary standards laboratories, (2) people working in research both in industry and in universities, and (3) people performing industrial and laboratory testing measurements on a routine basis. Because of the changes in the spectrophotometry program at NBS, discussion of the users will be deferred to section 4.5 which deals with the future.

\subsubsection{Alternate Sources}

In terms of the quality of the measurements, until recently almost any of the present NBS spectrophotometric Standards could be supplied by one (but not more than one) other of a number of good laboratories in each area of the measurement system. The reason is that the NBS measurements in the past have been made on commercial instruments for which there are unexplored potential sources of systematic error. Therefore, any one laboratory could also supply standards with a given systematic error. There would probably be no trouble until two laboratories, each with its own source of systematic error, began to supply standards. In terms of a few arbitrary requirements for traceability to NBS, some users are forced to go to NBS, but beyond that, alternate sources could supply measurements at that level. However, because of the highly dispersed nature of the measurement community and the sophistication of the instrumentation and techniques required to standardize spectrophotometric measurements at their optimum level, it is very doubtful that any source other than NBS could effectively improve on the present state of the measurements.

\subsubsection{Funding Sources for NBS Services}

The funding for the present NBS spectrophotometry program has been largely from NBS STRS (in-house) funds. The principal exception is the work related to clinical chemistry in IMR. In the past, a larger fraction of the funds of the Spectrophotometry Section came from contracts from other government agencies. However, the principal product of the work done under such funding was data on specific samples, and this funding in general did little to advance the ability of NBS to serve the measurement system. With regard to these agencies, NBS was a measurement service laboratory. Since 1971, outside 
funding has been discouraged, except for special cases in which it is felt that it would advance the NBS measurement capability. An example of this latter case of the clinical chemistry work in IBR and the Consumer Product Safety Commission's support of the IBS development of a basic capability in retroreflectance measurements. When it is justified in the interest of the national measurement system or because of the uniqueness of the NBS facilities, measurements are occasionally performed at NBS at cost for industries and other agencies and standards and standard reference materials are also sold to cover the cost of the routine portions of the measurements.

\subsubsection{Mechanism for Supplying Services}

Services are supplied principally through three mechanisms. The first is the standards and measurement services which have already been mentioned. The second is through consultation about measurement problems and techniques directly with users, principally those who are engaged in developing new applications of measurements. When a new application is promising, the NBS groups sometimes supply measurement assistance to enable a worker to determine what wavelength range or type of measurement he should employ for his purpose. The third way is through working directly with instrument manufacturers, commercial consultants, and commercial measurements laboratories. NBS personnel work with the staff of these organizations, both on a one-to-one basis and through their trade associations, in order to help raise the quality of the instruments, standards, and services offered by them. This portion of the measurement system is judged the most productive one through which NBS can supply its services, since each of these groups in turn influences the rest of the highly dispersed measurement community in a way in which NBS alone could equal only with much more effort. In a sense, NBS uses these groups as a multiplying agent for its efforts while at the same time assisting them in their efforts.

\subsection{Impact of NBS Services}

\subsubsection{Economic Impact of Major User Classes}

As has already been mentioned in section 3.1 of this report, the economic impact of the major user classes includes a very large fraction of the gross national product. This impact has not been evaluated, but an effort has been made to evaluate the potential worth of improvements in the measurements, which potential worth may be as high as $\$ 2$ billion per year if full advantage is taken of the improvements. In addition there are benefits in terms of health and safety which can be realized but which are difficult to give a monetary value. The NBS services of the recent past did little to make these improvements possible, and the present efforts at NBS are directed toward enabling NBS to assume a role of leadership in providing these improvements. The present NBS impact is still quite small, although it is growing, but the major NBS impact will occur in the future.

\subsubsection{Technological Impact of NBS Services}

The technological impact of the NBS services is indirect. Because of the immense size of the user community, the direct impact of NBS services will always be relatively smal1. However, the catalytic effect of the NBS instrument development assistance and measurement assurance efforts can provide a great impact in the future.

\subsubsection{Payoff from Changes in NBS Services}

In order to gain time, outside agencies have been discouraged from seeking routine measurement services from the IBS spectrophotometry group. The impact of this change has been small, since more and more commercial instruments with capabilities equal to NBS's commercial instruments have reached the field and since the standards provided by the instrument manufacturers have been of nearly as good quality as those which were offered by NBS in the recent past.

The principal change for NBS has been to direct its services toward the instrumentation industry through measurement assurance programs and other direct assistance at the level above that of the large body of users. only a very small portion of these programs are in operation yet, and the lag time from inception to payoff can range from five to ten years. As a result, the evaluation of the payoff for these changes must be judged in the future.

\subsection{Evaluation of NBS Program}

The principal characteristic of the present NBS Program is that it is in transition. The program which is being set up is distinctively different from that in the past, and, as a result, it is too early to be able to judge the strengths and weaknesses of the program. The needs for NBS services have been determined principally in the study conducted in 1971 and this determination has been constantly updated through contact with workers in the field. The stream of calls for consultation and measurement which NBS receives provides an automatic source of information which provides about half of the input needed 
to keep up to date on the needs for standardization services. The other half of the outside information is obtained through direct inquiry of those working in an area where a suspected need exists and through working meetings of standards groups and trade associations.

The present NBS sources are, as noted, inadequate to meet the challenge of the need to increase measurement accuracy at the user level, except in the area of regular transmittance. In those few areas in which NBS has adequate resources, at present priorities among users are assigned on the basis of highest multiplying power, i.e., which services are most valuable in the long run toward building up the measurement system. "Valuable" in this case may be in terms of feedback to NBS to help determine what is needed or "valuable" may be defined in terms of the user's ability to spread the benefits of NBS's service to him through the measurement community. As a result, most of the NBS services at present, with the exception of consultation, are directed toward the instrument industry and commercial and military measurement laboratories. The main exception is with respect to consultation, where listening to and helping users at all levels continues to be a valuable source of information about the spectrophotometric measurement system.

It is highly feasible to "contract out" the standards work in the sense of having standards issued by other laboratories which receive measurement assistance from NBS. In fact, this is the direction which should be taken. Likewise, most of the measurement service requests which come to NBS can be handled by other laboratories, so that NBS services should be limited to those with some strong measurement system "payoff".

The role which is being shaped for NBS is one which is clearly within the mandate of NBS and which should be unique. It is within the NBS mandate because it is a measurement standardization problem. Because of the highly dispersed nature of the user community it is probable that an adequate program to meet the challenge of spectrophotometric improvement can not be organized anywhere else. Furthermore, becaulse of the expense of realizing the type of capability which is required to advance these measurements, it is highly desirable that this effort be done centrally and not duplicated. Thus this work should be done mainly at NBS.

\subsection{The Future}

Actually, throughout this report it is really the future which is being addressed. The anticipated needs for improvement in accuracy amount to reducing the error by approximately an order of magnitude in almost every area of spectrophotometric measurement. The sort of instrumentation and expertise required for this sort of work would be prohibitively expensive for any user when viewed in proportion to the part spectrophotometry plays in his overall program. However, there are so many users that a relatively small program at NBS can lay the foundations for immense benefits.

The impact of the National Measurement System Study on this NBS program has been immense. This is natural, since this particular study was initiated on the recognition that there was something wrong with the NBS program at the time. As a result of this study, a radical change has been brought about in the NBS program for spectrophotometry which should make it very effective with only a modest additional initial outlay of funds during a five year re-instrumentation program. Continuing impact assessment and other evaluation of the measurement system is built into the way the program is conducted.

\section{SUMMARY AND CONCLUSIONS}

The National Measurement System in Spectrophotometry is currently far from Tiving up to its potential value. A rapidly developing technology supports improvements in these measurements and provides the material with which to develop these measurements to their full potential. A relatively modest program in NBS, augmented by active cooperation with instrument manufacturers and commercial laboratoreis, can provide the measurement support which is required for a much fuller realization of the benefits to be derived through spectrophotometry. NBS should proceed with all deliberate haste to meet the challenge of this potential. 
APPENDIX A. METHODOLOGY OF THE STUDY

The methodology of this study was chosen to fit the situation in which a lone investigator must probe a huge measurement system in which there exist really very few specialists and determine what NBS should do. The decision was to pursue a rather small number of representative samples of the field in depth, rather than make a shallow pass at the entire field.

The approach was quite simple. The records of the old Spectrophotometry Section were scanned to determine which fields were being served in the past. The Thomas Register and similar references were searched for representative samples of each type of user, and a list of these was made up. From these lists were planned a series of visits to these industries and laboratories based, principally, on geographic location. After several trips, certain of the fields were eliminated from the list as being ones for which the present measurement system was adequate. In the other cases, the visits were continued until sufficient understanding of the nature of the problems was obtained. As the study progressed and new fields of use were come upon, they were treated in the same way. The timing of the trips was planned in a way to allow attendance at as many relevant professional meetings as possible. At such meetings, the connection between the activities of these groups and the National Measurement System were observed. After a year and a half of such travels, punctuated by accompanying periods of literature search, three conclusions about the measurement system as related to NBS became apparent:

1. There was an immense potential value to be gained by providing improved spectrophotometric measurements, annual dollar value of which is ten thousand times the cost of the NBS program.

2. This potential would be so difficult to realize without leadership by NBS that the probability of its being realized through any other means was extremely low.

3. There is an approach, through reprogramming, by which NBS can supply this leadership without significant increase in funding. Once these three conclusions were reached, the cost effectiveness of further formal study of the measurement system dropped to nearly zero. Therefore, the results of the study were put into the 1972 report for IBS management and the formal study was ended. In short, the needs have been identified, they are great, and it is time to get on with the work. However, the National Measurement System in Spectrophotometry continues to be evaluated as a natural result of the pursuit of the NBS program. 


\section{APPENDIX B. A PROPOSED DIRECTION FOR NBS EFFORTS}

The following is section 7 of the report from the 1972 IBS study. It summarizes the rationale behind the current IBS program. With certain exceptions involving the emphasis on standards and the source of funding, it reflects the type of thinking behind the basic work being done in spectrophotometry by the IMR group as well.

\section{WHAT SHOULD NBS DO?}

Since there is no basic unit such as length or electric charge to be maintained in spectrophotometry, there is sometimes a tendency on the part of those not familiar with the field to assume that there is no need for IBS activity. However, in reality it is not sensible to expect that correct spectrophotometric measurements will occur unaided if the ratios have been defined, just as it is not sensible to assume that length measurements will be made correctly simply because the number of wavelengths per meter has been defined for an atomic emission line. The mission of the Institute for Basic Standards, as put forth in Department Organization Order 30-2B, November 16, 1970 is:

The Institute for Basic Standards shall provide the central basis within the United States of a complete and consistent system of physical measurement; coordinate that system with measurement systems of other nations; and furnish essential services leading to accurate and uniform physical measurements throughout the Nation's scientific community, industry, and commerce.

The United States clearly does not have a complete and consistent system of measurement in spectrophotometry, and a great deal of assistance from a central agency will be required before the measurements will be adequate for most of the scientific, indistrial, and commercial community. There is clearly a need for an active program in spectrophotometry. The general nature of such a program will be discussed in this section. Details of the program are also given in certain appendices. In particular, since the present activities of the group are the beginnings of this program, the discussion in each subsection describing a recent or current activity of the group in Appendix L (not included in the present report) provides insight into the nature of the program being proposed. 
7.1 THE GEIERAL GOALS of the spectrophotometry program are to:

7.1.1 DEVELOP UIIIFORM BASES for spectrophotometric measurement. Since a spectrophotometric measurement is a determination of a ratio, the basis for measurement consists of a definition of the ratio to be determined. In most cases, these ratios have not been defined carefully enough to allow for future improvements in the measurements, and in some cases there is no common definition at all. The definitions should be based on very general idealized physical abstractions in order to avoid placing arbitrary restrictions on instrument design, but at the same time the properties so defined must be measurable in practical ways and the quantities obtained must be useful to the technical community.

7.1.2 BUIL UP SPECTROPHOTO'IETRIC CORPETEICE AT : IBS to a much higher level than before. We must develop the instruments and procedures for highly accurate measurements in order to properly realize and maintain an absolute measurement scale, and we must build up a better understanding of the physics behind the measurements and the uses to which they are to be put in order to define the measurements and provide adequate leadership to the technical community.

7.1.3 EXERCISE LEADERSHIP in promoting accurate spectrophotometric measurements. It is quite clear that no all-encompassing organization of the diverse users of spectrophotometry will form, either spontaneously or through persuasion, to take the lead in spectrophotometry and define the needs for NBS. Rather the spectrophotometry group in IBS must take an active role in seeing that sufficiently accurate measurements can be carried out.

From the general goals outlined in the preceding paragraphs and the state of the measurement system as it now exists, a general

7.2 DIRECTIOH FOR NBS SPECTROPHOTO'IETRY, described briefly in the following paragraphs, has been worked out. It provides guidelines by which decisions to undertake specific actions will be made. Examples of such actions are given in Appendix I.

Competent pursuit of the spectrophotometry program will require much better 7.2.1 IISTRUMENTATIO' than has previously been available to the group. The general goals for the first phase of the program are to be able to make the following general measurements on selected gage materials:

a. Specular transmittance to an uncertainty of $10^{-4}$ units of transmittance or . $2 \%$ of the transmittance value, whichever is larger,

b. Directiona1-hemispherical reflectance and transmittance to an uncertainty of $10^{-3}$ or $.5 \%$ of the value, whichever is larger, 
c. Bi-directional reflectance factor to an uncertainty of $.5 \times 10^{-3}$ or $1 \%$ of the value, whichever is larger, (Al1 of the above are to be in the wavelength range 250 to $2000 \mathrm{~nm}$, but realized initially in the visible range from approximately 400 to $750 \mathrm{~nm}$.)

d. Fluorescence measurements which will allow determination of the transfer of energy from one wavelength to another with an uncertainty of less than $5 \%$, and

e. Infrared directional-hemispherical transmittance and reflectance over the range 1 to $50 \mu \mathrm{m}$ to an uncertainty of $.5 \times 10^{-3}$ or $2 \%$ of the value, whichever is larger.

The accuracy limits given above are based on the present needs of a large part of the users and on the current state of the art in sample preparation. The IBS instruments themselves should be stable enough and well enough defined to allow us to be sure that they contribute a relatively small part of the overall uncertainty.

To be able to perform such measurements will require substantial improvements on our present instrumentation and the construction of several high quality reference instruments by means of which the measurements can be placed on an absolute basis. Also, investigating potential sources of systematic error in detail will require a flexible automatic experiment control and data gathering system to handle the detailed measurements which will be involved. The instrumentation itself should reflect the IBS role in the measurement system. It should be flexible in order to meet the changes which occur on the technological scene. It should be developed in such a way that parameters can be varied conveniently in order to investigate for systematic errors. Auxilliary equipment such as would be used for mapping beams of radiation will be called for. Such instrumentation would enable the spectrophotometry group to measure definitively in a way which would be impossible for individuals in the various segments of the technical community. The same instrumentation could be used efficiently for investigating the comon areas of diverse measurements, as, for example, similar mapping techniques apply to studying the uniformity of filters, reflecting surfaces, fluorescing materials and the spread of light in translucent materials. A more detailed description of the instrumentation to be developed appears in Appendix M. (Not included in the present report).

A carefully planned and strong

7.2.2 IIVTERACTION with the technical and scientific community is essential if the IBS spectrophotometry group is to carry out its mission successfully without doubling or tripling in size. These interactions must be carried on at several levels. 
a. We must have a close working relationship with the instrument manufacturers in order to be aware of the measurements which are being attempted in order to assist in reducing measurement errors which are instrument related. In this latter respect, we might maintain certain special gages which could be loaned or rented to the instrument manufacturers for testing their instruments, making gages available which would not be practical to produce in large numbers. Such gages might for example be filters which have nearly equal transmittance but differ in their reflectance, thickness, scattering, or other properties.

b. We should work with secondary standards laboratories to assist them in issuing gages which are adequately documented and accurately measured. This would involve checking the materials for suitability, measuring the master gages, working with the secondary lab to see that its transfer of measurement is proper, and occasionally checking the laboratory's output. The gages issued in the past by IBS have been measured by comparison to master gages and could have been issued as well by any of several secondary laboratories with our cooperation. It should be noted that gages for evaluating the purity of materials and other special purposes may best be issued by IMR or possibly by IAT rather than by an agency outside NBS, in which case IBS would provide measurement support similar to that supplied to secondary standards laboratories. In any case, IBS should concentrate on measurements primarily, and should not become involved with developing gages. One important exception to this would be in seeing to it that suitable materials for certain general purpose gages are available. This might even include direct action by our group to procure and distribute to secondary labs certain hard-to-get materials in cases where no other organization can handle the job.

c. We should work with the many organizations and committees which are dealing with problems in spectrophotometric measurements, and particularly we should become strongly involved with the bodies such as ANSI, ASTM, ISO, and CIE which are determining general test procedures. Our involvement, however, should be limited to a technical nature, such as in assisting with definitions of the properties to be measured and testing the dependence of measurements on certain parameters. We should generally avoid assuming such positions as committee chairman or secretary, because such positions include much administrative work and would spread us too thin. 
d. We should interact through publications to promote accurate measurements. This should include "trade journals" as well as the scientific journals such as JOSA and Applied Optics. The natural tendency is for measurements in each industry or technical field to drift toward its own separate gage system. This results in the inability of others to take full advantage of the results of work which has been done in a particular field. This tendency can be countered in publications both negatively, by calling attention to departures which exist, and positively, by providing information about correct procedures, about help which is available through IBS, secondary standards laboratories and instrument makers, and about pitfalls and limitations in certain types of measurements.

e. We should follow up indications of difficulty within the measurements system. Sometimes these indications occur in the course of commerce when difficulties in meeting specifications are encountered. At other times organizations carrying out intercomparisons encounter discrepancies. In general, however, only a detailed investigation requiring specialized instrumentation can get at the basis for such difficulties. This type of investigation when carried through to the source of the trouble is probably the most fruitful means of getting the measurement system in order. NBS is by far best suited for such investigations both because of the special instrumentation required and because of the detached or neutral position which we can take in interacting with parties of opposing interests.

Whenever possible, the IBS group should take an active role in seeking out such interactions, rather than wait until we are approached. This active role has several advantages. By discovering problems early, we can prevent - diverse scales of measurement from becoming entrenched within the data base.

By simultaneously seeking out problems in several fields using similar measurements, we can develop standard techniques which have more universal application. By actively seeking problems at a time when our instrumentation is set up to handle a certain type of measurement, we can make more efficient use of our time. By working with groups as they develop standard procedures and by actively seeking to correct the faults in existing standard procedures, we can prevent the propagation of poor or mis-applied procedures. It is through taking an active role that the leadership which should be shown by NBS can be exercised. 


\section{Special steps must be taken to assist users in}

7.2.3 APPLYIVIG THE RESULTS OF BASIC RESEARCH to spectrophotometric measurements at a practical level. Although a great deal of very basic research can be done in the physics of absorption, scattering, fluorescence, transmission and reflection of radiation, and properties of gage. materials, this type of work should not be undertaken in general at first. These fields have been extensively worked over in the past, and there are other groups working on them at present, so that there is much information available and more being provided continually. However, there is a definite need to relate this basic information in a very pragmatic way to spectrophotometric measurements. The principal research and theoretical development efforts of the IBS spectrophotometry group for some time to come should be directed toward satisfying that need. Our initial basic physical research should be directly supplemental to the applied research, filling in gaps where information is not currently available, and it should be undertaken with extreme caution so that it does not become the principal occupation of the group. After the gap between theory and practice left by the former spectrophotometry program has been closed, the pursuit of basic physical investigations can be reexamined.

Since spectrophotometric measurements are many-dimensional and the problems of planning a measurement and evaluating the data are quite severe, means should be developed by which the information most needed for an application can be readily obtained. One of the most interesting and important aspects of applied spectrophotometry is the question of how much spectrophotometric data must be obtained, at what wavelengths, and how good must it be in order to determine the value of the related parameter in which one is really interested, such as the concentration of a solute in a solvent, the amount of a particular colorant in a paint pigment, what kind of soil or vegetation appears in a given part of an aerial photograph, or how well a given set of gages can be used to evaluate the performance of a tristimulus colorimeter. The mathematical bases for handling this problem are well developed, lying principally in the fields of statistics, information theory, and functional analysis. However, with the exception of statistics, very little has been done to put these mathematical tools in the hands of the person solving the day to day problems of industry. An intermediate step is needed between the esoteric product of the mathematicians and the myriads of everyday problems which arise in applied spectrophotometry. This intermediate step involves determining which theorems are applicable to evaluating spectrophotometric data and how, and then developing and explaining procedures by which the practical problems of spectrophotometry can be handled in a way useful at the applied level. In earlier times, this intermediate step would have been almost of academic interest only, since the amount of calculations to be performed in any but the simplest treatment would have been prohibitive. Only a few analog techniques such as using weighting filters, as in tristimulus colorimeters, or simply electronic differentiation and integration were available for practical handling of more than a few data at a reasonable rate. With the present ready availability of digital computers and automatic data gathering systems, the burden has been shifted to the mathematical analysis. In order to effectively evaluate our own efforts as a standards laboratory, we must develop and apply such analysis ourselves. Putting this analysis in a form which is understandable and useable by the rest of the scientific and industrial community is one of the most important contributions we can make. 
The type of applied research described above should initially be used to investigate spectrophotometric measurement per se, in order to provide explicit definitions of the quantities to be measured, evaluate natural limits of accuracy and sources of error in present methods of measuring these quantities, and developing better measurements for the future. The results of this research should be published in a way that they will be of value to even those whose background in optics and mathematics is relatively unsophisticated.

Our general goals strongly affect which

7.2,4 IEASUREIEVS we undertake. We should avoid routinely issuing standard gages, and in general, except for certainmeasurements made for groups within NBS and other government agencies, we should only undertake measurements which are directed specifically toward extending or improving the measurement process. This is a distinct departure from the policy of the former Spectrophotometry Section, but it is essential if we are to advance the measurement system. The emphasis here is on the reason behind the measurement rather than the measurement itself. For example, we might measure the reflectance of foliage to help an agricultural laboratory set up general methods for measuring foliage, but not simply to supply the laboratory with data on the reflectance of specific samples of foliage. We should undertake color measurements to determine how accurately a particular type of color measurement is being done, but not to provide a routine colorimetric measurement. We should make measurements in case of trade disputes regarding specifications, not simply to resolve the dispute but to get at the basic source of the descrepancy. We should make the results and outcomes of such measurements available to those making similar measurements through publications and, when necessary, through direct mailings. In this way, the greatest use can be had from the relatively small number of measurements which a group of our size can do while continuing in the other tasks listed in this section.

The final question of the program which the IBS spectrophotometry group undertakes is the means by which the

7.3 SUPPORT for the program is to be provided. The present indications are that the program should be supported between $80 \%$ and $90 \%$ directly from NBS. The reasons for this lie within the nature of the program. The principal need for direct support lies in the need for our keeping the 7.3.1 INITIATIVE, If, as is emphasized in the preceding section, we are to lead towards an improved measurement system, we must be supported internally in general. The direction the work takes is rightly decided by those providing the support. If we provide our own support, we can direct our own program. We can much more effectively influence the measurement system by volunteering those general services we feel to be necessary at a given time than by waiting to be called in as paid consultants.

7.3.2 EFFICIEICY depends upon internal support for three reasons. First, in losing the initiative in what we do we lose the advantage of scheduling our activities efficiently. Second, the time spent in negotiating contracts for complicated undertakings is completely lost to doing the more important technical work. Third, most contracted work is toward a specific end result other than improving the capability of the group or the measurement system as a whole. As a result, we would divert our efforts from our principal tasks. 
Finally, a very practical

7.3.3 REALISM calls for this type of support. The structure of the measurement system is such that approach to NBS regarding these measurements is voluntary. It would be cumbersome to the point of impracticality to try to legislate proper spectrophotometric measurements in the same sense that measurement of mass and length are legislated. Nevertheless, since these measurements are so universally used, the general public which pays for NBS and whose health, safety, and satisfaction depends upon them is entitled to have the best measurements possible in this field. It is highly unrealistic to expect the relatively few standards laboratories with which we deal to altruistically volunteer to support the system for the benefit of the general public. Neither will those involved in a dispute over satisfaction of specifications be interested in supporting general research into the basic causes of their difficulty as it affects the rest of the technical community. It is also quite unrealistic to expect those dealing strictly with us in the next five years to absorb the cost of catching up with nearly fifteen years of NBS neglect of the fundamentals of spectrophotometric measurements.

Direct charges should be made for direct or "service" measurements for other government agencies or other NBS groups. Such measurements have other end objectives than improving optical radiation measurements. Charges should be made for IMR and IAT master gage and other measurements which are covered by sponsors or are catalog measurements, but the cost of intercomparisons and other measurements undertaken for improving the measurements of both groups should be internally supported by each. Charges should be made to secondary laboratories to cover time spent directly on gage measurements and for routinely maintaining the capability to perform these measurements, but we should not charge for developing our capability to perform them. Likewise, in undertaking specific tests, we should charge for the direct measurements only as they are requested by the "customer", and we should not charge for developing the capability to make measurements or for services rendered to the rest of the technical community as a result of our undertaking such measurements.

Under the foregoing guidelines for the support of the program, the bulk of the financing must come from within NBS, particularly during the major instrument development stages. The benefits to the public are extensive enough and general enough to justify supporting most of the work directly.

Once the program outlined in this report is undertaken, the magnitude of the job to be done indicates that at least five years should be allowed to pass before a major

7.4 REVIEW OF THE PROGRA'' be undertaken. However, after that time a reassessment of the situation would very probably be advisable. 


\section{APPENDIX C. EVALUATING THE BENEFITS OF IMPROVING SPECTROPHOTOMETRIC MEASUREMENTS}

The following is Appendix R from the 1972 IBS Spectrophotometry study report. It represents an honest effort to evaluate the worth of improving measurements which are only partial contributors to an overall industrial or commercial application. Several points of possible overlap and double counting and one mistake in arithmetic in R.2.4 have been pointed out by Dr. Howard E. Morgan, an economist at the National Bureau of Standards. Dr. Morgan also pointed out that in some cases, the financial benefits would probably be diverted from the directions indicated. However making changes in this section would neither reduce the uncertainty in the final answers significantly nor increase the value of this section as an exercise in evaluating the need for improved spectrophotometry.

\section{Arithmetics of Relevancy and Impact}

As the principal worker in the survey of spectrophotometry, I have come to the conclusion that the present spectrophotometric measurements should and can be improved, that NBS should contribute to these improvements. This entire report has been intended to show the reasons for this conclusion and to indicate how we plan to make our contribution.

However, most of the discussion up to this point has been qualitative. Since a definite amount from public funds will be required to operate this program, it would be appropriate to R.1 QLANTIFY THE BENEFITS to be received by the public. When viewed from a quantitative standpoint and directed toward a complicated program, a question such as "What are the economic, social, and/or political implications? (Consider 5-10 year projections)" is obviously so general and ill-defined that it cannot be answered directly. What is an economic or social implication? How far into politics should measurement standardization extend? How does one define a benefit, and if one man's benefit is another's detriment how should this be handled? All of these questions involve so many value judgments and definitions that rational generalizations are impossible in all but the simplest case.

When this report was first planned, the aforementioned complications made attempts at quantitative descriptions of benefits appear impossible. However, it became apparent during the course of the study that quantitative estimates could be made in specific ways in

R.2 SPECIFIC CASES, and that these specific estimates could be presented along with their individual rationale for the reader shimself to evaluate for worth as he sees fit. This procedure is analogous to the way mathematicians define arithmetics. All that is required in their case is careful definitions of the ground rules and operations and self-consistent arguments. Thus $1+1=2$ or $1+1=0$ depending upon whether common decimal arithmetic or single digit binary arithmetic is being used. The value of the arithmetic depends upon the interpretation of the user and the application to which it is put. 
Since this presentation of some "arithmetics of relevancy and impact" has been added almost as an afterthought, several of the contributors were not included in the list of contacts since they were contacted so recently. Therefore, their help will be acknowledged at the end of the subsections to which they contributed. The numerical data, when not otherwise noted, is based on interpretation of Bureau of the Census Data. If the actual facts could be ascertained, it is highly unlikely that the figures differ by as much as a factor of 10 from real life. The examples given should illustrate why meaningful generalizations are difficult to make and yet should indicate in specific cases the value of the proposed spectrophotometry program.

\section{R.2.1 EXAMPLES FROI THE PAINT INDUSTRY}

NOTES: The paint industry is highly dispersed, with 1500 companies competing for $\$ 3$ billion in business. The top eight companies supply $36 \%$ of the product by value and the remaining production is spread among the others. As a result the competition is keen, with bids for government contracts often differing by as little as $0.25 \%$.

\section{a. EXAMPLE: Government Procurement}

The GSA procures more than 2 million gallons of paint per year for the civilian agencies and about half the military requirements. It can be assumed that procurements by state and local governments and the remainder of the military procurements would amount to an additional 3 million gallons. In the case referred to in L.2.3, a $1 \%$ difference in reflectance amounts to a 5 cent per gallon difference in production costs, and a similar amount applies to colored paints and other finishes. Because of the highly competitive nature of the paint industry, production will move toward the low end of the uncertainty. Therefore, reducing the present $.5 \%$ uncertainty leve 1 to $0.1 \%$ amounts to an increased value received by the taxpayers which can be calculated as follows:

Reflectance delivered with improved measurements. . . . . . . $85.9 \%$

- Reflectance presently delivered... . $85.5 \%$

= Reflectance increase with improved measurements. . . . . . . . $0.4 \%$

At $\$ .05$ per gallon per percent increase in reflectance, the increased value per gallon with improved measurements . \$.02

$\times$ Number of gallons purchased by government annually ....... $5 \times 10^{6}$

= Annual savings. . . . . . . $\$ 100,000$ 
However, it would be unrealistic to assume that this saving would actually result, since the increased cost in making the paint would simply result in higher prices for the paint. The real advantage to be gained is that the market could be made more orderly, thereby saving time such as that spent by GSA and Norris (L.2.3). As it now stands, the specifications are $86 \pm 0.5 \%$. Since this range of uncertainty is economically significant, the manufacturers will try to make the low side of the range, but since measurement techniques are good only to the same uncertainty they will quite often miss the mark, even when an honest attempt is made to hit the middle of the range. Ideally, for a market of this type to be orderly, three conditions must be met simultaneously:

1. The range of uncertainty in the specifications should be no less than really needed based upon the use to which the material is to be put.

2. The range of uncertainty in the measurements should be economically insignificant.

3. The range of uncertainty in the measurements should be at least two or three times less than the range of uncertainty in the specifications.

Thus, in the present example if the specifications were kept at the present $86 \pm 0.5 \%$ for paint reflectance but the reflectance measurements were improved to $\pm 0.1 \%$, reputable manufacturers would find it more economical to keep the reflectance around $85.6 \%$ than to try to control the production to bring it even closer to $85.5 \%$. The savings in wasted manpower in arguments and occasional litigation over failure to meet specifications could be 10 man-years among the many paint companies and governmental units.

Average salary per year of technologists . . . $\$ 10,000$

$x$ Number of man-years saved annually ...... 10

Annual saving through elimination

of non-productive labor (R.3)........ . $\$ 100,000$

\section{b. EXAMPLE: Automation}

Automatic mixing and shading in paint manufacture, which could be made possible with adequate accuracy in spectrophotometric sensing, could perform $20 \%$ of the monotonous and dirty labor in paint production for $1 / 4$ the cost. (Assume that only the eight largest companies automate extensively.) 
Annual paint production worker payroll . . .\$225 million

$\times$ Fraction in eight large companies. . . . . 0.3

$\times$ Fraction of work which could be done by automation . . . . . . . . . 0.2

$\times$ Fraction by which cost is reduced by automation ............ 0.75

= Annual increase in productivity (R.3)..... \$10 million

\section{c. EXAMPLE: Improved Uniformity of Production}

Since present procedures cannot be completely relied upon to produce a uniform product within visual acceptability limits, in the better paints efforts must be made to keep up with paints by lot. This effort costs roughly 200 man years throughout the country by paint warehouses, hardware stores, etc. numbering lots, keeping up with lot numbers when stocking shelves, and solving consumer problems arising out of differences between lots. Also by conservative estimates one quart per 100 gallons of paint is wasted in repainting to the edge of walls, pouring paint from container to container, repainting an entire panel to cover a single blemish, etc., because the control of the appearance is not yet quite adequate. Also, if an average of 7 minutes per 100 gallons is spent by painters avoiding mismatches, a million man-hours will be lost in this way alone. A solid improvement which would reduce the uncertainties by a factor of five in practical spectrophotometric measurements for use in the paint industry could reduce the difficulties from mismatching by more than half, industry-wide.

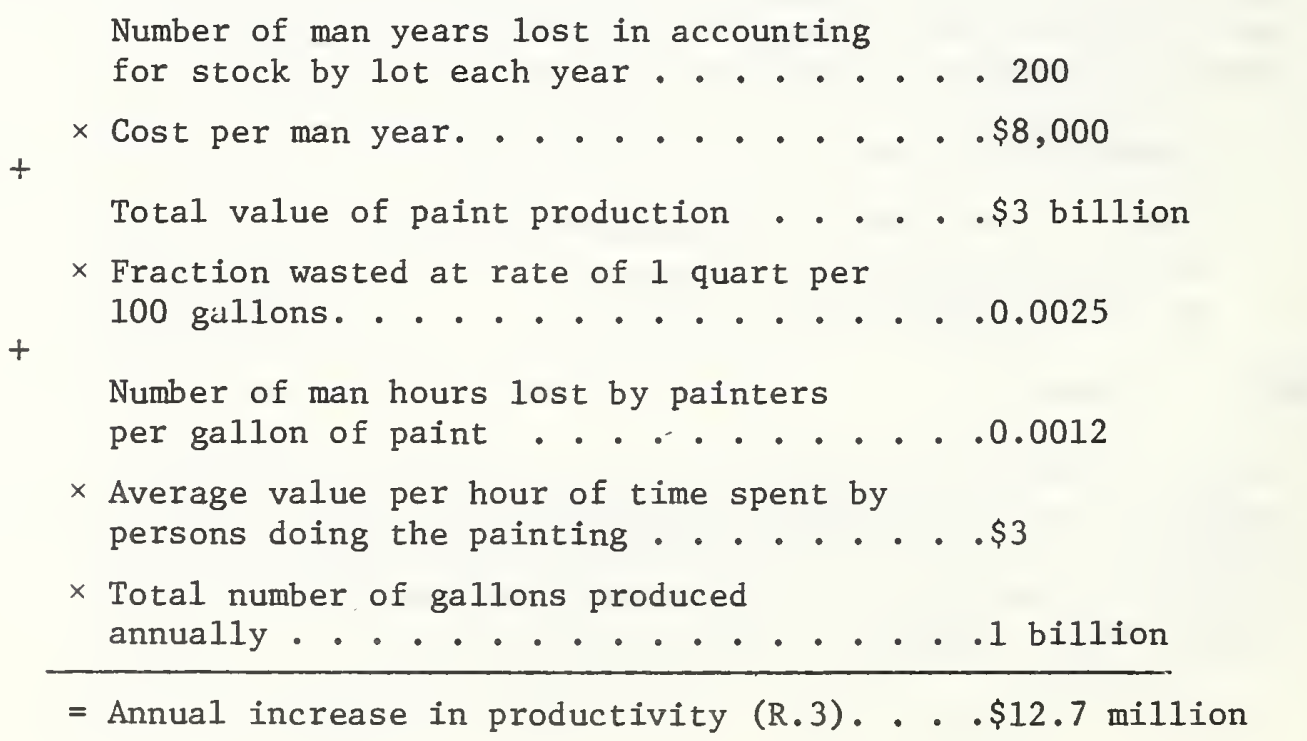




\section{R.2.2 EXAMPES FROM THE TEXTILE AND APPAREL INDUSTRY}

NOTES: In the textile industry, $7000 \mathrm{U} . \mathrm{S}$. companies produce each year shipments valued at $\$ 20$ billion. Unlike the paint industry, where shipping costs from abroad are prohibitive, the textile industry faces very strong competition from imports. In spite of the very favorable supply of raw materials for textiles in the U.S., our present import of textiles exceeds the output by $\$ 400$ million and the deficit is growing at the rate of $\$ 50$ million per year. One of the chief reasons for the clothing industry's favoring imported goods is higher quality in terms of freedom from flaws and uniformity of the product. Competing textile manufacturers abroad have been able to take advantage of inexpensive labor to perform more detailed inspections than could be afforded in this country. The United States' clothing industry itself, which grosses approximately $\$ 20$ billion per year with $\$ 10$ billion per year in value added, is suffering even more than the textile industry from competition from abroad, with a trade deficit which has been doubling every four years and currently stands at nearly $\$ 1$ billion. Although various import quotas have been applied to textiles and clothing, these are at the best stopgap and can be beneficial only if they are used to buy time for improvement of the domestic industry. The only productive answer to this problem is automation $(\mathrm{J})$, in which appearance measurements play a large part. Through proper automated control and inspection of fabrics, they can be made uniform enough to allow many cutting and preassembly tasks in clothing production to be automated as well.

\section{a. EXAMPLE: Inspection of Material Before Manufactur of Clothing}

Manufacturers of better quality clothing inspect much of the material going into their products. An inspector can visually inspect about 10 yards per minute at most, and there is some doubt that he sees very much after an hour on the job. Since $10 \%$ of the fabric used is inspected this way, the cost of this inspection along is $\$ 3$ million per year, of which $95 \%$ could be saved by automated pre-inspection. However, if automated preinspection were to become more widespread an even greater advantage could be realized. Approximately $0.1 \%$ of the garments produced contain flaws which on the average represent a real loss of $20 \%$ per garment for anything from extra handling in special sale to discarding. This savings can only be realized, however, if this type of inspection is accurate. By definition, a flaw can be seen. If an inspecting machine "sees" four times as many flaws as those which the human observer would consider important, the saving could be wiped out in wasted materials. Therefore, a standard method for determining the sensitivity level to set the instrument, a problem in appearance evaluation ( $I$ ), and a means of judging instrument performance, a problem in time-varying spectrophotometry, will both need to be solved before this type of 
inspection will be accepted. Solving this type of problem would be most efficiently done by NBS, since it would be a natural part of solving many similar problems. The value of solving this problem could be calculated as follows:

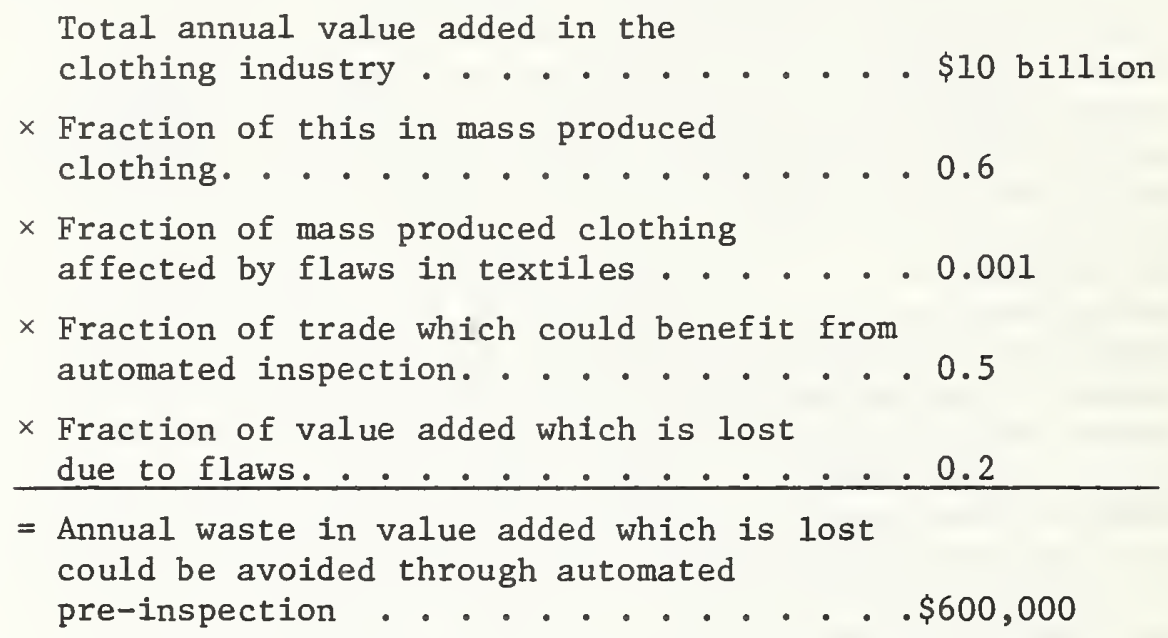

\section{b. EXAMPLE: Inability to Communicate Color and Appearance}

The color and appearance aspects of the textile market offer an excellent example of a disorderly market. In one manufacturer's knitted sportswear operations, $35 \%$ to $40 \%$ of the fabric received is rejected because of improper color. This material is not wasted, of course, since it can be resold, but the shipping, handling and half the inspection costs must be considered a total loss. These problems exist in a market where for the most part an honest effort is being made to communicate specifications and meet them. The estimated total value of production of this type of material is $\$ 2$ billion per year. Shipping out, handling, inspecting, shipping back, handling again and reselling will add about $10 \%$ to the cost of the material receiving this type of treatment, which would be over $10 \%$ of the production. If absolute specifications and accurate measurements could be made, most of these difficulties could be eliminated for an estimated increase in productivity of over $\$ 20$ million per year in this small segment of the industray alone. There is little doubt that if the three criteria for an orderly market (R.2.1a) could be met in this case through improved appearance abstractions (I) and spectrophotometric measurements, there could easily be an industrywide savings of time, handling, and confusion between textile distributer and clothing manufacturer, the value of which can be calculated as follows: 
Total value of textiles

Total value of annual

textile production ...... . \$20 billion

$\times$ Fraction of this used in

manufacture of colored clothes . . 0.25

$\times$ Fraction of this rejected because

of poor color control . . . . 0.05

$\times$ Fraction added to cost by

rehandling ............ 0.1

= Annual wasted effort which could

be avoided through an orderly

market.......... \$25 million

c. EXAMPLE: Advantage of Product Specification and Inspection

One of the principal advantages offered by import fabrics over domestic fabrics as far as the domestic clothing industry is concerned is that many of the imports guarantee flaw-free fabrics and better repeatability in appearance. U.S. industry cannot compete at this level if inspection and sorting is done by manyal labor. However, industry has in many cases been "burned" by failures of the early appearance instrumentation to live up to claims, and therefore regards such instrumentation with suspicion. Activity by the National Bureau of Standards in producing accurate, reliable, and practical measurement procedures would help dispel this reluctance to automate. Automatic inspection for flaws and classification by lot in appearance would enable the domestic manufacturers to compete on an even footing with the best import competition, and the deficit in import could be cut at least in half in a productive manner.

Annual trade deficit in textiles . . \$400 million
$\times$ Fraction of trade which could be
regained by improved U.S. goods . . 0.5
$=$ Improvement in balance of trade . . $\$ 200$ million

d. EXAMPLE: Advantage of Imperceptible Differences

The color control problem described in part $b$ of this section is brought about by the clothing manufacturer's attempt to produce garments which could be hung side by side on the same rack for sale. Even more care must be taken, with special marking procedures for cutting and assembling garments, to make sure that the material matches at seams, where very little difference can be tolerated. The type of technological 
advancement being considered in the ETIP proposal (J) is one by which fabrics would be produced to very high tolerances through automated controls. If such fabric production could be attained, marking and the associated handling could be eliminated and much sub-assembly work in garment production could be done automatically. This automation could easily reduce the value-added cost of U.S. clothing production by $20 \%$ in areas directly affected and would place our textiles at an advantage in the world markets as well. The benefits of success in such an undertaking could mean a reduction of the clothing deficit in the balance of trade by one-half. The over-all savings could be calculated as follows:

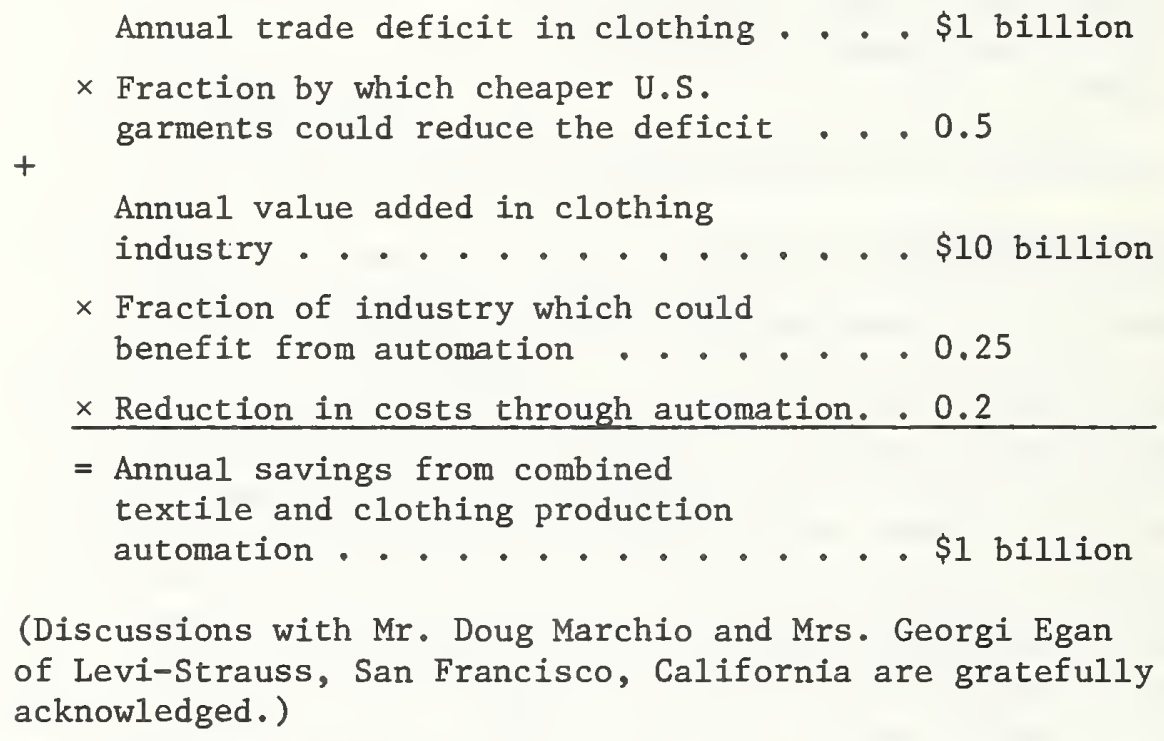

$\times$ Fraction by which cheaper U.S. garments could reduce the deficit . 0.5

(Discussions with Mr. Doug Marchio and Mrs. Georgi Egan of Levi-Strauss, San Francisco, California are gratefully acknowledged.)

\section{R.2.3 EXAMPLES FROM MEDICINE}

NOTES: The field of medicine is difficult to describe simply in terms of value of products, since much of what is involved is services. Therefore, for purposes of this discussion, the annual value of direct medical services will be set at $\$ 35$ billion, the sum of direct payments by individuals for medical care, insurance benefits for medical care, and government subsidy of medical care. (The latter is a small part of the total.) of this amount, it is probably reasonable to assume that five percent, which is $\$ 1.7$ billion, goes for clinical tests. An additional approximately $\$ 2$ billion, mostly in government funds, is spent annually on medical research. There are no figures available to connect suffering, disability, or death to improper diagnosis resulting from inaccurate laboratory tests. However, percentage values given to indicate an increase in the useful results of the tests would be presumed to apply as well to a reduction of these ill effects. 


\section{a. EXAMPLE: Clinical Tests - Present Techniques}

As mentioned in part 5.2, clinical tests are complex analyses performed on complex substances. In the present technology, although $90 \%$ of the clinical tests are evaluated in the final analysis through spectrophotometric measurements, the error in the spectrophotometry is a small part of the total error in many cases. Most current tests are regarded as fairly satisfactory, but there are difficulties in analyzing blood and urine of comatose patients, where often there are no clues as to the cause of the trouble. Tests for the presence of drugs often do not give correct results, and hormonal analyses regularly give wrong answers. Improvement of the type of spectrophotometric measurement routinely used could easily add one percent to the value of such tests overall in terms of improved determinations, but probably not much more. Proper publicizing of the approximate accuracy of the measurements under the conditions of the tests would add another two percent to the value of the tests by dispelling false confidence. Both contributions depend on the type of thorough knowledge of the measurement process which is the goal of the proposed spectrophotometry program. In terms of value received for present type clinical tests, the savings could be calculated as follows:

Annual cost of clinical tests . . . . \$1.7 billion

$\times$ Fraction of tests involving

$\times$ spectrophotometry ....... 0.9

Fraction of value gained by improving spectrophotometry . . . . 0.01

+ Fraction of value gained by better understanding of limitations . . 0.02

= Annual increased value of present clinical tests......... \$46 million

\section{b. EXAMPLE: Medical Research using Present Techniques}

Medical research in which clinical analysis is a tool undoubtedly suffers more from poor test results than general clinical practice. If more uniform data could be gathered from the results of general clinical practice, this would be extremely useful. Even more important is a thorough understanding of the magnitude of the uncertainties in the measurements and the propagation of error in the data analysis $(5.2, E)$. There is evidence to indicate that misunderstanding of the accuracy of spectrophotometric measurements and the reliability of corresponding correlations is quite common among medical researchers. Improving present spectrophotometric techniques and providing literature by which data analysis would be done more realistically would increase the effectiveness of medical research overall by two percent for the following annual increase in value of research: 


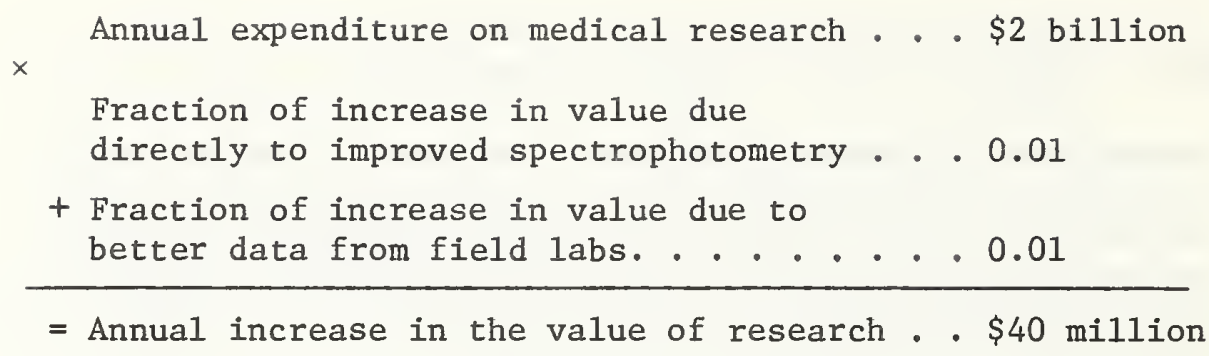

\section{c. EXAMPLE: New Approaches to Clinical Spectrophotometry}

In current procedures, the spectrophotometric measurement system as an indicator for the final stage of a series of chemical tests. Usually measurements are made at only one or two wavelengths in a particular test in order to evaluate the presence and quantity of one particular substance. However, much more is within the power of present technology. It is quite possible to measure and record an entire spectrophotometric "fingerprint" of a substance such as blood or urine, including photoluminescent data for many levels of excitation. Such data, taken at regular intervals as an individual receives medical checkups, could serve to indicate changes and point to further tests which could be made. There is every reason to believe that such a procedure could be done on a practical scale with instruments not much more complicated than closed circuit television, and that, properly standardized, such survey differential analysis based on individual records could make clinical testing $25 \%$ more effective for an increased value which can be determined as:

Annual cost of clinical tests ..... . \$2 billion

$x$

Fraction which could be eliminated by a good survey procedure. . . . . . 0.5

- Fraction which survey procedure would add to present tests . . . . . . . 0.25

= Annual savings in clinical tests. . . . \$500 million

(Discussions with Dr. Robert McCullough, heat pathologist of Holy Cross Hospital, and Dr. David Goldenberg, practicing physician, Silver Spring, Maryland, are gratefully acknowledged.)

\section{R.2.4 AN EXAMPLE FROM REMDTE SEISING}

NOTES: In a report to the House Committee on Science and Astronautics (C.3.95), the potential net benefits over a twenty year period of a program for remote sensing of earth resources was indicated to be in excess of $\$ 3$ billion per year. Unfortunately, the gross value of the program is not available, but from the description of the technology it is estimated that the program 
would be at least as expensive as the present space exploration program, or approximately $\$ 4$ billion annually. Therefore, benefits from the program will gross $\$ 7$ billion.

a. EXAMPLE:

Conservatively, half of the measurements will be done at wavelengths in the range of spectrophotometry as herein defined (2), and of these, half will depend upon spectrophotometric calibrations totally or in part. This means about $\$ 2$ billion worth of the annual results depend upon accurate spectrophotometry. If standardization at the present level is used, three-fourths of the value of this portion of the data is lost. If the best current techniques are applied, this loss could be reduced to one-fourth. With applications of the improvements in spectrophotometric measurements, particularly in reflectance, as proposed herein, it is quite probable that the measurements could be made as effective as described in the Thiel and Graves report (C.3.95), thereby resulting in an increased value which can be calculated as follows:

Average annual benefits estimated for remote sensing program. . . . . . . \$7 billion

$\times$ Fraction of measurements in spectrophotometric wavelength range (2). . . 0.25

$\times$ Fraction of measurements depending upon spectrophotometric calibration . . 0.25

$\times$ Fraction which cannot be calibrated unless spectrophotometry is improved. . . 0.25

= Annual loss if spectrophotometry is not improved . . . . . . . . \$109 million

\section{R.2.5 AN EXAMPLE FROM CONSERVATION}

NOTES: Copper is valuable and in short supply. As a result, approximately half of the copper produced in the United States is recovered from scrap. The production of copper alloys, such as bronze and brass, is over $90 \%$ from scrap. The present value of brass produced from scrap is in the neighborhood of $\$ 250$ million annually (C.3.96).

\section{a. EXAMPLE:}

In order for high quality brass to be made from scrap, the various types of brass must be separated. The highly trained labor for this task is vanishing (5.4.3), so that either the quality of sorting will drop or the price of the labor will rise, more likely the former. The result will be a net loss in productivity or value of product of about $10 \%$. There is reason to believe that sufficiently sophisticated data 
analysis (7.2.3) can be incorporated into a very specialized and inexpensive instrument to recognize scrap "shown" to it. Therefore, for about $1 \%$ additional cost for instrumentation, unskilled sorters can be employed to do the same job, providing employment for unskilled labor and maintaining productivity. The value of this can be calculated as follows:

Annual value of brass made from scrap . . . . . . . . . . \$250 million

$\times$

Fraction which would be lost under unskilled labor without instruments . 0 0.1

- Fraction of cost to buy sorting instrumentation ........ . 0.01

= Annual net value retained through instrumentation . . . . . . . . \$23 million

\section{R.2.6 AN EXA:PIL FROI AGRICULTURE}

NOTES: The United States produces about $30 \%$ of the wheat for export in the world. This market amounts to $\$ 1$ billion annually.

a. EXAMPLE:

The other large exporters of wheat are sorting their crops by food value through the use of chemical tests performed by military and other governmental personnel. Spectrophotometric methods would make it possible for the U.S. to perform such inspections without making use of government labor at a competitive cost. If such sorting enables us to increase our market by as little as one percent, the improvement in our balance of payments would be:

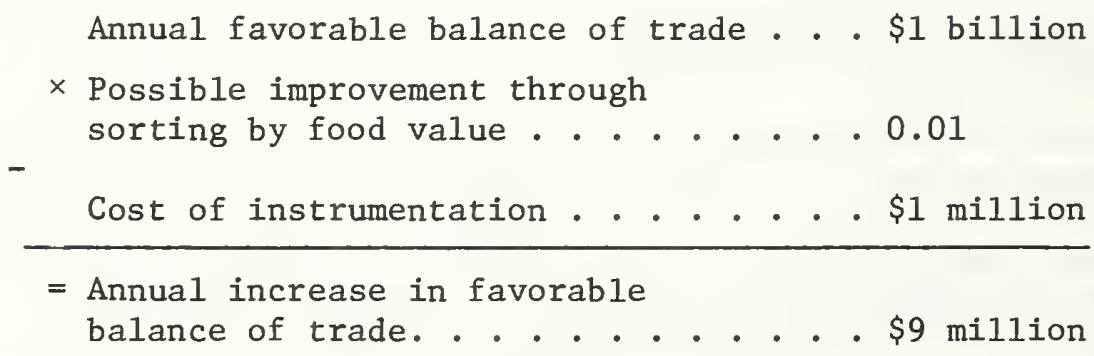

\section{R.2.7 AN EXAPPE FROM RESEARCH AID INSTRUMETATION}

NOTES: The current market for spectrophotometers (C.3.1) in the United States is $\$ 100$ million. Although the net export of U.S. scientific instruments is about $10 \%$ of our total production, analytic instruments face much stronger competition from abroad. A rough estimate would be that $60 \%$ of our analytic spectrophotometers are domestic and $40 \%$ come from abroad, 
and that the trend in the recent past has been for an increase in imports and a corresponding decrease in exports.

\title{
a. EXAMPLE:
}

Increased confidence in domestic instruments which would follow from improvements in performance and status brought about by a better measurement system and the backing of an effective national laboratory could bring $10 \%$ of the U.S. market back to domestic instruments and also increase our exports of analytic instruments by $10 \%$ of our present production. The value of this can be calculated as follows:

\author{
Annual market in U.S. for \\ spectrophotometers . . . . . . . . \$100 million \\ $x$ \\ Fraction brought back to U.S. \\ instrument companies . . . . . . . 0.1 \\ $+\quad$ Fraction being produced currently \\ in U.S. . . . . . . . . . . 0.6 \\ $\times$ Fraction of this for increased \\ exports . . . . . . . . . . . . 0.1 \\ = Annual increase in favorable \\ balance of trade........... \$16 milion
}

The examples for specific cases above add up to a

R.3 TOTAL SAVINGS of approximately $\$ 2$ billion per year. There are, of course, many other possible savings, but most of them would be relatively sma11. These savings take the form of increased productivity through automation and an improved balance of trade. A decrease in employment through automation is not regarded as a detriment, since this represents increased productivity which, through redistribution of labor, should result in shorter working hours and increased leisure time, both of which are generally regarded favorably.

Care must be taken in drawing

R.4 CONCLUSIOIS from analyses such as those obove. The total savings indicated above are in reality potential savings which depend upon many other factors besides improved spectrophotometric measurements. For every hour of effort by IBS to improve spectrophotometry, hundreds of hours of engineering and development will be required to take advantage of the improvements. However, none of these benefits can be realized without the improved measurements. In addition, a stable measurements system, backed by a national laboratory which can provide all-important verification of accuracy and assistance with improvements, has a catalytic effect, stimulating exploration and investment which might otherwise be discouraged. An effective program in spectrophotometry at IBS can provide an excellent return for the funds (P) invested in it. 
APPENDIX D. FACTORS AFFECTING ACCURACY IN SPECTROPHOTOMETRIC MEASUREMENTS

The following are two appendices, $E$ and $H$ from the 1972 report of the spectrophotometry study by the IBS group. They are included here to illustrate the difficulties which can be encountered in making accurate spectrophotometric measurements and the way in which good standards can make the measurements both easier and more accurate. 


\section{APPENDIX E (From 1972 Report)}

\section{ACCURACY IN SPECTROPHOTOMETRY}

Spectrophotometric standardization is probably best described as elusive, this elusiveness being revealed in the extreme care required to define what is to be measured and to make sure something else is not measured instead. An understanding of just what is involved in the concept "accurate spectrophotometric measurement" is essential to the full understanding of the need for a national standards laboratory to have an active program in spectrophotometry.

Certain errors, principally those from processes governed by chance such as the emission of photons and electronic noise, are random in nature. In principle, these can be reduced by means such as using stronger sources of radiation and measuring over longer periods of time. In practice, a point is usually reached at which the advantage to be gained by further reduction of this random error or imprecision is not worth the additional effort. At this point, by statistical analyses of the data from a number of similar measurements, one can assign a range of statistical uncertainty which is called the "precision" of the measurement. With modern instrumentation, the precision of transmittance and specular reflectance measurements is typically on the order of $\pm 10^{-5}$ on a scale in which 1 represents a clear path or perfect reflector. Measurements of bi-directional reflectance of diffuse reflectors are generally precise to about $\pm 10^{-4}$, where 1 is the reflectance of a perfectly reflecting diffuser under the same geometry. The precision figure gives a practical lower limit for the uncertainty in the measurements.

In spectrophotometry, far larger errors regularly result from systematic or non-random causes. It is these errors which result in poor technological communication, hampering scientific achievement and causing disputes in commerce, and it is to reducing these systematic errors that a standards laboratory should address itself. A few of the sources of such errors will be presented here in order to illustrate the types of difficulty which are encountered and indicate the magnitude of the error which can result from some of them. There have been numerous attempts to separate these sources of error into categories, as for example into "sample errors" and "instrument errors" (C.3.48). Such separations are artificial and not generally successful. The measurements must be considered as a whole--an interaction of experimenter, instrument and sample--if a basic understanding of errors is to be had. Therefore, although the sources of error are presented in groups of loosely related errors and numbered sequentially, the various sources of errors and groupings can be interrelated and often are.

One source of error is non-1inearity in the detection system, i.e., the spectrophotometer output is not simply proportional to the radiation flux being measured. This may be due to

E.I ION-LINEAR ELCTRONICS, either signal amplifiers or servo-systems, or it may be due to photodetector non-1inearity resulting from

E.2 SPACE CHARGE EFFECTS on the photocathode of vacuum photodetectors,

E.3 DEIECTOR SATURATION, or

E.4 DEIECTOR FATIGUE, which is particularly noticeable in photomultiplier tubes. The fatiguing effects can make the results depend upon the time between 
measurements and the duration of the measurements in an unpredictable way. The effects of space charge or saturation are more predictable, with care can be held to approximately $10^{-4}$ of the maximum signal, and are correctable (C.3.25). Other factors which affect the performance of the detection system include

E.5 FLUCTUATIONS IIN LINIE VOLTAGE and

E.6 MAGMEIIC FIELD FLUCTUATIOHS, Although the presence of a constant or a steady state alternating magnetic field will not usually affect the performance of a detector system adversely, performance will be degraded by changes in magnetic field, particularly at the detector, during the course of a measurement. Such changes can occur when nearby electrical equipment, particularly high current DC equipment, is switched on or off, or when large pieces of ferromagnetic materials or permanent magnets nearby are moved. Changes due to these causes can be as high as $10^{-2}$ of the detector output at the time.

A source of non-linearity which occurs in reflectance measurements when an integrating sphere is used to provide hemispherical illumination or viewing might reasonably be called a

E.7 SPIIERE EFFICIEICY error (C.3.9). This error comes about because the sample being measured is also part of the sphere wall, thus introducing the reflectance of the sample into the measurement both directly and as a factor in the efficiency of the sphere. This effect is greatest in single beam instruments where deviations of up to $10 \%$ of the measured reflectance can be expected. As long as the reflectance of the sample does not change significantly within the bandwidth of the instrument, this error is negligibly small in a double-beam spectrophotometer, however, in broadband double beam instruments such as tristimulus colorimeters and instruments measuring luminous or total reflectance, errors of several percent of the instrument output can occur.

E.8 LAIED RADIATION which enters the detector via the wrong route or from a separate source of radiation is particularly troublesome when unmodulated radiation is used in the measurements. E.9 RADIATION OF OTHER WAVELENGTHS than in the band desired, whether leaked in or passed by the monochromator system, as with other orders or ghosts in a grating instrument, can be particularly troublesome when measurements are being made in strong but narrow absorption lines. Another type of stray light error, referred to as

E.1J BLACK SAMPLF ERROR, occurs in integrating sphere instruments. Light scattered from the beam forms a diverging halo around the main portion of the beam. Much of this halo falls outside the port area on the sphere, causing reflectance readings even with ideal non-reflecting samples (black cavities). Even on high quality instruments these readings can be as high as $5 \times 10^{-3}$ of those from the ideal diffuse reflector (C.3.49).

The foregoing errors are more closely related to the instrument than to the sample. As the interrelation of instrument and sample are taken into account, more possible sources of error arise.

Most definitions of spectrophotometric measurements assume the absence of E.11 POLARIZATION OF IIVIDEIT RADIATIO'N and the absence of E.12 POLARIZATIOIN OF DETECTOR SEISITIVITY, Errors will be introduced in measuring specular reflectance and the transmittance of birefringent or dichroic 
materials, since these are dependent upon the polarization of the incident radiation or affect the polarization of the radiation which leaves the sample (C.3.50). Several other sources of error are related to the nonuniformity of photodetector sensitivity across the sensing surface. Not only is the sensitivity usually a strong function of position on the surface, but this function may also change with wavelength. Therefore it becomes important that the same portion of the photodetector surface be used at all times. Even when this effect has been effectively neutralized by using an integrating sphere, the presence of stops in the light path from the sample to the receiver may cause changes in the size and position of the flux of radiation from the sample to be important. In transmittance measurements, such changes can result from an image shift due to a

E.13 TILTED SAMPLE or

E.14 NON-PARALEL SAMPLF FACES, or a change in focus due to

E.15 CURVED SAPLE FACES or simply the

L.16 CHAIGE IN OPTICAL PATH LFIGTH due to introducing material of a different index of refraction into the beam. These effects can introduce errors of $10^{-2}$ or more if not carefully handled. In addition to defocusing caused by introducing a sample of a given index of refraction into a beam, E.17 IVTERREFLCTIOIS between the sample faces and other parts of the instrument can introduce stray light errors, and

E.18 MLTIPLE REFLCTIONS between faces of the sample can produce additional images, each with its own problem of focus. This latter effect can be on the order of $2 \times 10^{-3}$ of the incident flux for nearly transparent samples.

An intrinsic difference in measurements between instruments having different amounts of convergence in the beam, a

E.19 PATH LENGTH ERROR, can be introduced even in gage measurements. Data from the instruments cannot be simply reconciled because of the exponential dependence of attenuation upon path length, but in obtaining the ratio of the transmittance of one filter to that of another with transmittance a factor of 10 less a difference of approximately one half percent will be encountered when using a collimated beam instrument as compared to an $f 8$ instrument. Such an error can accumulate to several percent in calibrating very high density filters or measuring strong absorptions. Because of the E.20 INDEX OF REFRACTIOIV CHAiVGES giving rise to the anomalous dispersion phenomena near absorption lines, the measurement of absorption bands or lines to determine chemical concentration may be very strongly influenced by the factors listed in E.13 through E.19.

Other optical phenomena which must be accounted for in order to insure accurate measurement are

E.21 DIFFRACTION, which is particularly troublesome in dealing with attenuating screens (L.2.2) and

E.22 SCATTERIIV by macroscopic granular discontinuities in a substance.

If scattering is introduced unintentionally, or in any case in which the scattered radiation is not the quantity of interest, then its contribution 
to the measured flux must be determined and corrections made. Even when scattering is the phenomenon of interest, as in the measurement of haze, total transmittance of translucent materials, and diffuse reflectance, scattering introduces several other possible sources of error. One of the most difficult problems arises because of the

E.23 DIFFUSIO in OF RADIATIO, within the sample. In theoretical treatment of scattering media this phenomena is taken into account in only one direction, that normal to the surface of a uniform and uniformly illuminated infinite slab of material. A unique definition can be properly formulated in this way, but actual measurements are made with light beams, which are of finite cross section, so proper account must be taken of diffusion parallel to the surface of the sample as well. This is commonly done by illuminating a small area of the sample and observing a large area or vice versa. A one percent error in measuring the luminous reflectance of white paint has been traced to improper handling of diffusion (L.2.3) and there is reason to believe that substantial errors may result from the use of NBS calibrated vitrolite gages (N.2.2) for the same reason. Not only is the total reflectance affected, but errors in measured chromaticity also result from diffusion, since the extent of diffusion and hence diffusion losses will be greater at the wavelengths at which less absorption occurs. The effect of diffusion losses on color measurements is a trend in the direction which can be roughly described in the Munsell system as a decrease in both value and chroma, or on the CIE chromaticity diagram as a shift toward the source point. Developing proper measurement techniques to account for diffusion within the material, a difficult task for even the relatively opaque ceramic materials, is becoming extremely important with the increased use of highly translucent plastics (L.2.9). In measuring the properties of scattering materials, it will also be necessary to properly determine the effects due to

E.24 SAPPL THICKNESS and the contribution to reflectance measurements of the E.25 REFLCTANCE OF THE SAMPLE BACKING material (C.3.51).

Effects similar to diffusion occur in materials which fluoresce because of

E.26 IIITERIAL ABSORPTIOIV AND RE-EIISSION OF FLUORESCENICE RADIATION are even more difficult to treat. This effect is particularly strong near resonance lines. Failure to deal with this effect carefully is one of the reasons that estimates of uncertainty in fluorescence measurements are as high as 25 percent for strongly fluorescing materials (C.1.17). Including

E.27 UNRECOGIIZT FLUORESCENT RADIATION in a measurement of a property unrelated to fluorescence is a potential source of rather large errors.

If a very strong flux of radiation, such as that from a laser, is used to illuminate the sample, non-linear phenomena such as

E.28 SATURATION OF ABSORPTIOR LEVELS,

E.29 INDUCED ABSORPTION, and

E.30 INDUCED RE-EMISSION may occur, and must be properly taken into account.

E.31 HEATING OF THE SAMP can also occur as a result, producing a change in its properties. 
In the case of gage measurement $(H)$, the gages themselves can be a source of error. The usual difficulties which come to mind are E.32 ERRORS III GAGE CALIBRATIOif and either temporary or permanent E.33 INSTABILITY OF GAGE MATERIALS, However an equally important source of error in gage measurements which can embrace any or all of the other sources listed here is the

E.34 IMPROPER USE OF GAGES, i.e. using them for purposes other than that for which they are designated.

Another group of potential source of error is linked to the definition of the wavelengths involved in the measurements. An

E.35 IIICORRECT WAVELEIGTH CALIBRATIOiN can obvious1y result in errors. Errors can also be introduced by the

E.36 EFFECTS OF FINITE BAIDWIDTH, which are particularly noticeable in measurements in which the spectrophotometric properties undergo their principal changes within a spectral range which is within an order of magnitude of the instrument bandwidth. More rapid fluctuations tend to be properly averaged over the bandwidth as do less rapid fluctuations. In all measurements involving a finite bandwidth, but particularly in the broad band measurements used in colorimetry and photometry, accurate control of the E.37 RELATIVE SPECTRAL WEIGHTING of the source intensity - system transmittance detector sensitivity combination is necessary in order that the measurement defined will actually be the one performed (see also E.7).

Finally, a very important source of error is improper

E.38 SPECIFICATION OF SPECTROPHOTOMETRIC MEASUREUEITS, A11 of the foregoing discussion of errors in spectrophotometric measurements contains the implicit assumption that the measurements will be well-defined. Although it appears almost tautological to note that inaccuracy can be defined only after accuracy has been defined, it is quite probable that half of the difficulties in spectrophotometry arise from poor definition.

In order to amplify the foregoing assertions, an idealized step by step procedure for defining a measurement will be given. For practical or historical reasons, measurement procedures are seldom arrived at in such an orderly manner. Nevertheless, in order or not, all of the steps in the procedure should eventually be carried out to produce a useful, well-defined spectrophotometric measurement.

The first two steps, which are closely related, are to E.38.1 SPECIFY PRECISELY THE PROPERTY WHICH IS TO BE DEIERMIIIED and to E.38.2 DEIERIIIE CORRELATIOIS BETIEEII THAT PROPERTY AVD RELATED SPECTROPHOTOMETRIC MEASUREMENT, It should be emphasized that the property to be determined is usually not spectrophotometric and often not even optical. Examples of such properties are the rate of emission of fly ash from a smokestack or exhaust (Q.8), the composition of scrap material being reclaimed (5.4.3), the size of holes etched in a TV tube mask (L.2.2), the thickness of plastic films, and the concentration of nutrients in sea water (C.1.51). The definition of the property should be as precise as it can be made and should include the 
size errors which can be tolerated in the determination. It is important that these errors be estimated as well as possible, since the tolerences' being too tight might exclude attractive alternative measurement schemes from consideration, while their being too loose might result in the adoption of spectrophotometric measurements which could never yield adequate data to provide the accuracy which would eventually be found necessary. Once the first two steps have been carried out, one should then carefully

E.38.3 EVALUATE THE PRACTICALITY OF ALTERNATIVE MEASUREMEITS, This evaluation should look both ways, ahead to the conditions under which the measurement will be used in the "field" and back, through the correlations to the property which is to be measured. If the measurements are to be made out of doors by semi-skilled workers on a highway crew, for example, a scheme with poorer correlation may be chosen if the corresponding instrumentation can be made more rugged and easier to use. On the other hand, if the end use will occur in a research laboratory, the best correlation may be sought with little regard for the delicacy or complexity of the instruments.

Although these three initial steps appear obvious, the first two are often slighted. An example of this can be seen in the discussions of the pros and cons of narrow wavelength band versus broad wavelength band measurements of absorption in chemical work. Much of the controversy could be resolved by carefully defining the property which is to be evaluated. One may wish to determine the rate at which molecules are excited to a given state in order to study rates of photo-chemical reaction, or one may simply wish to determine the concentration of a particular solute in a solution. In the first case, the absorption of light, which is truly an optical property, is for all practical purposes the property of interest, and this correlates in a one-to-one fashion with the total absorption in the line or band of interest. Therefore, from the standpoint of correlation, one would use a broad band instrument or one which scanned the absorption lines to evaluate this property. Narrow-band measurements at the absorption peak would have to be supplemented by other experiments in order to obtain the same results, since the correlation is not as direct. In the second case, the property of interest is the concentration, which is not an optical property at all. In this case, since the absorption coefficient in different parts of the band, the simpler linear relationships between concentration and the spectrophotometric data known as Beer's law will occur only when the instrument bandwidth is very narrow compared to the absorption bandwidth (C.3.52). (This problem is mathematically related to the path length problem indicated in E.19). Therefore which bandwidth is used or what corrections are made for data obtained with an intermediate bandwidth will depend upon the property which is of interest. Unfortunately concepts such as these, which should be generally and easily understood, are confused in the literature with fuzzy rhetoric couched in poorly defined and often argumentative sounding terms such as "true absorbance".

The next step, once the spectrophotometric measurement to be used has been chosen, is to

E.38.4 DEVELOP AND TEST THE MEASUREMENT PROCEDURE, This would include determining whether gages should be used, and, if so, what gages. This step is almost universally regarded as important and is usually well done except for testing for the contributions of systematic errors and including corrections 
for these or means for avoiding them. This is generally either because those developing the measurements have been unaware of the magnitude of the errors which can be introduced by some sources or have not had instrumentation available to properly evaluate them. In this part of the development, the expertise and supplementary measurements which can be supplied by a well-equipped national laboratory can be extremely valuable.

When the measurement procedure has been developed and tested adequately, the next step should be to

E.38.5 THOROUGHLY DOCUMEVT THE DEVELOPIEIT OF THE MEASURE'E'IT, such documentation should include a complete and orderly summary of all of the work done under the preceding steps. It should include the complete definition of the property to be determined, alternative measurements considered, the reasons for rejecting the alternatives, the reasons for choosing the method used, the tests made in developing the procedure and summaries of the results, what possible sources of error were evaluated and how, what possible sources of error were not evaluated and why not, what gages are required and what properties of these are important, etc. This documentation should generally remain with the laboratory or group responsible for the measurement and should be open ended to allow for future testing or modifications of the procedure. This type of documentation is essential for standardizing organizations such as ANSI, ASTM, and NBS. It is also advisable in a somewhat less strenuous form for individual laboratories or industries developing their own measurements, since in almost every case the savings realized by being aware of potential pitfalls and avoiding repeated evaluation of sources of error will more then offset the cost in time spent on documentation. The information contained in complete documentation of this type is the only basis from which the accuracy of measurements made using the procedure can be evaluated. To the extent that the uncertainty in the definition of the measurement process affects the results of the measurement, it must be regarded as another source of error. Despite these considerations, careful documentation is rarely done (N.1).

Finally, if the measurement is to be performed by anyone other than those who develop the method, it is highly advisable to

E.38.6 DOCUIEIT THE MEASURE:EIT FOR PRACTICAL USE, i.e. provide simple descriptions of the equipment and procedure to be used and, when necessary, descriptions of the important difficulties which could be encountered. Such documentation would be a guide for those to whom the results of the measurement are of much greater interest than the measurement process itself. The standard procedures published by ASTM and ANSI are examples of such documentation.

All of the preceding discussion has been centered upon how accuracy is defined and obtained with no disucssion of

E.39 THE INEFD FOR ACCURACY, Particular calls for accuracy are mentioned or implied in the main body of this report, particularly in section 5. In general, the neet for accuracy in spectrophotometry arises in the same way that need for accuracy arises in any field of measurement. It arises from the need for specifications to govern commerce; it arises from the need to control the quality of production from day to day and year to year; it arises from the need to communicate between buyer and seller, between artist and artisan; between those who must enforce regulations and those who are attempting to conform to the regulations, and in general between technical workers of all kinds; and it arises from the need of scientists and technicians to be able to record the results of their efforts in such a way that they can be built upon in the future. 


\section{APPENDIX H (From 1972 Report)}

\section{GAGE MEASUREMENTS}

A spectrophotometric gage is a physical object which embodies a spectrophotometric property and which is used as a basis of comparison in measurements of that property. For example, white ceramic tile which reflects light diffusely and nearly independently of wavelength is often used as a gage in diffuse reflectance measurements; colored glass can be used as a gage of color measurement of transparent materials; polished black glass is used as a gage for gloss, etc. Almost all highly accurate measurements in applied spectrophotometry involve the use of one or more gages, and indeed most reflectometers can only make gage measurements. Because of this important role played by gages in spectrophotometric measurements, it is important that the advantages to be gained and the pitfalls to be encountered in gage measurement be fully understood by those with strong interest in spectrophotometric measurements.

As an illustration of the

H.1 ADVANTAGES OF USIVIG GAGES, consider an example of an instrument which is assumed to be linear. In this case, the evaluation of a property relative to the gage property can be expressed by:

$$
\mathrm{P}_{\mathrm{u}}^{*}=\frac{\mathrm{S}_{\mathrm{u}}}{\mathrm{S}_{\mathrm{g}}} \mathrm{P}_{\mathrm{g}}^{*}
$$

where

$\mathrm{P}_{\mathrm{g}}^{*}$ is the assigned value of the gage property

$\mathrm{S}_{\mathrm{g}}$ is the instrument output signal when measuring
the gage

$\mathrm{S}_{\mathrm{u}}$ is the instrument output for the unknown sample and

$\mathrm{P}_{\mathrm{u}}^{*}$ is the value of the property $\mathrm{P}_{\mathrm{u}}$ of the unknown sample as determined by the measurement.

It is obvious from the form of the equation that as 1ong as the instrument is linear $\left(\mathrm{S}_{\mathrm{X}}=\mathrm{kP}_{\mathrm{X}}\right)$, other details of the relationship between $\mathrm{S}_{\mathrm{X}}$ and $\mathrm{P}_{\mathrm{X}}$ need not be known. The

H.1.1 MEASUREMET IS CALIBPATED BY THE GAGE, This is by far the most important advantage of gage measurements, particularly in measurement involving scattering phenomena such as diffuse reflectance or translucence. Most instruments used to measure diffuse reflectance are incapable of being calibrated in any other way than with gages. This advantage is being recognized to the extent that in many new instruments gage comparisons are built into the measurement and data reduction procedures, and the operator only receives data after it is reduced by means of the assigned gage values (C.1.10, C.2.76, C.3.57). The raw readings from the instrument are used only to ascertain that the instrument is operating with signal levels within acceptable ranges. 
A requirement of a good gage is that it resembles the unknown sample as closely as possible. In applications to production quality control, a calibrated sample of the product can serve as an excellent gage. Under these conditions, properly used

H.1.2 GAGES CAN REDUCE IEASURE ENT ERROR, Suppose that in the example in the preceding paragraph, the instrument response were quadratically non-linear, i.e.

$$
S_{x}=k_{0} P_{x}\left(1+k_{1} P_{x}\right)
$$

Making a substitution based on this non-linear response in Eq. 1H, one obtains

$$
\mathrm{P}_{\mathrm{u}}^{*}=\mathrm{P}_{\mathrm{u}}\left[1+\frac{\mathrm{k}_{1}\left(\mathrm{P}_{\mathrm{u}}-\mathrm{P}_{\mathrm{g}}\right)}{1+\mathrm{k}_{1} \mathrm{P}_{\mathrm{g}}}\right]
$$

Thus, the error decreases with decreasing difference between the property and the gage. For example, in measuring a filter of transmittance 0.45 directly (open transmittance $=1$ ) an instrument might introduce a non-linearity error of 0.01 , whereas in measuring this filter against a gage filter of transmittance 0.5 , this nonlinearity error would be reduced to -0.0005 . Not only can nonlinearity be reduced, but gages can be used to reduce errors due to other instrumental causes such as drift and improper spectral and spatial weighting of instrument sensitivity. In general, there is no question that the proper application of gages can make measurements simpler and more accurate.

\section{The advantages and the}

H.2 DISADVASTAGES OF USING GAGES are very closely related. Since measurements are calibrated by the gages, the use of gages can lead to H.2.1 PROLIFERATION OF JEASURE'ENT SCALES through the use of many different gages. An excellent illustration of this occurs in diffuse reflectance measurements for which in various times and disciplines calcium carbonate blocks, deposite of magnesium oxide smoke, pressed magnesium oxide powder, pressed barium sulfate powder and coatings of sodium chloride deposited by spraying have been used as unity reflectance gages. Obviously, the literature in the field is quantitatively in a state of confusion. The only way in which this difficulty can be resolved is for standards organizations to define an ideal scale for each type of measurement and to assist those using gages to measure the gages relative to this ideal scale. (In the case of diffuse reflectance, for example, a natural basis for the scale is a perfect Lambertian reflector.) The user, in turn, has an obligation whenever possible to correct measurement and gage errors toward the ideal when such errors are discovered, rather than retain his own scale in order to "keep the numbers the same". Rarely is the continued use of an arbitrary scale justified, and values based on such scales should never by published deliberately.

In stark contrast to H.1.2,

H.2.2 GAGES CAN INTRDDUCE ERRORS, One way in which this can occur, of course, is through errors in measuring the gage. Another less obvious way is brought about because the instrument is in some way sensitive to properties other than that which it is desired to measure. If the gage and the sample being measured differ with respect to one or more of those properties, an error can be 
introduced. A clearcut example of this is presented in (L.2.3). In that case paint was being measured against an opal glass gage which differed in the way in which light spreads within the material by diffusion. Since the instrument was sensitive to such spreading, a measurement error resulted. If such an error arises because the instrument is affected by properties other than the desired property of the material to be measured, then appropriate modifications should be made to the instrument, auxilliary measurements should be made by means of which the errors can be corrected, or a more appropriate gage should be used. It is not recommended that a simple scaling of the value assigned to the gage be made, since the sensitivity of an instrument to a property other than the one which it is designed to measure is usually not stable in time. Generally, the use of gages cannot compensate for errors due to an instrument's sensitivity to periferal properties, and often the use of gages can introduce errors though this property.

In summary, there are two factors in a good gage measurement. First, the gages must be accurately measured, and second, the measurement procedure must be analyzed to be certain that the measurement is made in a way that the property of interest is dominant in determining the instrument output.

Principally as a legacy from the policies of the section of NBS which formerly handled this work, there are certain

H.3 SPECTROPHOTOMETRIC GAGES WHICH ARE CURRENTLY SUPPLIED BY THE OPTICAL RADIATION SECTION, which will be described here briefly.

H.3.1 VITROLITE TILES (212.14j.-o.(C.3.58); C.3.59) are a white ceramic material with a fire polished surface and are used as a standard gage for diffuse reflectance. The main advantage of Vitrolite over other materials is its uniformity, since it was originally manufactured in large quantities as a building material. This material has been replaced in buildings by enameled steel, plastic, and other materials, and as a result it has not been manufactured for a number of years. The limited supply which NBS still has on hand represents most of this material still in existence in a form useable as gage material. In addition to its near extinction, vitrolite has several other disadvantages. It is quite translucent, which causes the reflected beam to eminate from a much larger area than is struck by the incident beam, giving rise to "edge effects" difficulties in many cases (L.2.3). These tiles are porous in their interior structure and as a result when the surface is ground to a matte finish, which is desirable in some cases, it cannot be cleaned. In addition to the intrinsic problems associated with the material there are errors associated with the measurement of the master standard (N.2.3, N.2.4), which errors, however, are to be corrected soon.

H.3.2 DIDYMIUM AND HOLMIUP OXIDE GLASS FILTERS (212.14d.-i.(C.3.58)), which have a number of sharp minima in their spectral transmittance, are used as wavelength standards. These materials differ little from filter to filter and are very stable, both with respect to aging and thermal properties. The literature offered with the holmium oxide filters, however, contains an extrapolation to zero bandwidth which implies use for more accurate wavelength calibrations than can actually be obtained. A more careful study of these materials may show that they can be used for wavelength calibration without being measured glass by glass as is presently done. 
H.3.3 IBS GLASS STAIDARDS OF SPECTRAL TRAIISIITTAICE (212.14a.-e.(c.3.58); (C.3.60) consist of four filters, carbon yellow, selenium red, cobalt blue and copper green. They were chosen with the idea of allowing spectrophotometers to be checked rapidly for linearity, the absence of stray light, etc. For example, the cobalt blue has a strong absorption in the central region of the visible spectrum, and transmits well in both the red and violet ends of the spectrum. If an instrument measures the transmittance in this central wavelength region properly, there is little chance that there is stray radiation at either end of the spectrum. While these gages are quite useful within the range of accuracy for which they were initially designed, they are not adequate for many current applications.

As is pointed out in detail elsewhere (7.2.2b), the task of supplying measured gages will be turned over to other groups in order that the IBS spectrophotometry group can pursue the more basic tasks of standardization. Since these gages have served as a basis for the measurement system for many years, however, we plan to provide corrections for the known errors in the earlier measurement of these gages to the extent that one possessing such a gage can correct its calibration to within the uncertainties initially claimed by NBS.

In addition there are several

H.4 OTHER IBS GAGES RELATED TO SPECTROPHOTOIETRY, Chief among these are H.4.1 GLASS FILTERS FOR SPECTROPHOTOMETRY (SRM 930 (C.3.61)), a set of three neutral density filters for checking linearity;

H.4.2 LIQUID FILTERS FOR SPECTROPHOTO'ETRY (SRM 931 (C.3.6I)), the first in a series for gaging certain absorption measurements; and

H.4.3 COLOR STAIDARDS FOR SPECTROPHOTOUEIER-TRISTIMULLS IVITEGRATOR SYSTES (SRM 2101-2105 (C.3.61);(C.3.62)). The first two items are projects of IMR under sponsorship of the clinical chemists, while the color standards were developed by the IBS spectrophotometry section. Gold on glass and aluminum on glass are offered as

H.4.4 REFECTANCE STANDARDS FOR THE ULTRAVIOLET TO IIIFRARED (SRM 2001-2008; (C. 3.6I)). These specular reflectance gages were measured in 1970 by the Optical Radiation Section of IBS over the wavelength range 250-30000 nm.

In addition, other NBS gages and gage measurement services, such as for photographic density step tablets (NBS Tests 212.135a, 212.135b, and 212.135c (C.3.58)) and light sensitive papers and chips (SRM Nos. 700b, 701b, 702, 703 (C.3.61)) for fade testing, depend at least in part upon spectrophotometric measurements. 
APPENDIX E. WHAT IS AN APPEARANCE MEASUREMENT?

It is not all obvious to the uninitiated just what is meant by measuring color or measuring appearance. Nor is it obvious what can be gained by doing so. To provide some background in this area, sections 5.1 and Appendix I from the 1972 report of the spectrophotometry study by the IBS group are given here. Although the measurement of appearance is carried out through spectrophotometric measurements in the general sense in which they are defined in this report, this is only done after psychophysical research provides a model by which one can interpret the results of spectrophotometry in terms of what a human being will see. The responsibility within NBS for seeing to it that these psychophysical models are kept up to date is not clearly defined, and the latter part of Appendix I of the 1972 report is addressed to the question of what involvement should NBS have in fixing these models and where should the responsibility lie within NBS.

One can define the

5.1 APPEARANCE of an object as the impression an object makes upon a person through information conveyed to him by electromagnetic radiation and perceived through his eyes. The appearance of an object to an individual depends upon aspects of his judgement which have been based upon his past experience. As a result, absolute quantification of the appearance of a given object is only moderately successful. Similarly whether or not two objects which differ distinctly in appearance will "go together" to produce a harmonious effect on the observer depends upon his background and such "taste" will vary from individual to individual. However, the ability of observers to judge whether objects are alike is much keener, so that very small differences in appearance can be recognized. Furthermore, individuals almost universally associate small but noticeable differences in appearance with negative concepts such as "worn", "faded", "unstable" and "carelessly or unskillfully made". For this reason it is very important for manufacturers of consumer goods to control very carefully the appearance of products which might be placed together while being sold or used. Either the objects must differ from each other in appearance 
so much that it is obvious the difference is intentional or they must appear enough alike that only the keenest observer could tell the difference. The latter is the only practical approach in most cases.

With control of the appearance of products so important, there is a definite appeal to having

5.1.1 APPEARAICE IIISTRUMEITATION to assist in quality control. In the development of such instruments, appearance is first broken down into more tractable aspects (I) such as color, pattern, texture, brightness, whiteness, opacity, gloss and haze. A mathematical model must then be constructed to place a given appearance aspect in one-to-one correspondence with measurable optical parameters such as the spectral reflectance of an object and the spectral irradiance of its surface. Since the manufacturer is not usually able to control the lighting under which a product will appear, he must control the interaction of his product with light wavelength by wavelength over the entire visible spectrum. As a result, most appearance measurements are being done spectrophotometrically rather than by tristimulus colorimetry (I).

Because appearance is a human oriented field, one may well ask why a machine should do a man's job in observing appearance. In the past, human observers exclusively judged appearance, but several things have led to a trend to replace these observers with instrumentation. The labor movement has developed in such a way that tedious and exacting jobs of inspecting, such as shading paint, with all of their responsibility for decision pay little more than jobs which are far less demanding. This and certain psychological factors make it more and more difficult to find people to take such jobs. Also, the ability of a human observer to perceive differences can be affected by psychological or physiological factors such as boredome, fatigue, or diet. Therefore, it is becoming more common to use machines as observers. In the future it will probably become common to close the control loop directly from the instrument output, thereby completely automating the routine quality control of appearance $(\mathrm{J})$.

There are many

5.1.2 AREAS OF APPLICATION for appearance instrumentation, some of which have been exploited for some time and others which have been tried only recently. Very few applications have been completely successful to date, and many are still far from successful, but the advantages to be gained from solving the problems are great enough and the prospects of obtaining solutions are good enough that many companies are active in the field, including several new ones. A trade association has recently been formed by manufacturers of appearance instruments to further their common interests (K.3, L.2.10).

Color and gloss measurements have long been used successfully in manufacturing paint and other finishes (C.3.3). Specifications for the appearance of finishes used by the government as a whole have been drawn up and newer versions will include spectral reflectance factor curves of the sample colors as an aid to matching (C.3.4). This field has been considerably comlicated in recent years by the increased use of flake metal pigments (C.3.5) which add an irregular angular and wavelength distribution to the reflectance 
factor and causes it to differ from point to point on a surface. For such measurements, the instrumentation will have to recognize texture or pattern to produce an acceptable match (I).

A similar problem is faced in the textile industry. Color measurement for sorting bolts of smooth textured solid colored material into lots for mass production of clothing is fairly successful, but smooth solid colors account for only a small part of the textile market. An interest is developing in instrumentation with pattern recognition capability for textiles (C.1.52), and ultimately instrumentation for automated control of production (J).

There has long been a need for a means of communicating appearance from architect to builder, and for work in predicting the finished appearance of surfacing materials from the raw materials which go into them. This field has been dormant for some time, but the need has remained and new activity on an organized level is under consideration. Prefinished interior and exterior surfaces such as paneling, enameled steel, and decorative glass (C.1.173) have become more commonplace, allowing the architect to see the finish before the structure is built. However, quality control of such materials must be excellent in order to prevent a building's looking like a faded irregular checkerboard. Also, in order that matching replacement panels can be provided later for repairs, great demands are placed on appearance matching measurements either to communicate a description of what is needed or to produce a replacement from earlier specifications.

A rather unique mixture of spectrophotometry and spectroradiometry is needed by the television industry for providing a means of translating the scene that the program director creates on his monitor screen into standardized broadcast modulation signals. This, along with complementary work on color reproduction in photographic films intended for television, is necessary in order to provide the viewer with continuity in appearance as the programming source is abruptly changed between live scenes from studio cameras, scenes from remote field cameras, taped segments, and filmed segments. The basic procedures are being worked out through SMPTE and FCC cooperation, but the standardization should be placed on an accurate basis through the help of NBS.

Recent advances in the technology of colorants and materials, while opening the way to wider ranges of appearances which can be created, has produced corresponding appearance measurement problems. The wider use of plastics has created an urgent need for standard techniques to handle appearance measurement and specification of translucent materials (C.1.17,C.1.147). New highly stable organic pigments (C.3.6,C.3.7) have extended the range of colors which can be produced, and at the same time have increased the potential difficulties to be encountered with metamerism (I). Fluorescent colorants have come into wide use (C.2.29,C.2.87), and methods of measuring and specifying the appearance of such colorants is sorely needed (C.1.41,C.1.123), but is only beginning to be developed (C.1.53,C.3.8). Although it is far from complete, the coverage given appearance measurements in this subsection, along with the discussions of gloss (I.2.2) and haze (I.2.3) which appear elsewhere in this report, 
should serve to illustrate the nature of the work to be done.

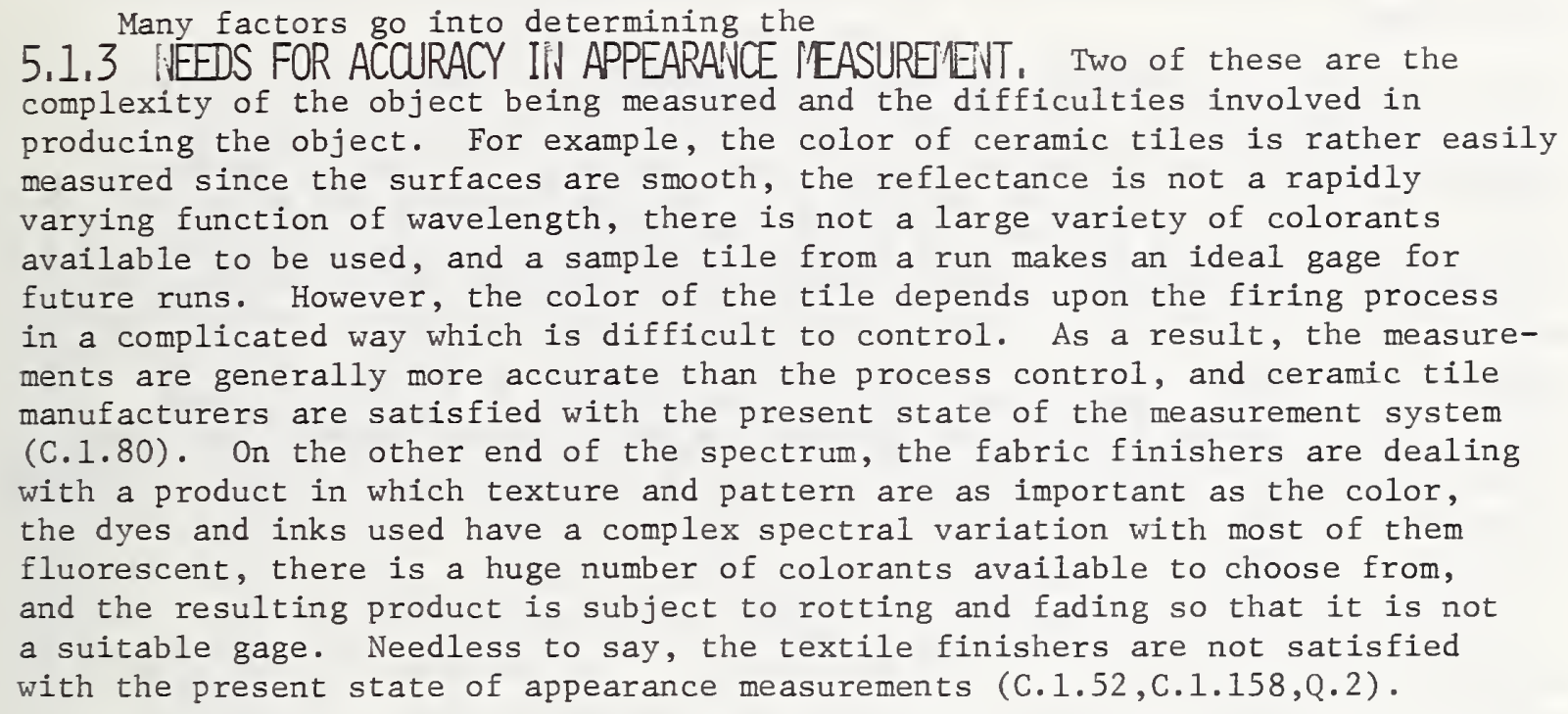

The need for a common basis of measurement in appearance becomes evident as soon as one has a need to communicate quantitative information about appearance as, for example, between buyer and seller (L.2.3) or between designers and manufacturers. Numerical specifications on such items as the color and gloss of paints, the color of cloth for uniforms, and the haze of automobile window glass have long existed. As the performance of the instruments improves, the number of such specifications goes up. The coil coating industry is an example of a new area in which tight color and appearance specifications have arisen. In this rapidly developing technology, metals are precoated with finish while they are still in the form of rolls or coils of sheet, and the final product is stamped out of the finished metal. If advantage is to be taken of this type of process, one must be able to depend upon the appearance to be uniform from one part of a coil to another and from coil to coil, and there must be a means of accurately specifying the appearance of materials to be supplied.

Quantitatively, the accuracy required in appearance measurements is based upon the ability of the eye to distinguish differences in appearance. Although this is a complex subject in itself (I), some quantitative estimates of the accuracy needed can be made. In color, Hoffman (C.3.9) estimates that each of the tristimulus values $X, Y$, and $Z$ should be known to within $0.2 \%$ of its value in order to make valid subjective assessments from the objective data. Simon (C.1.158) estimates that reflectance factors should be measurable within $1 \%$ of their value at the 0.1 level for dark color colorimetry. These limits, which are in fair agreement and are within the levels of repeatability currently being obtained, may have to be tightened by a factor of two or three if the measurements are to be used for feedback in automatic process control. The estimated inaccuracy of reflectance measurements, however, is an order of magnitude greater than these limits, so that work will be required in this 
field before the measurements will provide an adequate means of commication in the field.

5.1.4 THE VALUE OF ACCURATE APPEARAIICE MEASUREMENT to commerce 1 ies in the area of quality control. After all other factors are taken into account (and sometimes before) the buyer gravitates toward the better appearing product. If U.S. industry is to maintain its share of the world market for consumer goods, it must compete with the appearance of other goods as well as with their performance. Furthermore, if U.S. industry is to compete with countries with more favorable (to industry) labor conditions, it must automate, and the automation of finishing will require accurate instrumental appearance measurements with a sound basis in human perception of appearance. This fact is being recognized in many industrialized nations, notably by Japan through the Japan Industrialization Planning Association (Q.3) which, among other things is seeking to improve Japanese color technology and to fully automate fabric production and quality control.

Other values of appearance measurement and control to society are difficult to place directly on a monetary basis. Except for a few obvious safety applications involving road signs and automobile glass, the bulk of appearance work is aimed at psychological impressions. The difference between success and failure in dealing with appearance manifests itself in differences between having things seem well-kept or shabby, well or poorly made, carefully or poorly planned, harmonious or discordant--causing the beholder to have feelings of well-being or to be ill-at-ease. In these times of rising population density, this will probably become an increasingly important aspect of our national life.

The size of the portion of the economy which is involved in appearance is immense as is graphically expressed by Mr. Louis A. Graham in a recent letter (Q.2-6) to the Secretary of Commerce requesting continued NBS activity in the color field:

"a superficial consideration of the color industry might lead you to believe that the multi-million dollar colorant (dyes and pigments) industry and their suppliers might be the only beneficiaries of NBS efforts in this field. This is not true. The major beneficiaries will be the multibillion dollar color dependent industries such as textiles, paint, automotive, furniture, packaging and others."

The future promises expansion, and the value of good standardization of techniques and calibrations will expand correspondingly. 


\section{APPENDIX I}

\section{BACKGROUND in APPEARANCE}

A large portion of this report (5.1) has been devoted to a discussion of the uses of and needs for appearance measurements, but little has been said about the technical aspects of the measurement process. There are two I.1 REASONS FOR PRESEINTIIV BACKGROUiD information on appearance measurements. First, although the appearance of objects is observed to some extent by all who can see,

I.1.1 THE WAYS Iil WHICH APPEARANCE IS MEASURED ARE NOT WIDELY KNINI, Therefore, the physical measurements are explained briefly in the first part of this appendix, along with some details about how these measurements can be involved in various applications. Second, from information gathered in the study of spectrophotometry being reported here, it seems reasonable I.1.? TO SUGGEST THAT A STUDY OF APPEARAIICE MEASURENEITS BE UIDERTAKE. regarding the aspects of the measurements other than spectrophotometric. The reasons for this suggestion and the type of study being suggested are presented at the end of the appendix.

The whole of the experience of perceiving appearance has been broken into several parts by making certain

I.2 ABSTRACTIOIS from the experience. The abstractions presented in the following portion of the appendix are not to be regarded as unique, but rather as examples of present practice.

One of the more conspicuous aspects of appearance for an observer with normal vision is

I.2.1 COLOR, or difference in experience resulting from differences in wavelength reaching the eye. The summary of color measurement to be given here is necessarily brief. For those wishing to pursue the subject further, an excellent and easily comprehended introduction to the subject is given by Billmeyer and Saltzman (C.3.63) and more details can be found in books by Judd (C.3.64) and Wyszecki and Stiles (C.3.65), the NBS monograph by Nimeroff (C.3.66), and the NBS special publication on Colorimetry (C.3.67).

It has been found empirically from psychological experimentation that a proper combination of three spectrally different sources of light can create the experience of "matching colors", the matching being most easily done if each source emphasizes a distinctly separate region of the visible spectrum (approximately 380 to $700 \mathrm{~nm}$ wavelength). From experimental studies of this effect, three dimensional models of color vision have evolved. One such model, formally adopted by the CIE, will be described here. As an example, consider the color perception associated with a non-fluorescing diffusely reflecting object. For convenience, the description of the light flux is broken into two parts-- e $(\lambda)$, a function of wavelength, $\lambda$, representing the spectroradiometric properties of the radiation illuminating the surface and a function $r(\lambda)$ representing the spectral reflectance of the object's surface. The product of these two functions represents the amount of light entering the eye. The response of the eye is represented by a set of three functions $\bar{x}(\lambda), \bar{y}(\lambda)$, and $\bar{z}(\lambda)$ called spectral tristimulus values (Q.9). These were adopted from an infinite family of equivalent functions by agreement, and have the features that $\bar{y}(\lambda)$ is identically 
the function used in photometry to represent the overall sensitivity of the eye and that all three of the functions are positive definite. Three numbers, called tristimulus values, are calculated as follows:

$$
\begin{aligned}
& X=\int e(\lambda) r(\lambda) \bar{x}(\lambda) d \lambda \\
& Y=\int e(\lambda) r(\lambda) \bar{y}(\lambda) d \lambda \\
& Z=\int e(\lambda) r(\lambda) \bar{z}(\lambda) d \lambda
\end{aligned}
$$

(Mathematically, these numbers are classed as functionals. Thus, functional analysis should provide a good means of solving certain problems in colorimetry such as error limits (7.2.3).) The presence of fluorescence complicates the analysis since $r$ takes on the characteristics of a two dimensional transformation matrix rather than being a simple weighting function, but the outcome of the calculation is a set of three numbers, X, Y, and $Z$ which still have the same meaning. The basis of colorimetry is that any surface uniformly giving rise to a given value of $\mathrm{X}, \mathrm{Y}$, and $\mathrm{Z}$ will, in similar circumstances, appear to have the same color and brightness as any other combination of surface and illumination giving rise to the same value of $X, Y$, and $Z$.

Another aspect of appearance which is often abstracted is I.2.2 GLOSS, which can be expeditiously introduced through the example of a painted surface. In a painted surface, multiple scattering and selective absorption produces a diffused reflected light with which one associates "the color of the paint". However, a small fraction of the radiation, usually about five percent, does not penetrate to the pigment to be scattered but is reflected specularly (Fresnel reflection) from the surface of the binder in which the pigment is imbedded. This reflection is only slightly wavelength dependent, and hence gives the same impression of color as the incident light. The gloss value assigned to a surface is a measure of the regularity of this reflection-high gloss being "mirror like" and low gloss "dull". In current practice, gloss is measured by projecting collimated light onto a surface at a specified angle of incidence. The fraction of the light reflected into a small solid angle centered on the direction of specular reflection is a measure of the gloss.

I.2.3 HAZE is an abstraction made in an effort to describe "cloudiness" in a material which should be transparent. In present measurements it is quantified as the ratio of the amount of light diffusely scattered in the foreward direction by the material to the amount of light transmitted "straight through" the sample.

I.2.4 LIGHTNESS is a measure of the apparent ability of a material to diffusely reflect light. Once the source of illumination is specified, the $Y$ value of Eqs. II can serve as a measure of brightness.

I,2,5 WHITENESS, on the other hand, is a measure of the appearance of colorlessness in diffuse reflection. A departure from whiteness could be characterized as a departure from constancy of the $r(\lambda)$ curve at a magnitude near $100 \%$. 
I.2.6 PATTERN is the result of a highly organized arrangement of appearance aspects such as color, gloss and [.2.7 TEXTURE, where texture is used to describe the "three dimensional" properties of surface appearance as recognized by the presence of shadows and small-scale variations in gloss. A plaid is an example of a repetitive pattern based mainly on color, whereas embossing produces patterns based principally on texture.

Although abstractions such as those above seem straightforward enough, there are a number of

I.3 COPLICATIOUS IN APPEARAIICE PEASURERITS, One cause of complications is one of the same things which has given added impetus to spectrophotometry, namely, I.3.1 DEVELOPNENTS III TECHIOLOGY.

The effects of such technological change can be illustrated in terms of colorimetry. Since equality of integrals does not imply equality of integrands, one can see from Eqs. II that it is quite possible under a given illumination to have two objects with differing $r(\lambda)$ match in color. Such a color match is called a metameric match and the difference will not be detected under the given illumination by either a human observer or a tristimulus colorimeter. However, under a different illumination, a color difference may be noticeable. In the early years of colorimetry, metameric matches could be tolerated. Since the common forms of illumination, incandescent lamps and sunlight, had similar and continuous spectral distributions of radiant energy, and since the spectral reflectance functions of natural and early synthetic colorants varied slowly with wavelength (C.3.68), one was unlikely to produce a metameric match accidentally in which the $r(\lambda)$ curves differed greatly. As a result, adequate quality control could be maintained through tristimulus matching under sunlight and incandescent light. This is no longer the case, however. The newer synthetic colorants have strongly varying spectral reflectance and many of them fluoresce, either subtly or strongly (C.3.69). Thus it is quite easy to produce a metameric match in which the two $r(\lambda)$ functions differ strongly. Furthermore, new sources of light are being developed which depend on arc discharges and phosphors producing illumination which is rich in line structure and which has non-thermal continuum distribution. As a result of these differences, objects which match metamerically under one illumination can distinctly differ in color under another illumination. The implication of these developments is that tristimulus colorimetry (visual or instrumental) is becoming inadequate for quality control, and that control of $r(\lambda)$ by spectrophotometric means will be essential. For the same reason, specifications of color should be based on a spectrophotometric rather than a colorimetric basis.

The spectrophotometry group of NBS can contribute to the success of color quality control in two ways, first by seeing that the spectrophotometric measurement system is maintained at a satisfactory level of accuracy and second by developing procedures for determining limits of colorimetric error from spectrophotometric data. This will involve a generalization of procedures developed in earlier work (C.3.70, C.3.71), to include means of dealing with new colorants, new illuminants and perceptual sensitivity to color difference. The mathematical bases for such computations are closely related to those using observations at several wavelengths to solve the problem of specificity in chemical determinations $(5 \cdot 2 \cdot 2,7.2 .3)$. The same type of mathematical procedures can also be used to handle color formulation problems, efficient measurements for control of color processes, and color 
rendering measurements on sources of illumination (C.3.72). The color rendering measurements, which formerly have been based on a finite set of test samples, may need to be generalized to the entire color space in order to properly handle the new light sources and colorants. Concepts for such a generalization will also be useful in developing special variations of the color rendering indices as suggested by Judd (C.3.73). In fact, since efficiency of lighting is of prime importance in conserving power, color rendering properties of the lamps may have to be compromised in the process. This may place the burden on the colorant manufacturers to produce colorants the appearance of which is less sensitive to variations in the spectrum of illumination. The measure of this sensitivity, which might be called a "rendering color" index, could also be determined with the same type of mathematical procedure.

Naturally, color is not the only measurement which is affected by the mushrooming of technology. In general, the variety of surfaces being manufactured is increasing factorially with the introduction of new materials and finishing techniques. A combination of this increase in variety of products and the need to move to instrumental inspection has led to increasing recognition of the I.3.2 IIADEQUATE DEFI'IITIO:U OF THE ABSTRACTIO'IS, Although gloss is related to specular reflection, it is by no means as simple as the definition of I.2.2 might appear. The sparkle of plastic films, the glitter of metal flake top surfacing, and the luster of metallic paints not to mention the visual effects produced by plush fabrics and satin-like materials all belong in the category of gloss to some extent. In a 1937 paper on the subject (C.3.74), Hunter defined five different aspects of glossiness and specific measurements which correlated with each. Several procedures for measuring gloss-related parameters have since been adopted by standards organization, the latest being a two parameter technique adopted in 1967. Difficulties in obtaining correlation between the measurements and the desired appearance aspects still exist, however, and some sort of pattern recognition instrumentation may be required to solve the problem. (Earlier visual methods used clarity of reflected image as an indicator of certain aspects of gloss.) The problem is almost certainly one of definition, however, since brute force refinement of instrumentation, even to the point of requiring state of the art machining and alignment in the instruments (C.3.79), has not solved the problems. Needless to say, just what is meant by "pattern" and "texture" in appearance measurement terms is even more vague than gloss.

It should be borne in mind that what is being described here is not semantics, but a real problem in defining much needed measurements. Blemishes in appearance are just as damaging to trade whether they result from poor measurement practice or from poor definition of the measurement. Well defined measurements of appearance are needed for communication between buyer and seller, for specifications, and to allow items from next week's or next month's production run to be sold on the same counter as those made today.

Appearance measurements are also important in monitoring quality of production, but this implies another complication, the I.3.3 UEDD TD DEFIINE DIFFEREICES IN APPEARAHCE, Tolerances must be established for allowable differences in appearance in order to balance cost of production against acceptability of the final product. Mathematically, differences in measured values can be related to distances in the space in which the measurement is described. Ideally, equal distances in the space in which the measurement is described would represent equal impressions of appearance difference to a viewer. In this way, tolerances could be placed on measured difference values for various 
purposes. Differences between the measures of appearance abstractions are by logical necessity more poorly defined than the measures themselves, and in reality, with the exception of color differences (C.3.76), the differences are practically undefined.

The discussion above has wandered well out of the I.4 BOUIDS OF SPECTROPHOTOMETRY, As defined in section 2 of this report, spectrophotometry is a means of measuring the interaction of radiation with matter. Spectrophotometric measurements, once defined, are physical measurements with differences definable in physical terms. Appearance measurements differ from what are considered purely physical measurements in two important ways:

a. The concepts are not as easily isolated within the mind. The "primitive" concepts of distance connecting places, time connecting events, and objects being "made of something" were considered self-evident, objective concepts, and they formed the basis for the heirachy of classical physical science. These concepts serve well for most pragmatic uses, even though modern physics has shown that the choices were not as objective as they first seemed. The concepts of appearance, by contrast, are more complicated and have always been regarded as subjective and a part of the realm of psychology or psychophysics.

b. The physiology of the human being is involved directly in appearance measurements. Spectrophotometric properties such as reflectance or transmittance can be defined on a purely physical basis, but defining appearance involves the eye, its structure, and its function.

Spectrophotometry plays two roles in appearance measurement. First, it supplies psychologists and physiologists with accurate knowledge of the optical properties of samples which they use in experiments to define appearance. Once an appearance measurement is defined, it becomes a physical measurement and spectrophotometry is used as discussed in section 5.1 and the first part of this appendix.

I.5 FACTORS SLGGESTIING A STUDY OF IBS AND IBS IINOLVEUENT IN APPEARAICE MEASUREMEIT

were deduced from information gathered in the spectrophotometry study. From a practical standpoint, the measurements appear to be

1.5.1 URGEVTLY $: \mathbb{E E D E D , ~ U . S . ~ m a n u f a c t u r e d ~ g o o d s ~ a r e ~ f a c i n g ~ e v e r ~ s t r o n g e r ~ c o m p e t i t i o n ~}$ in the marketplaces of the world. Our general attitudes favoring high productivity and opposing tedious labor point to automation and instrumentation. If specific assistance should be required of NBS in appearance measurement, the initial part of it will be needed in the next several years. If the U.S. is to gain the necessary advantage from these measurements, we must be ahead of the rest of the world in their development and use.

I.5.2 GOOD SPECTROPHOTOMETRY IS NDT SUFFICIEFT for defining appearance measurements, it is only good for carrying them out. Psychological experiments and an understanding of the physiological functions of visual perception are necessary for defining measurements which correlate well with the desired appearance aspects. Such good correlation is abviously needed for efficient and effective use of the measurements, but there is an additional advantage for doing the measurements properly from the outset. If they are well defined and effective, they will be worked into international standards with little change. The advantages of having 
to change only a little to meet international standards are obvious.

\section{At present the}

$1.5,3$ RESPOISIBILITY FOR APPEARANCE MEASUREMENTS AT IPS IS POORLY DEFINED. When the Metrology Division was dissolved, the colorimetry section was transferred to IAT (Q.10), where its activity in providing measurement definition underwent de facto disassembly. No activity was instigated elsewhere in NBS to replace it, and there is no evidence that a careful study has been made to determine whether such an activity is needed.

\section{I.6 OBJECTIVES OF AVI APPEAPAMCE STUDY, if one is undertaken might include the} following:

I.5.1 DETERMINIING THE IIEEDS IN IIDUSTRY overall. Since the field is presently somewhat fragmented, such a determination must be made by a person or persons knowledgable both in the psychology and physiology of appearance and in modern methods of instrumentation who can deduce the real needs from the bits and pieces of evidence which can be obtained and who can foresee the reasonable future of such measurements. From such evidence the justification for support can be determined.

I.6.2 DEIERPIIHING THE SIZE OF THE TOTAL EFORT which will be required to develop the needed measurements.

I.6.3 DETERMINING WHAT THE NATURE AND EXTENT OF IHBS AID IBS IINOLVEMENT SHOULD BE. It may be that these should be nil, but this is really doubtful. A few incidental findings from the spectrophotometry study provide some indications of what this involvement should be like.

a. The NBS program should be efficiently directed toward developing general descriptive models of the process of visual perception from which solutions to pragmatic measurement problems can be sensibly derived. The recent advances in instrument and component technology (F,G) make it practical to build instrumentation with the sensitivity of the eye and which has pattern recognition capability. In order to take advantage of this technology to solve important problems in appearance measurement (J,R.2.1,R.2.2) a thorough quantitative understanding of the mechanisms and limits of visual perception are necessary.

b. The NBS program should provide leadership in developing foundations of appearance measurements. It should not, however, become involved in specific applications, per se, since these are too numerous and fragmented. In particular, NBS should establish a reasonable measure of distance for each general measurements space which is defined (I.3.3) in order to provide uniformity in the measurement system, but it generally should not become involved in the details of establishing the tolerances for acceptability in particular products (with the possible exception of government procurement specifications).

c. The person or group which does the work should be thoroughly grounded in physics, psychology, physiology, metrology, and modern instrumentation methods and also be able to develop and maintain a no-nonsense program directed toward pragmatic appearance measurement procedures. This combination will not just happen. 
To the outside world it appeared that NBS had dropped appearance measurement by default. This has caused concern among the users of such measurements which has often been expressed, some of these expressions appearing in the letters in Q.2. This concern was somewhat relieved when the spectrophotometry study was undertaken, but concern about the basic foundations of appearance measurement still exists in the technological community. The writer of this report shares this concern. 


\section{APPENDIX $F$}

\section{REFERENCES}

The following list of references is appendix C from the 1972 report of the study of the spectrophotometric measurement system by the IBS group. Since this list was prepared, the writer has made several dozen new contacts and a number of good articles on spectrophotometry have been published. However, this list will still serve to illustrate the extent of the background work which went into the study as well as listing most of those contributing to the study. The contributions of the writer's more recent contacts is gratefully acknowledged. 


\section{APPENDIX C (From 1972 Report) \\ REFERENCES}

\section{A large fraction of the}

C.1 IIWIVIDUALS contributing information on which the conclusions of this study are based are named in this 1ist. An effort was made to limit the list to the principal contacts, those with highly responsible positions in technology, sales, or management or whose contribution to spectrophotometric measurement is significant. A few of the principal contacts may have been omitted unintentionally. In addition, of course, there were many who contributed through group conferences and discussions who have not been listed here specifically. Their help is gratefully acknowledged.

The contributions were made for the most part through direct discussions, but a few contributed through letters to us or through delivering particularly informative lectures or seminars which one of us attended. Whenever a specific reference to an individual is made in this report, it is denoted by C. 1 followed by the number of the name in the list. For example, a reference to Dr. Abel would be indicated by (C.1.1).

1. Abe1, Dr. Peter G.; (C.2.72a) Calibration of Satellite Remote Sensing

2. Alden, Alex; (C.2.92) Overview of SMPTE Work

3. Alexander, John W.; (C.2.48) Use of Spectrophotometry in Chemical Manufacturer's Laboratory

4. Andrus, W.E.; (NBS:400.04) NBS Programs and Policy

5. Askew, John R.; (C.2.102) Jet Engine Smoke Emission Tests

6. Atkins, Joseph T.; (C.2.32b) ISCC Spectrophotometry Round Robin

7. Austin, Jack; (C.2.44b) Textile Properties

8. Auth, Jerry; (C.2.36) Applications of Infrared Measurements to Military Problems

9. Babb, Raymond; (C.2.59) Agricultural Colorimetry

10. Bader, William F.; (C.2.68) Abridged Spectrophotometry in Process Control

11. Bartky, Dr. Ian R.; (NBS:400.00) Plans and Activities of IAT

12. Bennet, Dr. J. M.; (C.2.65) Measurement Techniques

13. Bennett, Dr. Harold E.; (C.2.65) Thin Film Reflectance Measurements

14. Bertero, Edward P.;(C.2.71) Standardization of Color Television Systems 
15. Billmeyer, Fred W.; (C.2.88) Colorimetry

16. Blackman, W.; (C.2.77) IR Measurements

17. Bostick, Ronald E.; (C.2.89) Measurement of Translucent Materials

18. Brackett, Frank;(C.2.101) Color Film Processing

19. Brewer, Glen A.; (C.2.99) Pharmaceuticals

20. Brezinski, Dr. J. P.; (C.2.52) Optical Measurements for Paper

21. Bruening, Robert J.; (NBS:221.12) Photodetector Calibration

22. Brumfield, Robert;(C.2.29) Fluorescent Colorants

23. Budde, W.; (C.2.93) Diffuse Reflectance Measurements

24. Burke, Dr. Robert W.; (NBS:310.04) Absorption Measurements for Liquid Gases

25. Cattaro, Matthew; (C.2.18) Instrumentation

26. Charvat, Robert A.; (C.2.48) Pigments

27. Christie, John S.;(C.2.31) Appearance Instrumentation

28. Clarke, F.J.J.; (C.2.74) Spectrophotometric Gages and Measurements

29. Coulter, Jack; (C.2.10) Measurements for Military Applications

30. Conner, William; (C.2.35) Smokestack Emission Measurements

31. Cravitt, Sam; (C.2.37b) Fluorometry

32. Dearth, Leonard; (C.2.52) Paper Appearance Measurements

33. Derby, Roland; (C.2.30) Colorimetry in Industry

34. Dickson, George R.; (NBS:311.05) Opacity Standards for Dental Ceramics

35. Douglas, C.A.; (NBS:221.12) Retroreflectance

36. Dummer, Richard; (C.2.42) Spun Epoxy Mirrors

37. Eckerle, Kenneth L.; (NBS:221.12) High Accuracy Spectrophotometry

38. Elstad, John; (C.2.68) Retroreflectance

39. Erb, Wolfgang; (C.2.85) Absolute Reflectance

40. Fancy, Robert; (C.2.62) Monochromators, High Resolution Spectrophotometry

41. Fertig, Lloyd; (C.2.23) Specifications for Fluorescent Pigments 
42. French, Judson C.; (NBS:425.02) Photoconductor and Microelectronics Measurements

43. Fuchs, Dr. Jacob; (C.2.9) Spectrophotometry in Chemistry

44. Galloway, William; (C.2.14) Immersed Filters as Linearity Gages

45. Geist, Jon C.; (NBS:221.12) Reflectance Measurements, Detectors

46. Giesecke, Paul M.; (C.2.3) Absolute Diffuse Reflectance

47. Gilmore, John; (C.2.62) Monochromators

48. Glen, Jerry; (C.2.82) Coordination of Measurements in a Large Industry

49. Goebe1, David G.; (C.2.81) Measurement Techniques

50. Goldman, David T.; (NBS:200.00) NBS Programs and Budget

51. Gordon, Louis I.; (C.2.79) Measurement of Nutrients in Sea Water

52. Graham, Louis A.; (C.2.16) Textile Colorimetry

53. Grum, Franc; (C.2.34) Fluorescence, Lighting Materials

54. Haenni, Dr. E.0.; (C.2.39a) General Chemical Measurements

55. Haller, Dr. Wolfgang K.; (NBS:313.02) Glass

56. Halvorsen, Gary; (C.2.59) Agricultural Colorimetry

57. Hamilton, James M.; (C.2.92) Infrared Instrumentation

58. Hammond, H.K., III; (NBS:411.04) Reflectance Measurements

59. Hammon, H.K., IV; (C.2.41) Instrumentation

60. Hanes, Dr. Randall M; (C.2.54) Colorimetry

61. Hanst, Dr. Phil; (C.2.35) Multiple Pass Spectrophotometry

62. Harris, Chester; (C.2.31) Instrumentation

63. Hawes, Roland C.; (C.2.17) Standardization

64. Haupt, Mrs. Geraldine;(NBS:221.12) Colorimetric Gages and Visual Colorimetry

65. Heck, Patrick; (C.2.82) Industrial Spectrophotometry

66. Hemmendinger, Henry; (C.2.49) Calibration

67. Hilleary, D.T.; (C.2.72) Satellite Reflectance Standards 
68. Hillman, R.; (C.2.91) Colorimetry in Retail Trade

69. Hoffman, J. Gordon; (C.2.50) Needs for Improved Measurements

70. Holton, A.B.; (C.2.93) Overview of Paint Industry

71. Hooper, Page; (C.2.17) Instrumentation

72. Howard, Paul T.; (NBS:421.04) Paint Reflectance Standards

73. Howett, Dr. Gerald L.; (NBS:421.14) Color Vision

74. Hsia, Dr. Jack J.; (NBS:221.12) Reflectance, Color Differences

75. Huey, Dr. Sam J.; (C.2.93) Color Control in Paint Production

76. Hunter, Richard S.; (C.2.51) Appearance Measurements

77. Ingle, George; (C.2.69) Industrial Applications

78. Jakubowski, James; (C.2.108) Graphic Reproduction

79. Jasinski, John; (C.2.82) Glass Technology

80. Johnson, Dr. Gordon H.; (C.2.38) Inorganic Colorants, Ceramics

81. Johnson, Norbert L.; (C.2.68) Retroreflectance

82. Johnston, Ruth M.; (C.2.56a) Color Formulation

83. Jones, J. Grayson; (C.2.26) Color Television Monitors

84. Joseph, Meyer; (C.2.46b) Government Purchase of Paints

85. Kallet, Eli A.; (C.2.37b) Fluorometry, Stable Arc Sources

86. Kaskey, Gaden; (C.2.59) Agricultural Colorimetry

87. Kaye, Dr. Wilbur; (C.2.14) Instrumentation

88. Keane, Thomas J.; (C.2.41) Instrumentation, Gages

89. Keller, Charles; (C.2.14) Instrumentation

90. Keller, Elaine; (C.2.56a) Color Formulation Systems

91. Ke11y, Kenneth L.; (NBS:421.14) Colorimetry

92. Kenyon, George; (C.2.17) Instrumentation

93. Koplito, Richard E.; (C.2.46a) Government Procurement

94. Kostkowski, Dr. H.J.; (NBS:221.12) Optical Radiation Section Policy 
95. Kurth, Ralph; (C.2.82) Long Path Measurement in Glass

96. Lashof, Dr. Theodore W.; (NBS:411.03) Collaborative Reference Program

97. Leete, Charles W.; (C.2.60) Appearance Instrumentation Industry

98. Lewis, Dr. T.E.; (C.2.32a) Dyes

99. Levy, Dr. Gabor B.; (C.2.84) Instrumentation

100. Lockhart, Wayne C.; (C.2.20) Tuneable Dye Lasers

101. Locklin, Paul;(C.2.87) Fluorescent Colorants

102. Loeb, Harry; (C.2.108) Instrumentation

103. Luckern, Paul; (C.2.55) Spectrophotometry in Drug Patents

104. Ludwig, Klaus; (C.2.42) Many-pass Instrument

105. Lusk, Thomas E.; (C.2.43) Colorimetry in Lighting

106. Madden, Dr. Robert P.; (NBS:232.03) Former Activities of NBS Spectrophotometry Section, Instrumentation

107. Malthouse, David; (C.2.61) Instrumentation

108. Manning, Robert; (C.2.14) Instrumentation

109. Margesen, John; (C.2.35) Sulfur Dioxide Determination

110. Marciniak, Michael; (C.2.70) Absolute Reflectance, Color

111. Marsh, Jack; (C.2.105) Fluorescence

112. Martin, Robert; (C.2.32a) Dye Chemistry

113. Mavrodineanu, Dr. Radu; (NBS:310.04) Analytical Chemistry, High Precision Spectrophotometry

114. Maynard, A.W.; (C.2.67) Spectrophotometric Identification of Metals

115. McCamy, Calvin S.; (C.2.56b) Measurement Techniques

116. McClinney, Dr.; (C.2.35) Long Path Measurements, Dye Lasers

117. Menis, Dr. Oscar; (NBS:310.04) Analytical Chemistry Spectrophotometry Program

118. Michaels, Theodore D.; (C.2.63, C.2.83) Reflectance of Pharmaceutical Powders

119. Mielenz, Dr. Klaus D.; (NBS:310.04) Optical Design 
120. Miller, V.F.; (C.2.89) Heat Transfer Through Plastics

121. Mitteldorf, Mr. Arthur; (C.2.97) Fluorometric Instruments

122. Molter, R.C.; (C.2.57) Measurements in Glass

123. Morehead, Walter E.; (C.2.86) Fluorescent Brighteners

124. Meunier, Dr. Paul L.; (C.2.32a) Dye Production Quality Control

125. Nader, John; (C.2.35) Source Emissions

126. Neu, Mr. J. Turney (C.2.42) Bidirectional Reflectance

127. Neubrech, David A.; (C.2.41) Instrumentation

128. Nimeroff, Isadore; (NBS:221.12) Colorimetry

129. Norris, Karl H.; (C.2.1) Spectrophotometric Evaluation of Agricultural Products

130. Norris, Robert W.; (C.2.78) Reflectance Measurements on Paint

131. O'Connor, John; (C.2.39c) Retroreflectors

132. Oellrich, Dick; (C.2.50) Secondary Standards, Instrumentation

133. O'Keaffe, Andrew; (C.2.35) Environmental Monitoring

134. Owens, Paul; (C.2.42) Drug Patents

135. Popenoe, Charles; (NBS:221.12) Automation

136. Popsen, S.J.; (C.2.61) Instrumentation

137. Prior, Paul; (C.2.107a) Target Signatures

138. Rendino, John; (C.2.62) Monochromator

139. Rib, Dr. Harold T.; (C.2.104) Quantitative Measurement in Remote Sensing

140. Rich, R.B.; (C.2.28) Exhaust Smoke Measurement Senior Engineer, Instrumentation

141. Richard, Steve; (C.2.107b) IR Transmittance

142. Richmond, Joseph C.; (NBS:221.12) Reflectance, Ceramics

143. Rittner, Dr. Edward; (C.2.24) Heat Transfer

144. Robertson, Dr. Alan R.; (C.2.73) Goniophotometry 
145. Robinson, Roland D.; (C.2.90) Appearance Measurements

146. 1a Rocca, Jerry; (C.2.66) Remote Sensing, Goniophotometry

147. Rosenthal, Robert D.; (C.2.76) Instrumentation, Agricultural Uses for Spectrophotometry

148. Sanders, Dr. C.L.; (C.2.73) Detector Calibration

149. Schaeffer, W.D.; (C.2.45) Research Director, Graphic Arts Colorimetry

150. Schleter, John C.: (NBS:431.00) Activities of NBS Spectrophotometry Section

151. Schroeder, Norm; (C.2.15) Infrared and Ultraviolet Calibrations

152. Schwab, Hans J.; (C.2.21) Spectrophotometry in Sales and Production of Chemicals

153. Seabright, Dr. Clarence; (C.2.48) Ceramic Colorants

154. Sellers, Dr. D.E.; (C.2.69) Need for Inter-Laboratory Agreement

155. Shaw, Roderick K.; (C.2.40) Food Quality and Appearance

156. Silkman, Mr.; (C.2.107c) Photographic Materials

157. Sillag, F.C.; (C.2.13) Stack Emission Measurements

158. Simon, Frederick T.; (C.2.22) Textile Finishing

159. Sink, B.R.; (C.2.107a) Target Signatures

160. Siranni, J. Donald; (C.2.47) Production Control

161. Smith, John T.; (C.2.72b) Colorimetry and Densitometry in Mapping

162. Smith, Richard; (NBS:271.02) Laser Power Meters

163. Steiner, Dr. B.W.; (NBS:221.12) CORM, Radiometry and Photometry Sensing

164. Stenius, Ake S:son (C.2.100) Absolute Diffuse Reflectance

165. Stensby, Per; (C.2.21) Visual Fluorescence Evaluation

166. Stepchuk, Zenon; (C.2.68) Instrumentation

167. Stevison, Donald F.; (C.2.107b) Materials Research

168. Stewart, James E.; (C.2.33) Biophysica1 Measurements

169. Stewart, Michae1; (C.2.8) Garment Production 
170. Steirwalt, D.L.; (C.2.75) Infrared Measurements and Information

171. Strieby, Robert A.; (C.2.24) Needs for Infrared Measurements

172. Suga, Nagaichi; (C.2.103) Gloss and Haze Measurements and Standard Gages

173. Swift, Dr. Howard R.; (C.2.57) Specular Measurements, Glass

174. Takkunen, Bil1; (C.2.68) Instrumentation

175. de Torres, Manuel; (C.2.64) President, Colorimetry in Advertising and Printing

176. Tripp, Robert W.; (C.2.37a) Linear and Angular Encoders

177. Trumble, Capt. Kenneth C.; (C.2.107a) Target Signatures

178. Turner, G.K.; (C.2.105) Fluorometry, Instrumentation

179. Ulrich, Dr. William; (C.2.14) Instrumentation

180. Valez, Michael; (C.2.14) Instrumentation

181. Van Fleet, Mr.; (C.2.44b) Textile Production

182. Velapoldi, Dr. Rance A.; (NBS:310.04) Spectrofluorometry

183. Weidner, Victor R.; (NBS:221.12) Infrared Measurements

184. Weissler, Dr. Alfred; (C.2.39a) Cosmetics

185. Werner, Alan J.; (C.2.27) Filters

186. Wernicke, Bruno; (C.2.107a) Target Signatures

187. Wilcox, John; (C.2.34) High Density Measurements

188. Willey, R.R.; (C.2.106) Infrared Instrumentation

189. Winters, William; (C.2.77) IR Measurements

190. Wood, Dr. L.A.; (NBS:311.00) Fading Tests for Dyes

191. Worley, Robert; (C.2.98) Textiles

192. Yates, Harold; (C.2.77a) Reflectance Gages for Use in Satellites

193. Yeatman, John N.; (C.2.39a) Food Colorants

194. Yonemura, Dr. Gary; (NBS:462.02) Psychology and Physiology in Color Vision

195. Zissis, George; (C.2.66) Remote Sensing 


\section{A number of the}

C.2 ORGANIZATIOHS which contributed to the conclusions reached in this study are listed in this section. An asterisk by the name of an organization indicates that it was visited by a member of our group during the source of this study. Information was obtained from the other organizations through contacts with representatives or through letters, brochures, catalogs, tech notes, or advertisements. This list also serves as an address list for the individuals named in C.1. References to this list are indicated by C.2 followed by the number locating the organization in the list. For example, the U.S. Department of Agriculture would be indicated in the text by (C.2.1).

1. *Agriculture, U.S. Department of Instrumentation Research Laboratory Market Quality Research Division Beltsville, Maryland 20705 (301) $474-6500$

2. American Association of Textile Chemists and Colorists AATCC Technical Center P.O. Box 12215 Research Triangle Park North Carolina 27709 (919) 549-8141

3. *American Cyanamide Co. 1937 West Main St. Stamford, Conn. 06904 (203) 348-7331

4. American Instrument Co. 8030 Georgia Avenue Silver Spring, Md. 20910 (301) 589-1727

5. American National Standards Institute, Inc. 1430 Broadway New York, N.Y. 10018 (212) 868-1220

6. The American Society of Photogrammetry 105 N. Virginia Avenue Falls Church, Virginia 22046 (703) $534-6617$

7. *American Society for Testing and Materials 1916 Race St. Philadelphia, Pa. 19103 (215) 569-4200

8. Apparel Research Foundation, Inc. 1120 Connecticut Ave. N.W. Washington, D. C. 20036 (202) 233-2517 
9. *Arizona State University

Chemistry Department

Tempe, Arizona 85821

(602) 965-3462

10. *Army, U.S.

Mobility Equipment Research and Development Center

Night Vision Laboratory

Fort Belvior, Va. 22060

(703) $664-6071$

11. Atlantic Research Corporation

3333 Harbor Blvd.

Costa Mesa, California 92626

(714) $546-8030$

12. Avco Everett Research Laboratory

2385 Revere Beach Parkway

Everett, Mass. 02149

(617) 389-3000

13. Bailey Meter Company

Wickliffe, Ohio 44092

(216) 943-5500

14. *Beckman Instruments, Inc.

2500 Harbor Blvd.

Fullerton, California 92634

(714) 871-4848

15. *Bendix Aerospace Systems Division 3300 Plymouth Road

Ann Arbor, Michigan 48107

(313) 665-7766

16. Burlington Industries Research Center

P.0. Box 21327

Greensbora, North Carolina 27420

(919) $379-3240$

17. *Cary Instruments

2724 S. Peck Road

Monrovia, California 91016

(213) 446-7181

18. Cattaro Scientific Controls

Rt. 1, Box 236,

Chantilly, Va. 22021

(703) $471-4131$

19. Chicago Miniature Lamp Works

4433 N. Ravenswood Ave.

Chicago, I11. 60640

(312) 784-1020 
20. ثhromatix

1145 Terra Bella Ave.

Mountain View, Ca. 94040

(415) 969-1070

21. Ciba-Geigy, Inc.

Geigy Industrial Chemicals

Ardsley, New York 10502

(914) 478-3131

22. *Clemson University

Textile Department

Clemson, South Carolina 29631

(803) 656-3177

23. Color-Vu Corporation

45 West 13 Street

New York, N.Y. 10011

(212) 924-2036

24. Colspan Environmental Systems, Inc.

P.0. Box 3467

oulder, Colorado 80303

(303) 449-4411

25. Comsat Laboratories

Linthicum Road

Clarksburg, Md. 20734

(301) 428-4541

26. *CONRAC Corporation

Video Monitor Group

Covena, California 91722

(213) 966-3511

27. Corning Glass Works

Corning, New York 14830

(607) 962-4444

28. Cummins Engine Co., Inc.

Columbus, Indiana 47201

(812) 372-7211

29. *Day-Glo Color Corp.

4732 St. Clair Avenue

Cleveland, Ohio 44103

(216) $391-7070$

30. *Derby Co.

49 Blanchard St.

Lawrence, Mass. 01842

(617) 683-8726 
31. *Diano Corp.

P.O. Box 347

75 Forbes B1vd.

Mansfield, Mass. 02048

(617) 339-3701

32. Dupont

a. *E. I. du Pont de Nemours \& Co.

Organic Chemicals Department

P.O. Box 386

Wilmington, Delaware 19899

(609) 299-5000

b. E. I. du Pont de Nemours \& Co.

P.0. Box 1217

Parkersburg, West Virginia 21601

(304) 863-5311

33. *Durrum Instrument Corp.

3950 Fabian Way

Palo Alto, California 94303

(415) 321-6302

34. Eastman Kodak Company

Research Laboratories

Rochester, New York 14650

(716) 458-1000

35. *Environmental Protection Agency

Technica1 Center

Research Triangle Park

North Carolina 27711

(919) 549-8411

36. *Eocom Corp.

4630 Campus Drive

Newport Beach, California 92660

(714) 540-8453

37. Farrand
a. *Farrand Optical Co.
117 Wall Street
b. *Farrand Controls, Inc.
115 Wall Street
Valhalla, New York 10595
(914) 428-6800

38. *Ferro Corp.

Research Center

7500 E. Pleasant Valley Rd.

Independence, Ohio 44131

(216) 641-8580 
39. Food and Drug Administration

*a. Division of Colors and Cosmetics (202) 962-2470

*b. Division of Chemistry and Physics (202) 962-0744

c. Bureau of Product Safety Washington, D. C. 20204 (301) 496-7668

40. Florida Canners Association P.0. Box 780 Winter Haven, Fla. 33880

(813) 293-4171

41. *Gardner Laboratory 5521 Landy Lane Bethesda, Maryland 20014

(301) 656-3600

42. *General Dynamics/Convair

San Diego, Calif. 92112

(714) 279-7301

43. General Electric Co. Nela Park Cleveland, Ohio 44112 (216) 266-2339

44. Greenwood Mil1s, Inc.

a. P.0. Box 117 Greenwood, S.C. 29646 (803) 229-5311

*b. 111 West 40th St. New York, N.Y. 10018 (212) 695-2626

45. Graphic Arts Technical Foundation, Inc. 4615 Forbes Avenue Pittsburgh, Pennsylvania 15213 (412) 621-6941

46. GSA

a. Research and Testing Branch Federal Supply Service GSA Region 10 Auburn, Washington 98002 (206) 833-6500

b. Technical Operations Branch FMQO

Federal Supply Service Washington, D. C. 20406 (202) 557-7550 
47. GTE Sylvania

Precision Materials Group

Chemical and Metallurgical Division

Towanda, Pa. 18848

(717) 265-2121

48. *Harshaw Chemical Co.

1945 E. 97th St.

Cleveland, Ohio 44106

(216) 721-8300

49. *Hemmendinger Color Laboratory

R.D. Pequest Bend

Belvidere, N.J. 07823

(201) 475-2123

50. Hoffman Engineering Corporation

$183 \mathrm{R}$ Sound Beach Ave.

old Greenwich, Connecticut 06870

(203) 637-1719

51. *Hunter Associates Laboratory Inc.

9529 Lee Highway

Fairfax, Virginia 22030

(703) 591-5310

52. *Institute of Paper Chemistry

Appleton, Wisconsin 54911

(414) 734-9251

53. ISOMET

103 Bauer Drive

Oakland, N.J. 07436

(201) $337-3811$

54. Johns Hopkins University

Applied Physics Laboratory

8621 Georgia Avenue

Silver Spring, Maryland 20910

(301) 953-7100

55. *Justice, U.S. Department of

Anti-Trust Division

Washington, D. C. 20530

(301) 739-2385

56. Kollmorgen Corp.

*a. Color Systems Division

67 Mechanic Street

Attlebora, Massachusetts 02703

(617) 222-3880 
*b. Macbeth Research Laboratories Newburgh, New York 12550 (914) 561-7300

57. *Libbey-Owens-Ford Co.

Technical Center

1701 East Broadway

Toledo, Ohio 43605

(419) 242-5781

58. Lovibond

The Tintometer, Ltd.

Waterloo Road

Salisbury, Wilts

Great Britain

072227242

59. *Magnuson Engineers, Inc.

Instruments Division

1010 Timothy Drive

San Jose, California 95133

(408) 287-1260

60. Manufacturers Council on Color and Appearance

9416 Gamba Court

Vienna, Virginia 22180

(703) 938-4345

61. *Martin Sweets Co., Inc.

P.0. Box 1068

Louisville, Ky • 40201

(502) $774-5786$

62. *McPherson Instrument Corp.

530 Main Street

Acton, Massachusetts 01720

(617) 263-7733

63. Merk Sharp and Dohme

West Point, $\mathrm{Pa}$.

(215) 699-5311

64. Metro Litho-Graving Inc.

101 Moonachie Avenue

Moonachie, New Jersey 07074

(201) 935-1450

65. *Michaelson Laboratory

China Lake, California 93555

(714) 939-2869

66. *Michigan, University of

Infrared and Optics Laboratory

Ann Arbor, Michigan 48104

(313) 483-0500 
67. *Mines, U.S. Bureau of College Park Metallurgy Research Center College Park, Maryland 20740

(301) 864-3100

68. *Minnesota Mining and Manufacturing Co.

3M Center

St. Paul, Minnesota 55101

(612) 733-1374

69. Monsanto Company

Technical Liaison

1101 17th Street, N.W.

Washington, D. C. 20036

(202) 296-0050

70. *Munsel1 Color Co., Inc.

2441 N. Calvert St.

Baltimore, Md. 21218

(301) 243-2171

71. *National Broadcasting Co.

30 Rockefeller Plaza

New York, New York 10020

(212) 247-8300

72. National Oceanic and Environmental Administration

*a. National Environmental Satellite Center

Federal Office Building 4

Suitland, Maryland 20233

(301) 440-7114

b. Coastal Mapping Division

(301) 146-8230

73. *National Research Council of Canada

Division of Physics

Ottowa 7, Ontario

Canada

(613) 993-2478

74. National Physics Laboratory

Metrology Centre

Teddington, Middlesex

England

01-977-3222

75. *Naval Electronics Laboratory Center

Infrared Technology Division

271 Catalina Blvd.

San Diego, Calif. 92152

(714) 226-6951 
76. *Neotec Instruments, Inc.

6110 Executive Boulevard

Rockville, Maryland 20852

(301) $770-3525$

77. *Newark Air Force Station

Infrared and Laser St ndards Laboratory

Newark, Chio 43055

(614) 522-2171

78. Norris Paint and Varnish Co., Inc.

1675 Commercial Street, N.E.

Salem, Oregon 97308

(503) $364-2277$

79. Oregon State University

Department of Oceanography

Corvallis, Oregon 97331

(503) 754-3504

80. Optical Coating Laboratory, Inc.

2789 Giffen Ave.

Santa Roas, Calif. 95403

(707) $545-6440$

81. *0ptronics Laboratories, Inc.

7676 Fenton Street

Silver Spring, Md. 20910

(301) 587-2255

82. *owens-Illinois Technical Center

$1700 \mathrm{~N}$. Westwood St.

Toledo, Ohio 43607

(419) 242-6543

83. Pharmaceutical Manufacturer's Association

1155 15th St., N.W.

Washington, D. C. 20005

(202) 296-2440

84. *Photovolt Corporation

1115 Broadway

New York, N.Y. 10010

(212) 989-2900

85. Physikalisch-Technische Bundesanstalt

Abt. 4

D-3300 Braunschweig

Bundesallee 100

West Germany

86. The Proctor and Gamble Co.

Spring Grove and June St.

Cincinnati, Ohio 45217

(513) 562-1100 
87. *Radiant Color

2800 Radiant Avenue

Richmond, California 94804

(415) 233-9119

88. *Rensselaer Polytechnic Institute

Troy, New York 12181

(518) 270-6458

89. *Rohm and Haas Company

P.O. Box 219

Bristol, Pennsylvania 19007

(215) $788-5501$

90. Roland Robinson Associates

P.O. Box 132

Chantilly, Virginia 22021

(703) 471-7088

91. Sears Roebuck and Co.

Department $\mathrm{D} / 817$

3301 W. Arthington

Chicago, Illinois 60607

92. Sci Tech Corp.

301 West High St.

West Chester, Pennsylvania 19380

(215) 692-7861

93. *Sherwin-Williams Co.

101 Prospect Ave.

Cleveland, Ohio 44115

(216) $566-2242$

94. * Society of Motion Pictures and Television Engineers

9 East 41st St.

New York, N.Y. 10017

(212) $867-5410$

95. Spectral Data Corporation

Box 555

Hicksville, New York 11802

(516) 433-3910

96. Spectral Imaging, Inc.

572 Annursnac Hill Road

Concord, Mass. 01742

(617) 259-8330

97. *Spex Industries, Inc.

3880 Park Ave.

Metuchen, New Jersey

(201) 549-7144 
98. Spring Mills, Inc.

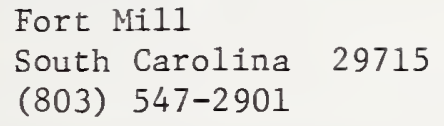

99. Squibb Pharmaceuticals

P.0. Box 191

New Brunswick, N.J. 08903

(201) $545-1300$

100. Swedish Forest Products Research Laboratory

Box 5604

S-11486 Stockholm

Sweden

101. *Technicolor, Inc.

6311 Romaine St.

Hollywood, Calif. 90038

(213) 462-6111

102. *Teledyne CAE

1510 Laskey Road

Toledo, Ohio 43601

(419) 475-4641

103. Toyo Rika Instruments Inc.

32 Banshu-Cho, Sinjuku-Ku

Tokyo, Japan

Phone Tokyo (341) 4191

104. *Transportation, U.S. Department of

Fairbanks Highway Research Station

ChainBridge and Great Falls Roads

McLean, Va.

Washington, D. C. 20591

(703) $557-5214$

105. $* G$. K. Turner

2524 Pulgas Ave.

Palo Alto, Calif. 94303

(415) 324-0077

106. Willey Corp.

P.0. Box 670

Melbourne, Florida 32901

(305) 727-2076

107. Wright-Patterson Air Force Base

a. Target Signature Program

(515) 255-2759

b. Technology Division

c. Photographic Materials Lab.

Ohio 45433 
108. Xerox Corp.

800 Phillips Road

Webster, New York

14580

(716) 872-2000

109. *Carl Zeiss, Inc.

444 Fifth Ave.

New York, N.Y. 10018

(212) $736-6070$ 
C.3 LITERATURE REFEREICES which are specifically cited in the text and appendices of this report are included in this list. The order in the list is the order of appearance in the report, and the text reference is given as C. 3 followed by the number of the item in the list below. For example, the first reference would be indicated in the text as (C.3.1).

1. Knock, Richard T.; Long Range Planning Service Report 非447, Stanford Research Institute, Menlo Park, California; (October 1971); "Analytical Instruments".

2. Lorah, L. D.; Mechanical Engineering, 27 (January 1972);

"Infrared Spectrophotometry: A Quality Control Tool" (Q.1).

3. Johnston, R. M.; Journal of Paint Technology 39, 346 (1967); "Spectrophotometry for the Analysis and Description of Color".

4. FED-STD 595 (3rd ed) January 1968 (Supplemented by MIL-STD 795 (Feb. 1962)) "Colors; (for) Ready-Mixed Paints".

5. Billmeyer, F. W., and J. G. Davidson; Journal of Paint Technology 41, 647 (1969); "A Research Spectrogoniophotometer".

6. Spengman, W. F.; Paint and Varnish Production (August, 1970) "Quinacridon Pigments".

7. Bartolo, H. F.; SPE Journal 26, 非3, 65 (March 1970) "Quinacridone Pigments in Plastics".

8. Simon, F. T.; Journal of Color and Appearance 1, 非, 5 (1972);

"The Two-Mode Method for Measurement and Formulation with

Fluorescent Colorants".

9. Hoffman, Konrad; The Journal of Color and Appearance 1 , 非2, 16 (1971); "Chromatic Integrating Sphere Error in Tristimulus Colorimeters".

10. Rand, R. N.; Clinical Chemistry 9, 839 (1969); "Practical Spectrophotometric Standards".

11. Gourley, J., Rib, H. T., and Miles, R. D.; Photographic Science and Engineering 12, 27 (1968); "Automatic Technique for Abstracting Color Descriptions from Aerial Photography".

12. Kortüm, Gustav; Reflectance Spectroscopy, Springerverlag, New York, Inc. (1969).

13. Little, Angela C.; Food Technology 23, 71 (1969); "Reflectance Characteristics of Canned Tuna".

14. Maurer, Frank W.; Glass Packer/Processor, 30 (June 1967);

"Flavor, Color, and Other Characteristics of Foods of the Future". 
15. Smith, Ora, and Davis, C. O.; Potato Chipper (November 1961); "Prevention of Graying in Dehydrated Potato Products".

16. Birth, G. S. and Norris, K. H.; USDA Technical Bulletin No. 1341 (September, 1965); "The Difference Meter for Measuring Interior Quality of Foods and Pigments in Biological Tissues".

17. Demas, J. N. and Crosby, G. A.: J. Phys. Chem. 75, 991 (1971); "The Measurement of Quantum Yields. A Review."

18. NBS List of Publications, LP39; "Colorimetry and Spectrophotometry, Publications by the Staff of the National Bureau of Standards, January 1906 through June 1962".

19. A Study Prepared for the Subcommittee on Science, Research and Development of the Committee on Science and Astronautics, U.S. House of Representatives. Ninety-second Congress, First Session, p 178 (Sept. 8, 1971); "National Bureau of Standards, Review of Its Organization and Operations".

20. Saunders, James B. and Robert J. Bruening; Astronomical Journal 73, 415 (1968);"A New Interferometer Test and its Application to the 84 Inch Reflecting Telescope at Kitt Peak National Observatory".

21. Eckerle, K. L. and R. W. P. McWhirter; The Physics of Fluids 9 81 (1966); "Departures from Local Thermal Equilibrium in a Magnetically Driven Shock Wave".

22. Berg, H. F., K. L. Eckerle, R. W. Burris, and W. L. Wiese; The Astrophysical Journal 139, 751 (1964); "Relative Oscillator Strengths of Some OII and OII Lines from Measurements on Shock-Heated Plasmas".

23. Roberts, J. R. and K. L. Eckerle; The Physical Review 153, 87 (1967); "Measurements of Relative Oscillator Strengths of Some CII Multiplets".

24. Haupt, G. W., J. C. Schleter, and K. L. Eckerle; NBS Technical Note 716 (1972); "The Ideal Lovibond Color System for CIE Standard Illuminants $A$ and C Shown in Three Colorimetric Systems".

25. Mielenz, K.D. and K. L. Eckerle; NBS Technical Note 729 (1972); "Design Construction, and Testing of a New High Accuracy Spectrophotometer".

26. Mielenz, K. D. and K. L. Eckerle; Applied Optics 11, 2294 (1972); "Spectrophotometer Linearity Testing Using the Double-Aperture Method".

27. Mielenz, K. D., and K. L. Eckerle; Applied Optics 11, 594 (1972); "Accuracy of Polarization Attenuators".

28. Hsia, J. J.; M.S. Thesis, Purdue University (1964); "The Reproducibility of Mechanically and Electrolytically Prepared Surfaces".

29. Hsia, J. J.; Ph.D. Dissertation, Purdue University (1968); "Experimental Investigation on the Reflectivity of $\mathrm{Al}, \mathrm{Cu}, \mathrm{Zn}$, and $\mathrm{Ni}$ and $\mathrm{Its}$ Comparison with Theory". 
30. Touloukian, Y. S. (Ed.); Thermophysical Properties of High Temperature Solid Materials, MacMillan Co. (1967) (J. J. Hsia contributed sections on thermal radiation properties and thermal conductivity to this work.)

31. Hsia, J. J. and D. P. DeWitt; Journal of the Optical Society of America, 59, 449 (1969); "Infrared Reflectance of Metallic Elements".

32. Richmond, J. C. and J. J. Hsia; HTD-Vol. 3 Recent Developments in Thermophysical Properties Research ASME (1971); "Thermal Radiation Properties of Solids and Methods of Measurement".

33. Richmond, J. C. and J. J. Hsia; presentation at AIAA 6th Thermophysics Specialists Conference, Tullahoma, Tennessee (26 April 1971); "A High Resolution Bi-Directional Reflectometer".

34. Richmond, J. C. and J. J. Hsia; NBS Special Publication 260-38 (May 1972); "Standard Reference Materials: Preparation and Calibration of Standards of Spectral Specular Reflectance".

35. Venable, W. H., Jr.; MS Thesis, University of Florida (1956); "The Development of a Recording Gamma Radiation Spectrometer"; and Nucleonics 15(非), 84 (July 1957); "Simple Recording Gamma-Ray Spectrometer".

36. Venable, W. H., Jr.; Ph.D Dissertation, University of Alabama (1962); "A Disk Loaded Waveguide Design for a Submillimeter Radiation Generator".

37. Venable, W. H., Jr.; The Review of Scientific Instruments 37, 1443 (1966); "Tunnel Diode Chronotron Circuit for Picosecond Range".

38. Venable, W. H., Jr. and J. B. Shumaker, Jr.; Journal of Quantitative Spectroscopy and Radiative Transfer 9, 1215 (1969); "Observations of Departures from Equilibrium in a Nitrogen Arc".

39. Venable, W. H., Jr.; Applied Optics 9, 609 (1970);"Effects Upon Radiant Intensity Measurements Due to Scattering by Optical Elements".

40. Keegan, H. J., J. C. Schleter, and V. R. Weidner; Journal of the Optical Society of America 51, 1470 (1961); "Ultraviolet Wavelength Standard for Spectrophotometry".

41. Keegan, H. J., G. W. Cleek, J. C. Schleter, and V. R. Weidner; Optical Society of America Spring Meeting, Jacksonville, Florida (March 1963); "Absorption Spectra of the Lanthanide Series of Rare-Earth Glasses".

42. Keegan, H. J., G. W. Cleek, J. C. Schleter, and V. R. Weidner; Optical Society of America Fall Meeting, Chicago, Illinois (October 1963); "Further Progress Towards Development of a Single Filer for the Wavelength Calibration of Spectrophotometers Between 0.25 and 2.6 Microns". 
43. Keegan, H. J., J. C. Schleter and V. R. Weidner; Symposium on Thermal Radiation of Solids, San Francisco, California (March 1964); "Effect of Surface Texture on Diffuse Spectral Reflectance. Diffuse Spectral Reflectance of Metal Surfaces".

44. Gates, D. M., H. J. Keegan, J. C. Schleter, and V. R. Weidner; Applied Optics 4, 11 (1965); "Spectral Properties of Plants".

45. Keegan, H. J. and V. R. Weidner; Optical Society of America Fall Meeting, Philadelphia, Pennsylvania (October 1965); "IR Spectral Reflectance of Frost".

46. Keegan, H. J. and V. R. Weidner; Optical Society of American Spring Meeting, Washington, D. C. (March 1966); "IR Spectral Reflectance at Controlled Temperatures".

47. Keegan, H. J. and V. R. Weidner; Optical Society of America Fall Meeting, San Francisco, California (October 1966); "IR Spectral Reflectance of Black Materials".

48. Bennett, J.M. and E. J. Ashley; Optical Society of American Spring Meeting, Tucson, Arizona (April 1971); "Calibration of Instruments for Measuring Reflectance and Transmittance".

49. Clarke, F.J.J.; National Physical Laboratory Report MC3020 (March, 3, 1971); "Calibration of a Set of Ceramic Colour Standards".

50. Robertson, A.R.; Applied Optics 11, 1936 (1972); "Effect of Polarization on Reflectance Factor Measurements".

51. George, Dianne, and T. Limperis; Air Force Avionics Laboraoory Technical Report AFAL-TR-65-331, Vol. II (1965); "Sources of Experimental Errors in Spectrophotometric Measurements".

52. Burke, R.W., E. R. Deardorff and O. Menis; (Scheduled to be published in Journal of Research, NBS, December 1972); "Liquid Absorbance Standards".

53. Byrd, R.E. and P. H. Almand; Electro-Optical Systems Design $\underline{4}$, 非6, 10 (June 1972); "Molded Plastic Optics are Coming".

54. Johnson, S.M.; Electro-Optics System Design 4, 非3, 20 (March 1972); "Photomultiplier Tubes: Surviving the Rugged Life".

55. Olson, G.; American Laboratory (February 1972); "Applications of an Optical Multichannel Analyzer".

56. Sakalys, V.R.; American Laboratory, p. 15 (March 1972); "A Programmable Calculator-Controlled Spectrophotometer Data Processing Sys tem". 
57. Lord, J.S.; United States Patent 3,646,331 (Feb 29, 1972);

"Automatic 100\% Line Adjustment of Spectrophotometers"

58. NBS Special Publication 250 (yearly); "Calibration and Test Services of the National Bureau of Standards"

59. NBS Letter Circular LC-1017 (January 1967); "Standards for Checking the Calibration of Spectrophotometers"

60. Keegan, H.J., J. C. Schleter, and M. A. Belknap; Journal of the Optical Society of America 54, 69 (1964); "Recalibration of the NBS Glass Standards of Spectral Transmittance"

61. NBS Special Publication 260 (periodic); "Catalog of Standard Reference Materials"

62. Keegan, H.J., J. C. Schleter, and D. B. Judd; Journal of Research NBS 66A, 203 (1962); "Glass Filters for Checking Performance of Spectrophotometer-Integrator Systems of Color Measurements"

63. Billmeyer, F.W., and M. Saltzman; Principles of Color Technology, Interscience Publishers, New York (1966).

64. Judd, D.B.; Color in Business, Science, and Industry, John Wiley and Sons, Inc., New York (1952).

65. Wyszecki, G. and W. S. Stiles; Color Science, John Wiley and Sons, Inc., New York (1967).

66. Nimeroff, I.; NBS Monograph 104, (January 1968); "Colorimetry".

67. Nimeroff, I., editor; Precision Measurement and Calibration, Selected NBS Papers on Colorimetry, NBS Special Publication 300, Vol. 9 (June 1972).

68. Seabright, C. A.; Ceramic Bulletin 49, 269 (1970; "Metamerism in Colored Glazes"

69. Commanday, S.; Fina1 Report, Project 01-327-11, Burlington Industries Research Center, (February 1971); "Colorimetry of Fluorescent Dyes"

70. Nimeroff, I.; Journal of the Optical Society of America 43, 531 (1953); "Propagation of Errors in Spectrophotometric Colorimetry"

71. Nimeroff, I.; Color Engineering, p. 24 (March-April 1967); "The Variability of Color Measurement"

72. Nickerson, D. and C. W. Jerome; Illuminating Engineering 60, 262 (1965); "Color Rendering of Light Sources: CIE Method of Specification and Its Application" 
73. Judd, D.B.; Illuminating Engineering 62, 593 (1967); "A Flattery Index for Artificial Illuminants"

74. Hunter, R.S.; Journal of Research, NBS 18, 19 (1937); "Methods of Determining Gloss"

75. Hunter, R.S. and others; Tappi 54, 2073 (1971); "Specular G1oss of Paper and Paperboard at 75 Degrees; Proposed Revision of T 480 ts -65 as a Standard"

76. Judd, D. B.; Applied Optics 6, 13 (1967); "Physiological Optics at the National Bureau of Standards"

77. Federal Register 35, 17308 (November 10, 1970); "85.124--Smoke Measurement System"

78. Rich, R.B.; Cummins Technical Report, Document Number 5425 (May 19, 1972); "Calibration of Neutral Density Filters"

79. A report by the Council for Optical Radiation Measurements, an activity of Technical Committee 1.2, United States National Committee, CIE (1972); "Pressing Problems and Projected National Needs in Optical Radiation Measurements, A Consensus of Services Desired of NBS"

80. Goebe1, D.G., B. P. Caldwe11, and H. K. Hammond III; Journal of the Optical Society of America 56, 783 (1966); "Use of an Auxillary Sphere with a Spectrophotometer to Obtain Absolute Reflectance"

81. Budde, W. and C. X. Dodd; Die Farbe 19, 94 (1970; "Absolute Reflectance Measurements in the D/0 Geometry"

82. Korte, H. and M. Schmidt; Lichttechnik 19, 135A (1967); "Uber Messungen des Leuchtdichtefaktors an beliebig reflektierenden Proben"

83. Billmeyer, F.W. and J. G. Davidson; Journal of Paint Technology 41, 647 (1969); "A Research Spectrogoniophotometer"

84. Yegerov, G.N. and Yu. M. Grigor'yev; Svetnotechnika, No. 8, p. 14-16 (August 1969); "Type GF-65 Goniophotometer"

85. Blair, M.E., D. C. Cramer and S. R. Stewart; Technical Report AFAL-TR-70-161, Air Force Avionics Laboratory, Air Force Systems Command, WPAFB Ohio; "A Gonioreflectometer Facility Using Coherent and Incoherent Sources"

86. Brandenberg, W. M. and J. T. Neu; Journal of the Optical Society of America 56, 97 (1966); "Unidirectional Reflectance of Imperfectly Diffuse Surfaces"

87. Turner, G.K.; Science 146, 183 (1964); "An Absolute Spectrofluorometer"

88. Turner, G. K.; G. K. Turner Associates (C.2.101)(1967); "Fluorometry Princlples, Techniques, Advantages, Applications" 
89. Velapoldi, R.A.; Conference on Accuracy in Spectrophotometry and Luminescence Measurements, National Bureau of Standards (March 22-24, 1972); "Fluorescence Standards"

90. Simon, F.T.; The Journal of Color and Appearance 1, 非, 18 (1972); "The Two-Mode Method for Measurement and Formulation with Fluorescent Colorants"

91. Keegan, Harry J. and Gibson, Kasson S.; Journal of the Optical Society of America 34, 770 (1944); "On the Use of Working Standards of Didymium and Vitrolite Glasses for Spectrophotometric Measurement" (Abstract)

92. Keegan, Harry J.; Journal of the Optica1 Society of America 38, 658 (1948) and Analytical Chemistry 20, 387 (1948); "Standards of Reflectance" (Abstract)

93. An internal NBS document providing instructions for writing issue studies for FY 74 (1972); "Issue Study Format and Schedule"

94. Department of Commerce, Bureau of the Census (1970); "Statistical Abstract of the United States 1970"

95. Thiel, A. K. and C. D. Graves, paper presented to The Committee on Science and Astronautics, U.S. House of Representatives (January 25, 1972); "Remote Sensing of Earth Resources"

96. U.S. Bureau of Mines (1972); Minerals Yearbook, 1970, Vol. I 

NBS-114A (REV.7.73)

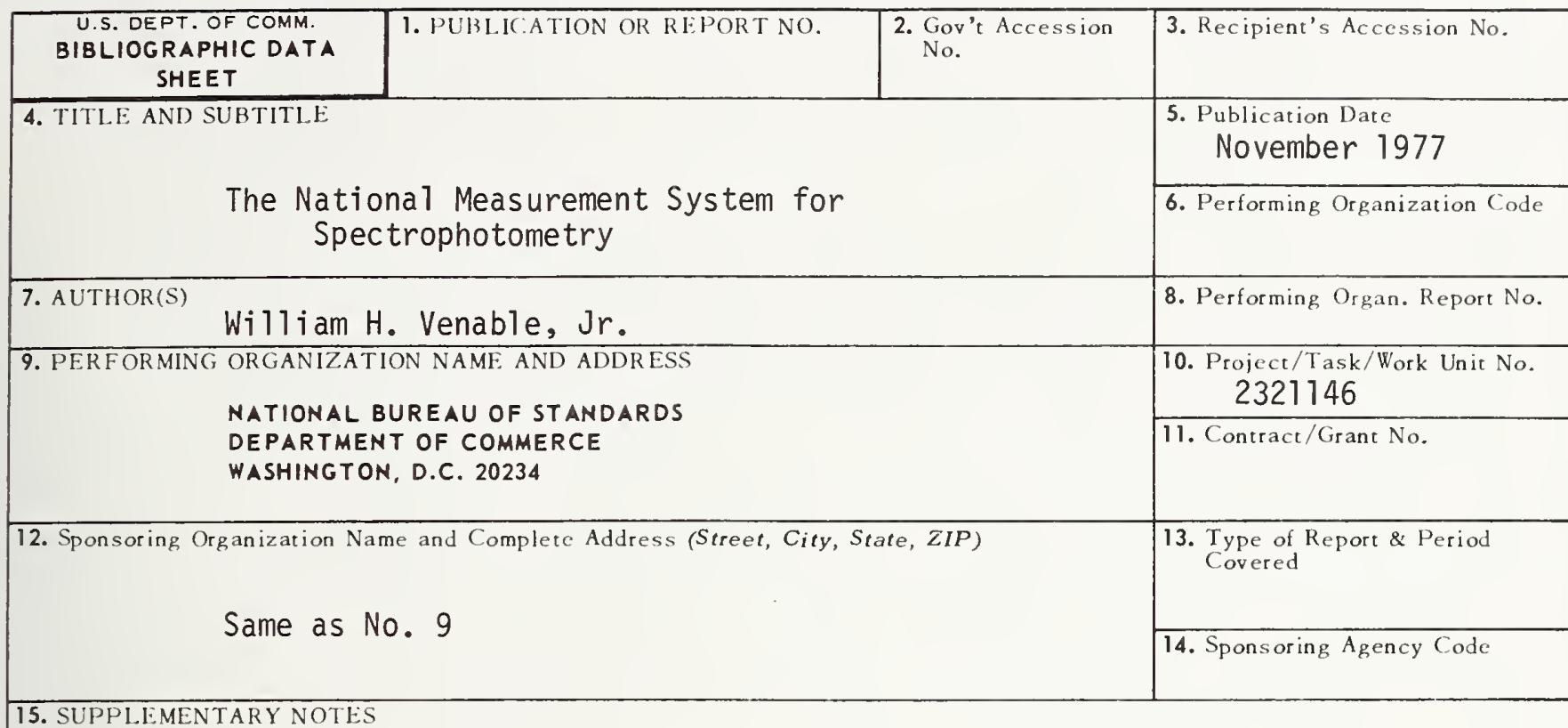

15. SUPPLEMENTARY NOTES

16. ABSTRACT (A 200-word or less factual summary of most significant information. If document includes a significant bibliography or literature survey, mention it here.)

A special study of the spectrophotometric measurement system was made in order to determine what could be done to improve these measurements and what benefits would result from the improvements. It was found that improvements in the measurements could make large contributions to productivity, health, and safety in the U.S., and that, because of the fragmented nature of this measurement community, the improvements in spectrophotometric measurements can be realized most efficiently through the efforts of a centralized agency such as NBS. With the aid of this study, the program in spectrophotometry at NBS has been revised in order to bring about these improvements more rapidly and effectively

17. KEY WORDS (six to twelve entries; alphabetical order; capitalize only the first letter of the first key word unless a proper name; separated by semicolons)

Absorption spectra; automation; chemical analysis; colorimetry; heat transfer; reflectance; remote sensing; retroreflectance; spectrophotometry; transmittance.

\begin{tabular}{|c|c|c|}
\hline $\begin{array}{l}\text { 18. AVAILABILITY }[X] \text { Unlimited } \\
\square \text { For Official Distribution. Do Not Release to NTIS }\end{array}$ & $\begin{array}{l}\text { 19. SECURITY CIASS } \\
\text { (THIS REPURT) } \\
\text { UNCI ASSIF IED }\end{array}$ & $\begin{array}{l}\text { 21. NO. OF PAGES } \\
100\end{array}$ \\
\hline $\begin{array}{l}\text { Order From Sup. of Doc., U.S. Government Printing Office } \\
\text { Washington, D.C. } 20402, \text { SD Cat. No. CI } 3\end{array}$ & $\begin{array}{l}\text { 20. SECURITY CLASS } \\
\text { (THIS PAGE) }\end{array}$ & 22. Price \\
\hline $\begin{array}{l}\text { X Order From National Technical Information Service (NTIS) } \\
\text { Springfield, Virginia 22I51 }\end{array}$ & UNCLASSIFIED & 00 \\
\hline
\end{tabular}


